\title{
Half a Century of Research on the Stroop Effect: An Integrative Review
}

\author{
Colin M. MacLeod \\ Division of Life Sciences \\ University of Toronto, Scarborough Campus \\ Scarborough, Ontario, Canada
}

\begin{abstract}
The literature on interference in the Stroop Color-Word Task, covering over 50 years and some 400 studies, is organized and reviewed. In so doing, a set of 18 reliable empirical findings is isolated that must be captured by any successful theory of the Stroop effect. Existing theoretical positions are summarized and evaluated in view of this critical evidence and the 2 major candidate theories-relative speed of processing and automaticity of reading - are found to be wanting. It is concluded that recent theories placing the explanatory weight on parallel processing of the irrelevant and the relevant dimensions are likely to be more successful than are earlier theories attempting to locate a single bottleneck in attention.
\end{abstract}

In 1935, J. R. Stroop published his landmark article on attention and interference, an article more influential now than it was then. Why has the Stroop task continued to fascinate us? Perhaps the task is seen as tapping into the primitive operations of cognition, offering clues to the fundamental process of attention. Perhaps the robustness of the phenomenon provides a special challenge to decipher. Together these are powerful attractions in a field of complex phenomena where the most subtle variation may exert a dramatic effect.

In writing this article, I have two primary intentions. The first is to create a taxonomy of the empirical work on the Stroop task and its analogs. At least $70 \%$ of the more than 700 Strooprelated articles in the literature have been published since the reviews by Dyer (1973c) and Jensen and Rohwer (1966). Furthermore, Dyer's theoretical framework now seems in need of reconsideration, so that his review no longer provides the optimal organization. The second aim, then, is to survey existing theories, showing the critical weaknesses in the standard explanations and dispelling some myths that have arisen. I argue for a new theoretical framework for the Stroop effect, informed by contemporary cognitive psychology. This framework is more comprehensive than many earlier experiment-specific hypotheses, and suggests directions in which future research might profitably proceed.

This research was supported by Natural Sciences and Engineering Research Council of Canada Grant A7459. I am grateful to the Ontario Science Centre for providing testing facilities and to their staff for assistance. I owe a considerable debt to P. J. Lootsteen, who did the bulk of the initial work locating articles for me. I thank Jonathan Cohen, Kevin Dunbar, and Gordon Logan for their careful readings of the theoretical section. I am especially grateful to John Flowers and an anonymous reviewer for their yeoman work as reviewers.

Correspondence concerning this article should be addressed to Colin M. MacLeod, Division of Life Sciences, University of Toronto, Scarborough Campus, Scarborough, Ontario Canada MIC 1A4. Electronic mail may be sent to macleod@lake.scar.utoronto.ca.

\section{Colors, Words, and Interference: Research From 1886 to 1935 \\ The Half-Century Before Stroop}

The roots of Stroop's research are evident 50 years earlier in the work of James McKeen Cattell (1886). In a doctoral project supervised by Wilhelm Wundt, Cattell reported that objects (and colors) took longer to name aloud than the corresponding words took to read aloud. Saying "red" to a patch of color was slower than saying "red" to the word red. His explanation is strikingly modern: "This is because, in the case of words and letters, the association between the idea and name has taken place so often that the process has become automatic, whereas in the case of colors and pictures we must by a voluntary effort choose the name" $(1886$, p. 65). Cattell's automatic/voluntary distinction strongly influenced psychologists then (e.g., James, 1890, p. 559; Quantz, 1897) and continues to do so (e.g., Posner \& Snyder, 1975; Schneider \& Shiffrin, 1977).

Most early research (e.g., Bills, 1931; Brian \& Goodenough, 1929; Gails, 1922) tested the intuitive differential-practice account for Cattell's observation (cf. Quantz, 1897, p. 10). I will focus only on the few most relevant to Stroop's work. Brown (1915) predicted that ink-color naming would benefit from extended practice more than would color word reading because color naming was initially the less practiced skill. Instead, he found that the ratio of the two times remained quite constant with practice. He concluded that differential practice could not explain Cattell's findings. ${ }^{1}$

Lund (1927) disagreed with Brown, and held that the differential practice hypothesis was quite viable. Lund found that

\footnotetext{
${ }^{1}$ In Experiment 2, Brown printed congruent words or parts of words on color backgrounds. Contrary to his expectation, such "assistance" was actually detrimental to color naming. On this basis, Brown argued that the two processes-reading words and naming colors-did not overlap. This is the first published instance where color and word cooccurred, and where the word interfered with naming the color. Strangely, the interference appeared in the congruent condition.
} 
children younger than reading age were faster on color naming than on word reading, even with careful assurance that they knew the stimulus words. Furthermore, for one 5-year-old child, 4 weeks of alternating practice on the two tasks suggested a common asymptote. However, a larger scale developmental study conducted by Ligon (1932) again questioned the differential-practice concept. Both color-naming and color word-reading times improved across Grades 1 through 9, yet the difference between the skills remained unchanged. Ligon contended that a "common factor" improved-perhaps time to articulate the response-but that the tasks were otherwise independent.

In the same year as his classic article, Stroop (1935a) demonstrated that Ligon's data did show differential improvement with age, perfectly in accord with the differential-practice idea. Stroop also faulted Ligon's correlational analysis on statistical grounds. Given Lund's criticism of Brown, Stroop (1935a) advocated the differential-practice hypothesis, as indeed did Dyer (1973c) four decades later.

Other studies offered alternative views of Cattell's well-replicated observation. Hollingworth $(1912,1915,1923)$ suggested that word reading required only articulation, but that color naming demanded articulation plus association. Brown (1915) and Ligon (1932) maintained that both tasks involved two processes but with a different association element for each test. Garrett and Lemmon (1924) held that color naming was longer because of an interference factor, which they failed to specify. Perhaps they had in mind what Peterson, Lanier, and Walker (1925) suggested: that many responses might be conditioned to a single color, but only one response was conditioned to a single word. Telford (1930), a student of Peterson's, also adopted this interpretation. An earlier variation on this was put forth by Woodworth and Wells $(1911$, p. 52$)$, who argued that the few color names typically used in these experiments "all are equally ready and get in one another's way."

It is difficult to believe that no one thought to combine colors and words until Stroop (1935b). ${ }^{2}$ It may help to place Stroop's insight in context to realize that he developed his color-word task less from an interest in stimulus-naming time-the motivation for most prior research-than from an interest in interference between conflicting processes.

\section{Stroop's Classic Article}

Elsewhere (MacLeod, in press) I have written a biographical sketch of John Ridley Stroop; I do not recapitulate that here. However, before discussing the vast literature fostered by Stroop's dissertation, I will briefly outline his lead article in the December 1935 issue of the Journal of Experimental Psychology. His basic conclusion is correctly reported and widely understood, but what he actually did has been somewhat transformed in secondary sources. Stroop's contemporary, Bartlett (1932), would probably not be surprised by the transformation. I simply wish to refresh our memories with the original study.

Stroop was concerned with how best to explain interference. With Peterson, his dissertation supervisor, Stroop had been engaged in studies of color naming versus word reading, and hit upon the idea of a compound stimulus where the word was incongruent with the ink color. His two major questions were what effect each dimension of the compound stimulus would have on trying to name the other dimension, and what effect practice would have on the observed interference.

Experiment 1 examined the effect of incompatible ink colors on reading words aloud. Stroop used five words and their matching ink colors: red, blue, green, brown, and purple. For the experimental condition, each ink color appeared twice in each row and column of a $10 \times 10$ stimulus card. Each word appeared twice on every line, equally often in each of the other four ink colors. The stimuli appeared in reverse order on a second card. The control-condition cards were each identical to one of the experimental cards but in black ink only. After a 10-item practice card, all 70 subjects were tested on all four cards, half in the order of Control 1, Experimental 2, Experimental 1, Control 2, and half in the reverse order. Subjects were to read the words aloud as quickly as possible, leaving no errors uncorrected.

The top row of Table 1 presents the data from Experiment 1 . Although subjects averaged $2.3 \mathrm{~s}$ longer to read the 100 words on the experimental cards, this $5.6 \%$ increase was far from significant. I recently replicated this experiment: My data for 50 subjects appear in the bottom row of Table 1, and are remarkably consistent with Stroop's data. There was no interference from incongruent colors in reading words, $F(1,49)=1.86$, $M S_{\mathrm{e}}=2.45, p=.17$.

In Experiment 2, the task was switched to naming the colors aloud. The control cards had the ink colors in the same order as the experimental cards; solid color squares were substituted for words. ${ }^{3}$ The experimental cards and the procedure were identical to Experiment 1, except that twice the average response time per item was added to a subject's total for every uncorrected error, a procedure Stroop admitted was "arbitrary." The data of the 100 subjects in this experiment are presented in the top row of Table 2.

Subjects averaged $47 \mathrm{~s}$ longer to name ink colors of incongruent words than solid-color squares. Stroop described this $74 \%$ increase as a "marked interference effect"; $99 \%$ of the times on experimental cards exceeded those on control cards. I also replicated this experiment using 40 subjects. My data, in the bottom row of Table 2, again duplicate those of Stroop; my slightly lower values are perhaps due to my not using the arbitrary correction for errors. There was highly significant interference from incongruent words in naming colors, $F(1,39)=$ $363.65, M S_{e}=99.36, p<.001$.

Stroop's little-known third experiment was more complicated. Thirty-two subjects named the ink colors of incompatible words for 8 days. Over days, color-naming times decreased $16.8 \mathrm{~s}$ from $49.6 \mathrm{~s}$ to $32.8 \mathrm{~s}$ (for a card of 50 words). Thus, interference from incompatible words appeared to decrease

\footnotetext{
${ }^{2}$ According to Jensen and Rohwer (1966), Jaensch (1929) was the first to combine the word and color stimuli in a potentially conflicting situation. Perhaps, then, Jaensch should receive at least partial credit, but the "Jaensch-Stroop effect" is an extremely unwieldy label.

${ }^{3}$ Stroop changed the color-naming control-condition cards from Experiment 2 to Experiment 3 . The solid-color squares were replaced by a nonalphanumeric character, which, in Stroop's view, was more like a letter in appearance and more easily colored to match the shades of the letters on the experimental cards. The stimulus Stroop chose was the swastika.
} 
Table 1

Experiment 1: Mean Times (in Seconds With Standard Deviations $[S D]$ ) for Reading Color Words in the Experimental Condition (Incompatible Colored Inks) and in the Control Condition (Black Ink Only)

\begin{tabular}{lccccccc}
\hline & & $\begin{array}{c}\text { Experimental: } \\
\text { words in color }\end{array}$ & & \multicolumn{2}{c}{$\begin{array}{c}\text { Control: } \\
\text { words in black }\end{array}$} \\
\cline { 3 - 4 } Experiment & Sample size & $M$ & $S D$ & & $M$ & $S D$ \\
\hline Stroop (1935b) & 70 & 43.30 & 6.15 & & 41.00 & 4.84 \\
MacLeod (1986) & 50 & & 41.58 & 6.98 & & 41.16 & 7.12 \\
\hline
\end{tabular}

with practice. However, there may be a general practice or learning-to-learn effect here: Ink color-naming baselines were not collected each day.

Experiment 3 also explored the impact of practicing color naming on the development of interference in word reading. Comparison of a pretest and a posttest where subjects read words in incongruent colors showed that the intervening 8 days of practice introduced interference into word reading (from $19.4 \mathrm{~s}$ before to $34.8 \mathrm{~s}$ after), but that this newly developed interference quickly disappeared in a second posttest $(22.0 \mathrm{~s})$. This was the first report of what is now called the "reverse Stroop effect."

Overall, Stroop took his experiments to show that differential practice did offer a reasonable account of the asymmetrical interference pattern he obtained, and accepted the Peterson et al. (1925) explanation that words evoked a single reading response, whereas colors evoked multiple responses, thereby making naming colors slower than reading words. Indeed, in his 1938 article, Stroop directly tested this idea and reported support for it.

The misconceptions about Stroop's work are subtle but noteworthy. People often talk as if there was a single experiment contrasting four conditions; in fact, he performed two separate experiments. Frequently, too, his word-reading data (Experiment 1) go unmentioned. I have even heard Stroop credited with a compatible condition-color words in congruent ink colors-which he never used. He also never timed single stimuli; his experiments used only lists of stimuli. On the other hand, he did observe reverse Stroop interference first. Although his theoretical account did not mention automaticity, it did rely on a primitive type of response competition.

In summary, Stroop's article was a careful treatment of an interference phenomenon. His scholarly acknowledgment of his intellectual precursors, his succinct data analysis, and his clear writing all contributed to the article's influence. The reliability, size, and apparent simplicity of the effect also no doubt captured the interest of later investigators. I now consider what these investigators have found out about the Stroop effect since his dissertation.

\section{Investigating the Stroop Effect: Research From 1935 to 1989}

The set of articles on the Stroop effect numbers in excess of 700. At least 300 of these feature Stroop interference as a mea- sure of attention in studying individual differences, drug effects, and the like. Some of these may assist theory building in other domains, but they are not particularly relevant to a theoretical account of the Stroop effect. I shall omit these "applied" studies, leaving them for another reviewer. Even with such pruning, however, it would still not be reasonable to discuss all of the remaining articles in equal detail. Thus, I will describe pivotal studies on a topic in detail and then provide reference pointers to other pertinent work as appropriate. The review is selective, but the bibliography is comprehensive.

The studies are divided into five sections. The first section examines the various versions of the Stroop task, now actually a family of tasks. Next are two sections on stimulus manipulations: first those conducted on individual trials and then those involving experiment-wide variables. The fourth section summarizes manipulations pertaining to the subject's response, and the fifth section surveys subject-related variables. Each section is in turn subdivided in terms of the sorts of manipulations involved to allow a particular facet of the work to be located easily. Appendix A outlines this organization and serves as an index.

\section{Variations on the Stroop Procedure}

\section{The Stroop Color-Word Interference Test}

The standard Stroop Color-Word Test, sometimes called the Serial Color-Word Test, is the procedure Stroop (1935b) used in his Experiment 2. Typically, subjects are tested only on naming colors of incompatible words and of control patches. Interference is expressed as the difference between the times on these two types of cards. Total time per card divided by number of stimuli on the card occasionally is used to estimate time per stimulus. Jensen and Rohwer (1966) detailed many of the subtle shadings of this standard procedure, focusing particularly on the Thurstone (1944) version.

It is surprising how few studies investigating interference have been concerned at all with Stroop's Experiment 1: reading words in black versus incongruent colors. I agree with Smekal and Dvoracek (1977) that more attention should be given to this second measure if only to reduce misinterpretation of the standard interference measure. This may be especially crucial in clinical settings and individual-differences studies, where more convergence would be helpful.

Table 2

Experiment 2: Mean Times (in Seconds with Standard Deviations (SD]) for Naming Ink Colors in the Experimental Condition (Incompatible Color Words) and in the Control Condition (Solid Color Squares)

\begin{tabular}{lccccccc}
\hline & & \multicolumn{2}{c}{$\begin{array}{c}\text { Experimental: } \\
\text { words in color }\end{array}$} & & \multicolumn{2}{c}{$\begin{array}{c}\text { Control: } \\
\text { squares in } \\
\text { color }\end{array}$} \\
\cline { 3 - 4 } Experiment & Sample size & $M$ & $S D$ & & $M$ & $S D$ \\
\hline Stroop (1935b) & 100 & 110.3 & 18.8 & & 63.3 & 10.8 \\
MacLeod (1986) & 40 & 102.27 & 18.06 & & 59.76 & 8.09 \\
\hline
\end{tabular}


How should the standard color-word test be scored? Jensen and Rohwer (1966, pp. 45-48) discussed many approaches, but the most prevalent is to calculate a difference score (interference card time - pure color card time) following Stroop (1935b). ${ }^{4}$ Various more complicated scoring systems have been proposed (e.g., Smith, 1959; Smith \& Borg, 1964; Smith \& Klein, 1953), but their use is nowhere near as widespread as the straightforward difference score. The same applies to attempts to deal with errors on the task (e.g., Gardner, Holzman, Klein, Linton, \& Spence, 1959; Rand, Wapner, Werner, \& McFarland, 1963).

Although Sjöberg $(1969,1974)$ was pessimistic about the reliability and validity of the Stroop Color-Word Test based on his regression analyses of various clinical populations, others have been more optimistic. Smith and Nyman (1974) and Schubo and Hentschel $(1977,1978)$ argued that reliability was actually quite good. Santos and Montgomery (1962) directly examined reliability, finding it to be good and uninfluenced by events interpolated between test and retest. Uechi (1972) also reported high reliability. In the most comprehensive study, Jensen (1965) concluded that, with multiple administrations, the Stroop test was probably more reliable than any other psychometric test.

Of course, many studies have centered on methodological issues in the Stroop task. Zajano, Hoyceanyls, and Ouellette (1981) pointed out that ink color and shape change repeatedly on the standard interference card, but only ink color changes on the standard control card. Changing shapes on the control card to correct this confound did not alter the basic effect, however. Sichel and Chandler (1969) argued that variation over stimuli was too great in the standard test; their procedure using pairs of stimuli and tighter controls on hue, brightness, and so forth also left the basic pattern intact.

Modifications only modestly affect its magnitude, not its qualitative form. McCown and Arnoult (1981) printed the stimuli vertically versus horizontally using either the entire color word or just its first three letters, and reported equivalent interference in all cases. Regan (1978) found interference even using only the first letter of a conflicting color word (e.g., the letter $B$ in red ink). Nor do instructional manipulations have much impact. For example, Peretti (1971) found that varying the degree of competitiveness in instructions to subjects affected their performance, but substantial interference appeared in both instructional conditions.

Group versions of the color-word test originated with Kipnis and Glickman (1958, 1959a, 1959b, 1962). They had subject groups view cards containing 150 stimuli and then write down the first letter of each ink color, scoring the number of items correctly identified in a 3-min interval. Similar schemes were developed by Uhlmann (1962) and by Podell (1963). Unfortunately, as Kipnis and Glickman (1962) noted, these tests actually measured clerical speed more than anything else.

Golden (1975) had subjects in a group silently read as many items as they could on both experimental and control cards in $45 \mathrm{~s}$. (Although he claimed that performance was equivalent to the same task done aloud, I do not recommend switching from overt to covert naming.) Work by Harbeson and her colleagues (Harbeson, Kennedy, \& Bittner, 1981; Harbeson, Krause, Kennedy, \& Bittner, 1982) including a group Stroop test found individual card times to be reasonably reliable, but not the derived difference scores. Thus far, then, use of group tests has been infrequent and the results not very compelling.

On the whole, the Stroop Color-Word Test as a psychometric tool appears to have reasonable reliability and validity (although the appropriateness of any given criterion of validity could be questioned). Coupled with its ease of administration, this has made the test a widely used diagnostic instrument in its standard form. Not surprisingly, then, many variations on the test have been developed and tested.

\section{The Individual Stimulus Version of the Color-Word Task}

Researchers interested in studying interference wanted a more analytic methodology whereby individual stimuli could be presented and timed. Although Dyer (1973c) credited Dalrymple-Alford and Budayr (1966) with first using this procedure, Tecce and Dimartino (1965) used it a year earlier to study shock effects and response competition. However, Dalrymple-Alford and Budayr's (1966) concern was with the procedural modification itself, and they found it acceptable. They did note, though, that the standard color-word test introduced list-structure effects in addition to item-specific interference.

By the time of Dyer's (1973c) review, quite a few studies had used this procedure; it has certainly become predominant in laboratories since then (e.g., Dunbar \& MacLeod, 1984; Neill, 1977). Indeed, it was not enough to isolate a single Stroop stimulus; investigators then began to modify the format of that stimulus. For example, Kamlet and Egeth (1969) embossed color words in white letters on colored plastic tape and had subjects name the tape color. They observed interference virtually identical to that in the integrated, word-in-color standard procedure.

To examine laterality and stimulus-integrality effects, Dyer (1973a) separated word from color, placing one on each side of the fixation point. In like manner, Kahneman and Chajczyk (1983) placed a word above or below a color patch in their studies of automaticity. Both studies obtained robust interference. Dyer and Severance (1973) also separated word and color, presenting an incompatible color word $0,25,50$ or $100 \mathrm{~ms}$ before a color patch. Although they observed interference in every case, it was about half that of the normal integrated stimulus. Their procedure has now become conventional for the investigation of stimulus onset asynchrony (SOA) (see later discussion). Indeed, all of these innovations are now firmly ensconced, and the single-trial (or single-response) procedure dominates the field.

\section{Sorting and Matching Versions of the Color-Word Task}

Rather than naming or reading stimuli aloud, subjects can be asked to sort stimuli into categories. The originators of this procedure, Tecce and Happ (1964), showed that sorting coloronly cards was much faster than sorting incongruent color-

\footnotetext{
${ }^{4}$ Saunders (1980) suggested the use of the logarithm of this difference score on the curious grounds that willingness to take part in psychological experiments, especially Stroop studies, seems to correlate with this measure.
} 
word cards into categories identified by color patches. Dyer (1973c) wondered what would have happened had the piles been labeled with color words instead. The answer came when Chmiel (1984) labeled the bins both ways (in separate conditions), and observed both normal Stroop interference and reverse Stroop interference. Martin (1981) also obtained a reverse Stroop effect using the card-sorting procedure.

Treisman and Fearnley (1969) had subjects sort cards containing two words, two colors, or a word and a color into one of two piles identified by whether the two stimuli on a given card were the same or different. When both stimuli were words or both were colors, sorting was rapid. When the stimuli were a word and a color, sorting was slower, especially when one of the two was an incongruent stimulus.

The sorting task continues to appear periodically in the literature (Flowers \& Blair, 1976; Flowers \& Dutch, 1976; Naish, 1980; Taylor \& Clive, 1983; Virzi \& Egeth, 1985), sometimes using materials others than colors and words (e.g., Morton, 1969). Because some of these findings suggest that the sorting task may not be perfectly analogous to the standard Stroop task, it will be necessary to compare results from the different procedures directly (as already begun by Taylor \& Clive, 1983).

Although a common cognitive task, most notably in the work of Posner (1978), matching has seen limited use in the Stroop situation. Flowers (1975) first used the technique to examine time to match sequentially presented color words to color patches. If printed in an incongruent ink color, time to match the word with the color patch was slowed (relative to the congruent or control cases). Compton and Flowers (1977) replicated and extended this observation. Others (e.g., Alivisatos \& Wilding, 1982) have used matching to study interference in Stroop analogs, but only rarely. There appears to be room for more research using matching, particularly in attempting to determine the role of response modality in interference (see Response Modality: Oral Versus Manual).

\section{The Picture-Word Interference Task}

Cattell (1886) emphasized the naming of colors and pictures being slower than the reading aloud of corresponding words (see also Fraisse, 1969). So it is surprising that the picture-word interference task did not appear until after Dyer's (1973c) review. Hentschel (1973) embedded words inside line drawings and required subjects to name the pictures. Although uncertain whether the two tests measured precisely the same phenomenon, he validated the resulting interference against the standard Stroop test.

Hentschel used the multiple-stimulus form; more prevalent today is the individual-stimulus version, originating with Lassen (1975) in an unpublished dissertation. He observed the largest interference when the word preceded the picture by $100 \mathrm{~ms}$. (Note that his parallel study of word reading with incongruent pictures also demonstrated some interference, although this was unaffected by SOA.)

The task quickly caught on. Rosinski, Golinkoff, and Kukish (1975) demonstrated that incongruent words printed inside pictures interfered substantially with picture naming, but that incongruent pictures had only small effects on word reading. As in the color-word task, this asymmetry has come to be the expected pattern (e.g., Glaser \& Düngelhoff, 1984; Smith \& Magee, 1980). Golinkoff and Rosinski (1976) showed that pictureword interference was unaffected by reading-comprehension ability. Rosinski (1977) reported that same-category words interfered more with picture naming than did unrelated words or nonsense trigram control items. These studies set the stage for subsequent work on picture-word interference.

The major advantage of the picture-word task is its greater flexibility in allowing many manipulations not possible with the restricted set of colors in the color-word task. In comparison to pictures-only, rows of Xs, or other controls (e.g., *\#@?\%), incongruent words consistently interfere with picture naming. Also congruent words speed responding (Posnansky \& Rayner, 1977; Rayner \& Posnansky, 1978; Underwood, 1976). Nonwords cause less interference than words (e.g., Lupker, 1982), and unpronounceable nonwords cause less interference than pronounceable nonwords (e.g., Guttentag \& Haith, 1978).

More intriguing, perhaps, are the findings unique to the picture-word task. Consider first the semantic domain. Given the numerous demonstrations of semantic facilitation as a result of association (e.g., Meyer \& Schvaneveldt, 1976), it is puzzling that an associated word printed on a picture (e.g., the word cheese on a picture of a mouse) does not produce more interference in picture naming than does an unassociated word (Lupker, 1979). Yet a member of the same semantic category (e.g., the word ankle on a picture of a hand) does produce more interference than an unrelated word (e.g., Ehri, 1976; Golinkoff \& Rosinski, 1976), regardless of exposure duration (Rayner \& Springer, 1986). Furthermore, although category typicality has no influence on interference (Lupker, 1979), category centrality apparently does (Job \& Rumiati, 1984). Obviously, this is a complicated issue.

There is now a large data base of studies manipulating semantic relations between word and picture (e.g., Babbitt, 1982; Bryson, 1983; Dunbar, 1986; Irwin \& Lupker, 1983; Lupker \& Katz, 1981, 1982; Lupker \& Sanders, 1982; Magee, 1982; Rayner \& Springer, 1986; Reiner \& Morrison, 1983; Smith \& Kirsner, 1982; Smith \& Magee, 1980; Toma \& Tsao, 1985). Many of these are discussed later in more detail. Although a quick glance might suggest that increasing the semantic similarity between the word and the picture increases the interference in picture naming, this comforting summary is flawed. For example, it does not capture the difference just noted between categorically and associatively related words. A complete account awaits further research.

A smaller subset of picture-word studies has been concerned with nonsemantic relations. Ehri (1977) demonstrated that picture-naming latencies showed less interference as the words changed from nouns to adjectives to functors, and that functors did not differ from control nonsense syllables. Thus, syntactic function (or meaningfulness, or both) plays a role roughly in line with intuition. However, most variations have centered on the phonemic, graphemic, or orthographic characteristics of words. The basic message is that these variations influence interference, but not as much as semantic manipulations (e.g., Briggs \& Underwood, 1982; Posnansky \& Rayner, 1977). As one example of a nonsemantic effect, Rayner and Posnansky (1978) found that nonwords that resembled words graphemically (e.g., leuf for leaf) assisted naming of the corresponding 
picture when presented very briefly $(35 \mathrm{~ms})$. With increased exposure duration, this facilitation gradually became interference, although interference was never as great for these lookalikes as for dissimilar nonwords. To complicate matters, they observed that phonemically related nonwords (e.g., lefe for leaf) led to increased facilitation with exposure duration, in opposition to the graphemic effect.

Posnansky and Rayner (1978) established that first-letter coincidence of the word and the picture exerted its effect through the graphemic rather than the phonemic route. Like Rayner and Posnansky (1978), Lupker (1982) and Underwood and Briggs (1984) showed that the graphemic similarity effect was due to letters appearing in the correct location, and that they did not have to overlap in the first position (e.g., the word bomb on a picture of a comb produced the effect). (Note that this observation is consistent with the predictions of McClelland and Rumelhart's, 1981, activation model.)

What do these studies tell us? Lupker (1982; Lupker \& Sanders, 1982) suggests that graphemic effects are a consequence of easier word retrieval, and are unrelated to the response-competition factors underlying the basic interference effect. Rayner and Springer (1986) showed that graphemic similarity between the picture and the word actually reduced the size of the semantic-category effect. They maintained that the bulk of the interference in the picture-word task stems from semantic evaluation, not response competition. Investigators seem to agree that there is more than one factor involved in picture-word interference, but what the factors are and how fundamental each is remain to be worked out.

A critical question is how directly the picture-word and color-word findings relate to each other. Given the quite similar patterns outlined, I will discuss them together in the rest of this article. However, the essential work of ascertaining empirically just how similar the two tasks are remains to be performed. This is not a straightforward problem given the different sorts of questions being addressed in the two domains. One way to make some inroads would be through an individual-differences study examining the correlation between interference in the two tasks. The greater the comparability of results in the two tasks over the same individuals, the more confident we will be that they measure the same cognitive processes.

\section{Auditory Analogs of the Stroop Task .}

If people could selectively filter by modality (as Broadbent, 1958 , suggested), then there ought not be much cross-modality interference. A number of studies called this prediction into question (e.g., Greenwald, 1970), so creation of an auditory Stroop task was only a matter of time. Credit goes to Hamers (1973) in her dissertation (see Hamers \& Lambert, 1972). Her compatible condition required subjects to say "low" to the word low presented at a low pitch $(110 \mathrm{~Hz})$ and "high" to the word high presented at a high pitch $(175 \mathrm{~Hz})$. In the incompatible condition, the word at $110 \mathrm{~Hz}$ was high and the word at $175 \mathrm{~Hz}$ was low. Examining only her monolingual condition, she reported strong interference: The incompatible case $(1,169 \mathrm{~ms})$ took $138 \mathrm{~ms}$ longer than the compatible case $(1,031 \mathrm{~ms})$ on average.

Unfortunately, as Dyer (1973c) pointed out, we cannot be sure how much of this difference truly is interference caused by incongruent words and how much is facilitation resulting from congruent words because there was no neutral-word control condition. This omission is all too frequent in studies of interference and facilitation, complicating interpretation. Without such a control, all that can be examined is the difference between the congruent condition and the incongruent condition -the sum of facilitation and interference, each in unknown amounts. A second problem is closely related: What is the appropriate neutral control? I return to this thorny issue later (cf. Jonides \& Mack, 1984); for now, let us continue examining auditory Stroop analogs.

Dyer (1973c) described an unpublished experiment by Dyer and Mosko wherein subjects had to report the name of the speaker. Some words spoken were neutral, some were compatible (the speaker's name), and some were incompatible (the other speaker's name). They found no interference or facilitation, apparently in conflict with Hamers (1973). However, the Hamers result has been replicated (Cohen \& Martin, 1975; Shor, 1975). In fact, Shor obtained interference in both directions, although the word interfered more with identifying the pitch than vice versa. Bidirectional interference is rarely reported (partly because subjects are rarely required to name both dimensions of the stimulus), yet it has serious ramifications for interpreting the Stroop effect.

In an extension of Hamers's task, McClain (1983c) contrasted time to identify the pitch with time to identify the word using three response modes: verbal, buttonpress, or pitched hum. Interference occurred only when the to-be-reported dimension and the reporting mode differed (pitch-verbal, pitch-button, word-hum), and not when they were compatible (word-verbal, word-button, pitch-hum). She implicated response modality as crucial in interference, an issue discussed under Response Modality: Oral Versus Manual.

Other auditory procedures have been reported as well. Pieters (1981) used the auditory words left or right to the left or right of the subject, and obtained interference in reporting the spatial location of a conflicting word. Green and Barber (1981, 1983) obtained an auditory Stroop effect when subjects had to judge a speaker's gender in conflict versus no-conflict situations. Hatta and Kirsner (1983) reported a similar result, which also held with a buttonpress rather than a vocal response. Apparently, the Dyer and Mosko finding is the outlier.

Most recently, Zakay and Glicksohn (1985) used musical notes or the names of those notes printed at congruent or incongruent locations on the staff. Subjects responded either orally or on a piano keyboard. Zakay and Glicksohn implicated both stimulus-response compatibility and the relation between the dimensions as important, suggesting in fact that these effects were additive.

All of these authors explicitly or implicitly argue for a close analogy between their task and the Stroop task. As with picture-word interference, though, this connection has not been firmly established. Indeed, it may be somewhat less clear-cut here. Still the effects are generally qualitatively similar, suggesting generalizability of the interference phenomenon.

\section{Other Analogs of the Stroop Task}

These variants only hint at the ingenuity of investigators in creating interference tasks. Many of the others involve two (or 
more) verbal stimuli on the same trial (or on successive trials), where one is the target and the other is the distractor. These tend to be thought of in the literature more as priming studies, outside the domain of this review. As one illustration, though, a widely used procedure is the "flanker" task (e.g., Eriksen \& Eriksen, 1974; Eriksen \& Hoffman, 1972; Flowers \& Wilcox, 1982) in which irrelevant letters or words are presented adjacent to the target.

Eriksen and Eriksen (1974) showed that, for two response sets of letters ( $H$ and $K$ vs. S and C), irrelevant flankers from the wrong set interfered with making the response. This seems to be an attentional-selection problem, because presenting the flankers in a different color reduced the interference (Harms \& Bundesen, 1983). Hatta, Hatae, and Kirsner (1984) contrasted English monolinguals to English-Japanese bilinguals in identifying English letters, and found that flanker characters from either language interfered for the bilinguals, but not for the monolinguals.

Other investigators adapted this procedure for studying word rather than letter processing. Dallas and Merikle (1976) showed that presence of a distractor word influenced time to name the target word, with slower naming when the distractor was unassociated. Shaffer and LaBerge (1979) replicated the Eriksen and Eriksen (1974) pattern using categorized words instead of letters. Guttentag, Haith, Goodman, and Hauch (1984) used the technique with bilinguals to show that flanker words interfered even when they were not in the same language as the target, contrasting somewhat with the Hatta et al. (1984) result for letters, perhaps because of the semantic element. The bilingual Stroop situation is treated in more depth under Language Differences: The Case of the Bilingual.

The growing literature on the flanker task has been extended to the color-word and picture-word situations by Kahneman and Chajczyk (1983) and Glaser and Glaser (1989). Several studies also have investigated aspects of meaning using a priming procedure in a Stroop-like task (e.g., Conrad, 1974; Henik, Friedrich, \& Kellogg, 1983; Oden \& Spira, 1983; Regan, 1977, 1981; Warren, 1972, 1974), but these are all saved for the more extensive discussion of semantic variation later.

Most relevant interference experiments have used words as one dimension of the two-dimensional stimulus, such as when Warren and Lasher (1974) had subjects identify the type fonts of words that were in either the congruent or the incongruent font (e.g., the word bold typed in modern, nonbold font), obtaining the expected interference pattern. However, shapes have been used occasionally in an effort to eliminate words altogether (e.g., Irwin, 1978; Redding \& Gerjets, 1977; Shor, 1971). Thus, Hentschel (1973) developed a figure-word interference test in the same article in which he introduced the picture-word task. When geometrical shapes surrounded incongruent words (e.g., a square around the word circle), interference occurred for naming the shape.

Compton and Flowers (1977) had subjects match words to geometric shapes presented shortly after the words. Matching speed was slowed by incongruent shapes being present at the time of word presentation, but this was primarily true at short SOAs (100 ms or less). They took this interference to be visual, unlike the verbal interference in the standard Stroop task. MacLeod and Dunbar (1988) assigned color names to random polygons, and trained subjects in giving the new color name to each shape, monitoring the development of interference with practice. The advantage of studies using shapes is that they step free of words and reading, which dominate this literature.

Few studies have used naturally colored objects, although Cramer (1967) and Arochova (1971) did develop an objectbased test for use with children. When Ménard-Buteau and Cavanagh (1984) had subjects name the color of an incongruously colored object, such as a blue banana, as opposed to a neutral object, such as a blue book, they found interference. However, practice in the word version of the same task did not transfer to the object version, so they took these to be independent types of interference, the object-related one being due to a more perceptual process. This also relates to the semantic manipulations (discussed under Semantic Variation) and to the relation between the picture-word and color-word tasks.

Arrows have been moderately popular stimuli. In the first such study, Shor $(1970,1971)$ embedded the words left, right, up, and down in arrows pointing in directions other than the one named by the word. The control condition omitted the words. Shor observed interference in naming the direction of the arrow, but smaller in magnitude than common in the colorword task. This interference decreased as the semantic overlap between the embedded word and the arrow declined (Fox, Shor, \& Steinman, 1971). Shor, Hatch, Hudson, Landrigan, and Shaffer (1972) demonstrated that extensive training (30-50 days) in naming such incongruent stimuli did not eliminate the interference observed.

Shor's task is analogous to the picture-word task in that the two dimensions are not integrated, unlike the standard Stroop task. To integrate the two dimensions more, Dyer (1972) used a moving display in which the same four directional words (or the control stimulus $\mathrm{XXXX)}$ could be moved either in the named direction (congruent) or in another direction (incongruent). He observed both interference and facilitation for naming direction, but the interference was again small relative to the standard Stroop task. Two other similar studies produced the same results. Clark and Brownell (1975) had subjects judge whether an arrow was pointing up or down inside a rectangle; White (1969) used the words north, south, east, and west inside a rectangle, and had subjects name the word's position. Both studies reported small but reliable interference.

A related series of studies began with the work of Seymour $(1973,1974)$. He presented the words above, below, left, and right, and required subjects to name the location of the word relative to a dot. Subjects showed both facilitation and interference. Palef and Olson (1975) followed up this work, presenting the words above and below either above or below the fixation point. When spatial location was processed faster, responses to word meaning showed interference from incongruent locations; when word meaning was processed faster, responses to spatial location showed interference from incongruent words. This has become a hallmark finding in support of the idea that interference is a direct consequence of the speed of processing each dimension. Palef (1978) then complicated the stimulus, adding an asterisk so that subjects could respond to relative or absolute position as well as to the word itself. She argued that the effects of the two potentially interfering dimensions were additive. Logan and Zbrodoff (1979; see also Logan, 1980) ex- 
tended this work by manipulating the frequency of trial types (see Probability of Various Trial Types). More recently, Harvey (1984) examined SOA effects using the words $h i$ and $l o$ in compatible versus incompatible positions.

Another perennial favorite is numerosity. Windes (1968) first showed that counting is interfered with if the stimuli being counted are incompatible numerals. Shor (1971) and Fox et al. (1971) reported similar interference effects with numbers. Morton (1969) also obtained reliable interference from the presence of irrelevant digits in counting small sets of stimuli. In a more complicated study, Flowers, Warner, and Polansky (1979) demonstrated that there was also a major contribution of response modality to the likelihood of observing interference in a numerosity task.

Since Navon's (1977) and Stirling and Coltheart's (1977) articles on global versus local features in perception, this task has become popular as well. Here subjects saw a large letter composed of small letters (e.g., the letter $H$ formed from small $H$ s vs. small $S \mathrm{~s}$ ). When required to respond to the large letter, the small ones had little impact. When required to respond to the small letters, the large one interfered. A similar effect was obtained using shapes: The global feature again overrode the local feature. Later studies (e.g., Kinchla, Solis-Macias, \& Hoffman, 1983) pursued the role of attention in this remarkably good Stroop analog. Martin (1979) suggested that global features dominate for a multiple-element display, whereas local features take over for a few-element display.

Egeth, Blecker, and Kamlet (1969) found no interference when subjects indicated whether the word and its ink color matched using the responses "same" and "different," but reliable interference when the words were switched to the stimuli same and diff. Thus, words can get through even in a comparison task, but they must relate to the response. Francolini and Egeth (1980) found Stroop-like interference only when manipulations of the relevant, to-be-named stimuli were undertaken in a color-numerosity task. Virzi and Egeth (1984) used a version of the Stroop task in the perceptual domain to examine the phenomenon of illusory conjunctions, finding that subjects have difficulty discriminating whether information came from a color patch or a word.

Daniel $(1968,1969,1970 \mathrm{a}, 1970 \mathrm{~b})$ tried several variations to heighten interference in the standard color-word task. He printed the color words in color and added a differently colored background, or he had a tape recorder spewing out color words while subjects attempted to name the ink colors of incongruent words. Interference increased, but overall response rate also slowed down. Others also altered the standard color-word task (e.g., Dyer, 1973b; Friedman \& Derks, 1973; Hall \& Swane, 1973; Uleman \& Reeves, 1971). Sometimes more than one of the dimensions have been combined, as in the case of the colordigit interference task devised by Wolitzky, Hofer, and Shapiro (1972).

The recent past has seen extensions of the Stroop effect even farther afield to domains such as affect (Gardner, 1985) and even arachnophobia (Watts, McKenna, Sharrock, \& Trezise, 1986). How equivalent are all of these tasks that superficially resemble the Stroop task? Even for the very prevalent alternatives, such as the picture-word task, we do not know. Correlational studies are one way to find out, but few have been per- formed. Obviously, though, it is of theoretical importance to know whether similar processes are invoked in these many variations, but we have insufficient evidence at present.

From here on, the sections end with empirical generalizations where warranted. These are collected in Appendix B to form the basic findings that must be accommodated by any viable theory of the Stroop effect. Then, under Theoretical ACcounts of the Stroop Effect, the existing theories are considered in view of this fundamental evidence. Here, then, is the first such summary statement: The Stroop effect is observed with lists of stimuli, with single stimuli, and with many variations on the response required. Similar data patterns are evident in numerous Stroop analogs, such as the picture-word task. I now consider what has been learned about the causes of Stroop interference from the hundreds of studies over the past five decades.

\section{Manipulations of Information on Critical Trials}

From here on, empirical studies are grouped as to whether their manipulations pertain to individual trials, the overall approach to the whole task, the response demands, or qualities of the individual subject. Such divisions are common in cognitive psychology and serve a useful organizational function here.

\section{Hue Variation}

Most manipulations in the Stroop task have centered on the to-be-ignored verbal dimension. Only a few have examined the hues of the to-be-named inks (e.g., Sichel \& Chandler, 1969). Dyer (1971b) showed that subjects named achromatic color patches slightly faster than chromatic patches. When the patches were replaced with incongruent color words, interference was greater for the chromatic than for the achromatic version. Dyer argued that interference enhanced basic processingtime differences.

The only other approach to varying hue was that of Flowers and his colleagues (Flowers \& Blair, 1976; Flowers \& Dutch, 1976). Flowers and Blair had subjects classify six colors into two categories, and found that a "natural" split of adjacent hues (red, orange, and yellow vs. green, blue, and purple) caused interference only if blocks of nonadjacent hues were included (red, yellow, and blue vs. orange, green, and purple). However, interference was always present when using the nonadjacent classification. Flowers and Dutch replicated this, and argued that nonadjacent categorization required access to names, not just to perceptual qualities of the colors, perhaps because the nonnatural set members had to be constantly rehearsed.

Most Stroop studies use from two to six hues, usually highly differentiable, prototypical colors. Yet variations in number, saturation, similarity, or other features of the color dimension could be used to manipulate processing on that dimension, and would be relevant to the explanations discussed under Theoretical Accounts of the Stroop Effect. With so few relevant experiments, however, it is premature to offer an empirical generalization now.

\section{Acoustic Variation}

A common introspection attributes interference to the articulatory-phonemic-acoustic dimension. Before it can be pre- 
vented, the wrong response is begun, and its sound conflicts with producing the right response. Hollingworth (1915) suggested a version of this idea, which is quite consistent with the hypothesis that Stroop interference occurs at a response stage late in processing (e.g., Posner \& Snyder, 1975) after at least part of the word has been identified.

Bakan and Alperson (1967; see also Langer \& Rosenberg, 1966) found increasing interference with increasing pronounceability of nonsense syllables in the color-word task. However, pronounceability was not the whole story: Words equated with nonsense syllables for pronounceability produced still more interference. Thus, meaning also matters, as discussed under Semantic Variation. Still their study suggested some role for nonsemantic factors.

Shortly afterward, Dalrymple-Alford (1972a, 1972b) pursued pronunciation effects. In addition to color words, he used three types of noncolor words: same initial sound (e.g., run for red and grown for green), same terminal sound (e.g., fed for red and clean for green), or unrelated acoustically (e.g., cat for red and flown for green, an unfortunate choice given the common final phoneme). Color words caused the most interference $(177 \mathrm{~ms})$, but both types of acoustic relation - initial sound $(62 \mathrm{~ms})$ and terminal sound (49 ms)-also caused interference. Dalrymple-Alford proposed that a competing color name could be primed semantically (1972a) or acoustically (1972b).

Singer, Lappin, and Moore (1975) contrasted the effect on ink-color naming of the first, middle, or last two letters of a color word versus the full color word. First letters interfered more than later letters, but not as much as the whole word. Adding unrelated letters to the first letters did not alter interference, leading Singer et al. to speculate that the interference stemmed from activation of a motor program to articulate the beginning of a word. Regan (1978) confirmed this initial-letter effect, also showing that the first letter could produce facilitation in the congruent case. She took this as evidence for automatic processing of letters and words.

Underwood, Briggs, and Underwood (1984) manipulated the phonemic or graphemic relation of a word or a nonword to the ink-color name. For both good and poor 9- to 11-year-old readers, congruent items generated facilitation and incongruent items generated interference. So far all of these studies show at least an orthographic/graphemic effect: Common letters, especially beginning a word, have an influence. However, it is harder to tell whether there was any acoustic/phonemic effect (with the possible exception of the Bakan and Alperson study).

A study by Dennis and Newstead (1981) demonstrated that acoustic/phonemic effects are indeed present. They compared color words with pseudohomophones (e.g., blue vs. bloo) and found similar interference. Furthermore, this was not due just to their common initial letters because the baseline was a nonword matched for visual similarity and sharing the initial letters (e.g., blir). Interestingly, though, real color words led to facilitation on congruent trials but pseudohomophones did not. This is just one of many situations where facilitation and interference come decoupled.

In presenting a prime word before a Stroop trial, Tanenhaus, Flanigan, and Seidenberg (1980) found that if the prime was related orthographically or phonologically, or both, to the irrele- vant word on the Stroop trial, interference with color naming was greater than if the prime and irrelevant words were unrelated. This occurred for both auditorily and visually presented primes, generalizing the phonological effect in Stroop interference.

What about facilitation? Effler (1978b; see also 1977a) reported reduced interference when the irrelevant word was acoustically similar to its to-be-named ink color. The effect also obtained when the relation was between the ink color of item $n$ and the word in item $n+1$, but not vice versa. Apparently, having both dimensions converge on a common-sounding name speeds responding. Sequential effects like these are discussed more extensively under Trial Sequence.

Four studies have tried to tie up the articulatory system to determine what consequences this would have in the Stroop task. All used the card-sorting paradigm. Martin (1978) reported reduced interference in sorting by color when subjects had to say "blah, blah" concurrently. However, Besner, Davies, and Daniels (1981) reported no reduction in the same task. Martin (1981) found that simultaneous irrelevant articulation had no effect on the reverse Stroop interference she observed. Chmiel (1984) confirmed all three of these results, implicating the labeling of the sorting bins as critical. When labeled with color patches, interference was reduced during articulatory suppression; when labeled with words, there was no reduction.

Using the "large letter composed of little letters" task, Stirling and Coltheart (1977) argued against an acoustic effect. Making the small letters easier to confuse visually with the large letter increased interference, but making them easier to confuse acoustically had no impact. Possibly, this result reflects different processes in the two tasks. For example, letter-shape analysis seems to be more critical in this task than in the Stroop task. Investigation of response modality (e.g., vocal vs. buttonpress) might help elucidate such task differences.

In the picture-word task, Ehri (1977) demonstrated that nouns interfered more than adjectives or functors. Ehri took this to mean that interference was not phonologically based, or all word types should have caused similar interference. However, using nonsense syllables as a baseline does present problems (cf. Bakan \& Alperson, 1967), as Ehri acknowledged. Lupker (1982) obtained results more like Effler's (1978b): Orthographic and phonemic similarity between the word and the picture's name led to facilitation relative to a nonword (but not to a picture alone). Lupker attributed this benefit to decreased name-retrieval time for the picture, an effect he saw as separable from the basic response-competition source of interference.

At least for the standard color-word task, then, the visual or acoustic characteristics, or both, of the irrelevant word appear to exert an influence. Much of this hinges on the compatibility of the ink name and the first letter or two of the word, although later parts of the word can also have some effect. To summarize, both orthographic and particularly acoustic/articulatory relations between the irrelevant word (or part of the word) and the to-benamed ink color contribute to the interference.

As a final note, one useful study would combine the articulatory-suppression technique of Martin (1978, 1981), Chmiel (1984), and Besner et al. (1981) with the letter manipulations of Dalrymple-Alford (1972b) and Singer et al. (1975). Would incompatible letters interfere as much if they could not be articu- 
lated? Regardless, nonsemantic features of the words do contribute to interference, supporting the intuitions-and the articulatory stumbles-of subjects in Stroop experiments.

\section{Semantic Variation}

Since Klein's (1964) benchmark study, how word meaning influences color naming has been attacked from a host of different angles. Indeed, the enterprise has come full circle: The Stroop task has become a common tool in understanding how we draw meaning from words. In this section, I begin with studies manipulating the meaning of a single irrelevant word, and then turn to studies involving priming with words or phrases.

Semantic variation and the irrelevant word. The classic study is that of Klein (1964, Experiment 1). His goal was to understand the sources of the word's interfering effect in color naming and the processes involved in that interference. To do this, he manipulated the relation of four words to four ink colors (red, green, yellow, and blue). All subjects performed the control, "colors-alone" card, averaging about $44 \mathrm{~s}$ for the card, and then performed one of six interference cards. As always, the standard incongruent condition (where red, green, yellow, and blue are the words) showed large interference: an increase of about $37.5 \mathrm{~s}$. When four other color words were used (tan, purple, gray, and black), interference was cut to $18 \mathrm{~s}$. Interference decreased further to $15.5 \mathrm{~s}$ for color-related words ( fire, grass, lemon, and $s k y$ ). Substituting common, unassociated words ( $p u t$, heart, take, and friend) or rare words (sol, helot, eft, and abjure) dropped interference to $12 \mathrm{~s}$ and $7.5 \mathrm{~s}$, respectively. Finally, unpronounceable, nonsense syllables (hjh, evgjc, bhdr, and $g s x r q$ ) produced only $5 \mathrm{~s}$ of interference.

Although some of Klein's items were not ideal (e.g., bhdr, gsxrq, and especially grass, which share initial letters with target color names), his basic point was sound: The more meaningful the irrelevant word, the more interference it caused. This was particularly true for color-related words, but even noncolor words produced some interference. Klein's experiment opened the floodgates for numerous studies of how word meaning affects color naming.

Dalrymple-Alford $(1968,1972 a$; Dalrymple-Alford \& Azkoul, 1972; see also Harrison \& Boese, 1976) extended Klein's procedure. Dalrymple-Alford (1972a) found that, compared with unrelated control words, color words interfered more than color-related words (red, $131 \mathrm{~ms}$ vs. blood, $43 \mathrm{~ms}$ ), but both caused reliable interference, replicating Klein. More novel, both also caused reliable facilitation on congruent trials (red, 63 $\mathrm{ms}$, and blood, $42 \mathrm{~ms}$ ). Dalrymple-Alford discounted a purely articulatory explanation because words like sky and snow (for blue and white) caused just as large effects as words like grass (for green) even without shared letters.

As Stroop knew, choosing the appropriate control stimulus is not trivial and warrants an aside here. Some studies use an unrelated word, some a nonword, some a row of Xs or other redundant character, and some a color patch. For example, Dalrymple-Alford's (1972a) study also included a XXXX control. If XXXX rather than the unrelated word is used as the baseline, interference estimates for the incongruent cases increase by $65 \mathrm{~ms}$, and there is no facilitation for the congruent cases. A nonword control might have produced yet another baseline value.

In general, using any characters in the control condition stands to be distracting and to increase the time to respond to the color, but substantial changes in interference typically require some connection to the concept of color (or some kind of priming). Thus, although Hintzman et al. (1972) obtained reliable interference and facilitation for color words relative to a nonword control, words unrelated to color did not differ from the control. A similar result was reported by Redding and Gerjets (1977), who also found that scrambled color words were equivalent to noncolor words. Using unrelated words versus nonwords, then, makes little difference, but the switch to color patches or XXXX-type controls may have more effect.

Scheibe, Shaver, and Carrier (1967) found that amount of interference in color naming was a direct function of amount of color association for the irrelevant words, and argued that word frequency was critical. ${ }^{5}$ Langlois (1974) reported that a direct manipulation of word frequency influenced amount of interference, but he failed to separate response-set membership from the frequency manipulation, a common problem in Stroop research. Effler $(1977 \mathrm{a}, 1980,1981)$ has also reported frequency effects.

Proctor (1978) pointed out that strength of association and frequency were typically confounded with response-set membership. He broke this confounding and showed that responseset members still interfered more than nonmembers. For color words not in the response set, interference was a direct function of the strength of association of the words to the concept of color, a conclusion in accord with that of Fox et al. (1971).

Alperson (1967) trained subjects on paired associates where the response terms were either connected or unconnected to the color-naming task. When the stimulus terms were made the irrelevant materials in the color-naming task, semantic relatedness of the response terms had a considerable effect, even with these newly learned pairs. To bolster the conclusion that meaning was the key, Bakan and Alperson (1967) demonstrated that words interfered more than did nonsense syllables equated for pronounceability.

Using the same approach, Pritchatt (1968) had subjects associate nonsense syllables with colors, and observed interference when the nonsense syllables appeared later as the irrelevant dimension in a color-naming task. Analogously, Stirling (1979) required subjects to learn to respond to color patches with letter names. When these letters became the incongruent dimension in color naming, interference resulted. Similar procedures have been used elsewhere (e.g., Glaser \& Dolt, 1977; MacLeod \& Dunbar, 1988). Of course, whether these studies speak to the role of meaning in interference depends upon the representation underlying such paired-associate learning.

More in keeping with Klein's procedure, White (1969) had subjects identify color versus direction attributes in the presence of incongruent attribute names. The more semantically similar the incongruent attribute name, the more interference

\footnotetext{
${ }^{5} \mathrm{~A}$ set of norms for colors and color words has since been constructed and could be used in a detailed investigation of association (Solso, 1971).
} 
was obtained, particularly for the color dimension. Fox et al. (1971) showed semantic gradients of interference on several Stroop analogs, including spatial direction and numerosity, and strongly supported Klein's arguments.

Murray, Mastronardi, and Duncan (1972) also supported Klein in showing that subjects named the colors of color words more slowly than those of animal words. However, when subjects were required to sort items on the basis of whether the words or the ink colors were the same or different, colors were sorted faster than words. The nature of the task can completely determine the form of the interference observed. Similar points have been made in the picture-word work (Glaser \& Glaser, 1989; Smith \& Magee, 1980) and in the priming work (Henik et al., 1983).

In an often-cited study, Keele (1972) argued that interference must occur after the memory-retrieval stage. When subjects pressed buttons to indicate their responses (rather than speaking them), only color words interfered; noncolor words and scrambled color words did not differ from his control (letterlike Gibson forms). The scrambled-condition result is surprising, though; every stimulus began with the same letter as its corresponding word (rde, gnere, ywoloe, and belu), which ordinarily causes interference (see Acoustic Variation). ${ }^{6}$ Possibly Keele's use of manual responses, known to decrease interference overall, is responsible (see Response Modality: Oral Versus Manual).

Many investigators have manipulated the meaning of the single, irrelevant word. For instance, Effler (1978a) practiced subjects on color-related versus color-unrelated words and reported a decreased difference in interference with practice. Also Ridley, Johnson, and Braisted (1978; see also Ridley, 1980) presented evidence that semantic-differential ratings of noncolor words predicted color-naming times. In sum, the many manipulations of meaning of the irrelevant word on a single Stroop trial all converge on this empirical generalization: Compared with naming the ink color alone, irrelevant verbal stimuli unrelated to the concept of color interfere only minimally with color naming. However, as the word's semantic association to the concept of color increases, so does its potential to interfere.

Semantic variation induced by priming. Since the early 1970s, the semantic-priming technique has had increasing contact with the Stroop literature. Probably the two most widely known members of this set are the dissertations of Warren (1972; see also Warren 1974) and Conrad (1974). Discussing these in detail will both introduce the method and set the stage for the variations that have succeeded them.

Warren's (1972) basic idea was that the irrelevant word on a Stroop trial should interfere more if it had just been activated by a preceding event. Preceding each critical color-word trial, he placed a priming event. On control trials, this event consisted of the phrase "No list this trial." On priming trials, the event consisted of a list of three words from a single semantic category: aunt, uncle, cousin or dog, cat, horse, for example. Then the critical color-naming trial occurred, with either the category name (relatives), a repeated category member (aunt), an unrelated word (doctor), or a row of Xs as the "word."

What Warren observed was increased interference in naming the ink color when the irrelevant word was primed. For the words aunt or relatives in red ink, subjects were slower to say "red" if they had just seen relevant primes; the effect was somewhat larger for aunt. In later experiments, Warren established that this activation persisted over at least five intervening items when subjects had to remember earlier words for a final test, but only a bit over one intervening item ( $30 \mathrm{~s}$ ) when this requirement was dropped. This was true whether the critical irrelevant word was the category name or a repeated category member. He did not test nonstudied category members.

In his 1974 follow-up study, Warren varied the associative strength between an auditory prime word and the irrelevant visual word on the critical color-naming trial. The relation could be high (king-queen), medium (bath-clean), or low (wishdream). Subtracting the control times for unrelated auditory primes (e.g., food, law, or hand), there was significant interference for high $(95 \mathrm{~ms})$ and medium $(50 \mathrm{~ms})$ but not for low $(20$ $\mathrm{ms}$ ) items. Thus, interference declined systematically with associative strength. Warren then demonstrated that this occurred only for forward associates, not backward associates, strongly suggesting that the prime activates the irrelevant word (rather than the reverse) on the critical trial.

Conrad's (1974) thesis used Warren's as a springboard, extending the priming domain from words to sentences. When the sentence context came before the ambiguous word (e.g., "The toy costs a nickel"), there was considerable interference in color naming for the ambiguous word itself (nickel, $100 \mathrm{~ms}$ ), the appropriate category (money, $106 \mathrm{~ms}$ ), and even the inappropriate category (metal, $64 \mathrm{~ms}$ ), relative to a control sentence (e.g., "The craftsman made the chair"). Apparently, both senses of nickel were activated by the sentence despite its clear meaning.

Interestingly, when the sentence context came after the ambiguous word (e.g., "That nickel is from her coin collection"), interference in the three conditions virtually disappeared $(19,2$, and $35 \mathrm{~ms}$, respectively). Conrad took this to indicate either decay of activation or interference from succeeding words. The critical result, though, was the context-before condition. She went on to show that the interfering capability of an ambiguous word was no greater in an ambiguous sentence: Both senses of the word were activated regardless of how it was used in the sentence. Oden and Spira (1983) confirmed that both senses of an ambiguous word were indeed activated, but that their extent of activation was affected by context. All candidates were activated, and then further processing narrowed the possibilities.

Many studies sprang from those of Warren and Conrad. McClain (1983a) attempted to link their logic with Klein's (1964). She manipulated both the prime word and the irrelevant word on the color-naming trial using incongruent combinations only. There were four critical relations: (a) prime-red, irrelevant-blood, (b) prime-apple, irrelevant-fire, (c) prime-apple, irrelevant-apple, and (d) prime-nail, irrelevant-nail. Because Condition (a) explicitly activates color and Condition (b) repeats the irrelevant but color-related word, she predicted that these two conditions would produce more interference, which they did.

Merrill, Sperber, and McCauley (1981) pursued the influence

\footnotetext{
${ }^{6}$ Furthermore, Michael Masson and I have data showing that scrambled color words with no letters in the correct position still cause interference in an oral response.
} 
of context on semantic interpretation. On a critical trial, a target word such as claw appeared in a color to be named. Before the critical trial, either an appropriate ("The girl fought the cat"), an inappropriate ("The girl touched the cat"), or a neutral ("The man fixed the car") sentence or word (cat vs. car) was displayed. Poor and good comprehenders showed equivalent interference when the prime was an appropriate or inappropriate word. However, when the prime was a sentence, poor comprehenders again showed interference for both types of primes, but good comprehenders showed interference only for appropriate primes. Merrill et al. concluded that good comprehenders encode words with reference to an entire sentence's meaning, whereas poor comprehenders encode the words as distinct units.

Dosher and Corbett (1982) examined whether sentences like "The man swept the floor" activated relevant instruments (e.g., broom). If so, then broom should interfere with naming its color of print. There was no evidence for such activation, relative to an unrelated prior sentence, except if subjects were explicitly told to think of the instrument. Interestingly, such an instruction led to facilitation, not interference, contrary to the other studies in this section (but see Keenan, Potts, Jennings, \& Golding, 1988, and Whitney, 1986, for similar findings). Perhaps if a primed irrelevant word is processed especially quickly, it is dealt with before it can exert a negative effect. This idea merits further exploration; it may represent a potentially useful tool in psycholinguistic research.

In a series of studies, Whitney and his colleagues (Whitney, 1986; Whitney \& Kellas, 1984; Whitney, McKay, Kellas, \& Emerson, 1985) examined lexical access using the Stroop task. Initially, Whitney and Kellas (1984) presented sentences that biased a typical member of a category (e.g., "The guest saw the bird that landed on the branch"-robin) or an atypical member (e.g., "The guest saw the bird that roasted on the grill"chicken), or that were neutral (e.g., "The guest saw the towels that hung in the bathroom"). Regardless of the prime sentence, the typical word always caused interference, whereas the atypical word did not. Yet typical words were better retrieval cues for typical sentences, and atypical words were better retrieval cues for atypical sentences. They concluded that category referents are not necessarily instantiated for single sentences.

On the basis of manipulations of item dominance and delay before testing, Whitney et al. (1985) confirmed the findings of Conrad (1974) and of Oden and Spira (1983) that initial semantic access is independent of context both for ambiguous and unambiguous nouns. Whitney's (1986) dissertation extended this work to anaphoric reference. Priming with atypically biasing sentences led to interference in color naming for atypical words, whereas priming with typically biasing sentences led to facilitation for typical words, the latter reminiscent of Dosher and Corbett's (1982) finding. Clearly, word meaning matters; even noncolor words can produce (or increase) interference-or even facilitation-under suitable priming conditions.

Also important is the subject's strategy. Henik et al. (1983) demonstrated that when subjects named primes before the color-naming trial, normal interference was observed. However, when subjects examined the primes for specified target letters, very little interference was observed. A corresponding pattern occurred for facilitation in lexical decision. Again meaning matters: Diverting the subject from thinking of the meaning of the prime word virtually eliminated the usual effects.

Much of the research on word meaning has been in the picture-word task, where the meaning of both the picture and the word-and their relation-can be varied. Probably the best known work using this task was by Lupker (1979; Lupker \& Katz, 1981, 1982). In his 1979 paper, he confirmed Rosinski's (1977) finding that same-category words magnified interference relative to either unrelated words or pronounceable nonwords, which caused equivalent interference. Categorical relations have a similar effect in the "flanker" task where both stimuli are words (Shaffer \& LaBerge, 1979).

Lupker went on to show that association between the picture and the word did not increase interference, nor did instance typicality modulate the extra interference as a result of shared category. Thus, some semantic variables are not potent. Word imageability was a critical determinant in Lupker's study, which led him to suggest that the word's relevance to response demands was crucial, as in the color-word task. Lupker (1979, p. 494) went so far as to maintain that the two tasks were "nothing more than two sides of the same coin."

Smith and Magee (1980; see also Magee, 1982) demonstrated that although incongruent words interfere with picture naming, incongruent pictures interfere with word categorization. They argued that pictures gain access to semantic information more readily than to name information, but the reverse is true for words. Glaser and Glaser (1989) took this argument considerably farther, building a model for naming versus categorizing. These studies, like that of Henik et al. (1983) with the colorword task, highlight the point that the task required of the subject when faced with a multidimensional stimulus is a crucial determinant of the pattern of interference observed.

The empirical generalization is straightforward: $A$ colorunrelated word can be made to cause greater interference (or facilitation, or both) with color naming if its meaning is activated by a related word or phrase shortly before the color-naming trial. Related words and primed words are hard to ignore. Certainly, questions remain to be addressed here (e.g., the time course of such priming effects), but the basic result is well established.

\section{Congruency Effects}

So far this review has focused on Stroop interference. However, there is another side to the coin: Stroop facilitation. If the wrong word can slow ink-naming performance, then intuitively the right word ought to speed performance. Curiously, the congruent case (e.g., red in red ink, respond "red") was not investigated until the advent of the individual-trial version of the Stroop task. Although Langer and Rosenberg (1966) had a congruent condition of sorts in their study, the first actual use of color-word congruent trials was by Dalrymple-Alford and Budayr (1966). Their inclusion of congruent items among incongruent ones on Stroop cards made little difference in overall response time.

Shortly thereafter, Sichel and Chandler (1969) used the individual-item procedure, and reported that color naming was in fact faster for congruent items $(645 \mathrm{~ms})$ than for incongruent items $(777 \mathrm{~ms})$, but that both showed interference relative to a 
XXXX-type control (541 ms). Thus, it is more reasonable to say that there was reduced interference rather than true facilitation for the congruent condition. Perhaps the extent of apparent facilitation depends on the choice of control condition; recall that Dalrymple-Alford (1972a) observed no facilitation relative to a XXXX control but reliable facilitation relative to an unrelated-word control.

Although there were reports of interference in the congruent condition (e.g., Nealis, 1973; Schulz, 1979), more often some degree of facilitation was reported (e.g., Kalkofen, 1969). One complication was whether congruent and incongruent items were mixed or separated (blocked), as indicated in the exchange between Smith (1970) and Kalkofen (1970). Indeed, using a spatial analog, Logan and Zbrodoff (1979) showed that the proportion of congruent trials over the entire task affects processing time (see Probability of Various Trial Types). A further complication is that congruence of word and color across successive trials can also have an impact (Effler \& Rabenstein, 1979).

Dyer (1973a) presented word and color on different sides of the fixation point and observed $26 \mathrm{~ms}$ of facilitation for the congruent case (compared with a XXXX control). Interference was $48 \mathrm{~ms}$ in the incongruent case. In a same-different analog also using the XXXX control, Dyer (1973b) found significant interference $(179 \mathrm{~ms})$ and facilitation $(55 \mathrm{~ms})$. Recalling Dalrymple-Alford's (1972a) findings of $131 \mathrm{~ms}$ of interference and $63 \mathrm{~ms}$ of facilitation, it is clear that there is usually much less facilitation than interference (see also Dyer, 1974).

Hintzman et al. (1972) reported $42 \mathrm{~ms}$ of facilitation relative to a scrambled color-word control or a "neutral" control, both retaining the first letters of color words. My concerns are that (a) such controls would themselves be expected to interfere, so the facilitation might disappear with a more standard control, and (b) the claim that neutral words do not interfere in the individual-trial version of the task (contrary to Klein's finding that they do in the list version) is suspect given their choice of control condition. Strengthening my suspicions, Redding and Gerjets (1977) found facilitation in the congruent condition relative to scrambled color words and neutral words, but not relative to nonword controls.

In her dissertation, Regan (1979) obtained facilitation for congruent words and interference for neutral words; she also obtained facilitation using just the first letter of the correct color name (see also Regan, 1978). Yet turning the words upside down and backward to slow reading, Dunbar and MacLeod (1984) obtained little facilitation in the congruent condition despite huge interference in the incongruent condition. In fact, the congruent condition was almost identical to the XXXX control condition across our experiments.

Glaser and Glaser (1982) obtained $16 \mathrm{~ms}$ of facilitation and $72 \mathrm{~ms}$ of interference, relative to a XXXX-type control, when the color and word were simultaneous and the task was color naming. Thomas's (1977) dissertation presents similar data. This asymmetry is by now the expected pattern: Facilitation is not a necessary concomitant of interference, although this may have more to do with measurement than with a true theoretical decoupling.

With a neutral word as the control condition, Duncan-Johnson and Kopell $(1980,1981)$ found reliable facilitation in the congruent condition (and strong interference in the incon- gruent condition). However, they observed no change in P300 latency, an event-related brain potential assumed to be a "pure" measure of stimulus processing. On this basis, they favored a response-competition account of the Stroop effect, as did Warren and Marsh (1979) in a similar study.

Rayner and Posnansky (1978) obtained facilitation for pseudohomophones (e.g., bloo) in the picture-word task, but their use of blocked trial types allowed a strategy of responding by reading the words. Mixing trial types, Dennis and Newstead (1981) obtained facilitation for color words but not pseudohomophones, although both produced interference. This suggests that the slow-to-read pseudohomophones could not be processed sufficiently quickly to assist color naming in accord with a relative speed-of-processing account.

There have also been demonstrations of facilitation in Stroop analogs. Certainly, this is evident in the picture-word task (e.g., Ehri, 1976; Golinkoff \& Rosinski, 1976; Underwood, 1976). For example, Ehri (1976) reported facilitation in picture naming for congruent pictures and words using a picture-only control. More recently, Glaser and Düngelhoff (1984) showed reliable facilitation for the correct name of a picture relative to a XXXX control, although the facilitation of $44 \mathrm{~ms}$ was substantially less than the interference of $131 \mathrm{~ms}$ caused by a different member of the same category.

Using color naming of season-appropriate or inappropriate words, Seymour (1977) obtained facilitation plus interference. Using the arrows task, Clark and Brownell (1975) found subjects to be faster to identify which way an arrow was pointing (up or down) if it was located in the appropriate place in space (top or bottom, respectively). For letter identification in the presence of irrelevant letters, Taylor (1977) observed reliable facilitation as well. Of course, facilitation is very well known in the word-priming domain.

To summarize, here is the general conclusion: Congruence between the irrelevant word and the to-be-named ink color often produces facilitation. However, this facilitation is much less than the corresponding interference in the incongruent condition, and the choice of control condition may be crucial. Partly, this is a consequence of the relatively smaller amount of facilitation usually obtained, itself no doubt resulting partly from the problem of trying to speed up an already rapid naming response.

It would be interesting to perform a color-word study along the lines of the recent work by La Heij and Vermeij (1987), which showed that, whether reading words or naming pictures, interference decreases and facilitation increases as a function of increasing target set size. The small facilitation we have come to expect may be at least partly a consequence of the small set size usually used in Stroop experiments. ${ }^{7}$

\section{Integration of the Two Dimensions}

So far in this section, I have considered studies focusing on the relevant dimension (color) and on the irrelevant dimension (word). The only aspect of the single trial that remains to be

\footnotetext{
${ }^{7}$ Note, however, that Marina Vanayan and I have data from the picture-word task showing an increase in interference with increasing set size, so this matter is not resolved as yet.
} 
dealt with is the relation between the two dimensions. On a given trial, the two dimensions of the stimulus can be more or less perceptually integrated. We know that stimulus integration can be a powerful determiner of performance in many tasks (see Garner, 1974); how much does it influence the Stroop effect?

Despite relatively little published work, this issue must be addressed if we are to compare various versions of the Stroop task meaningfully. For instance, the word is not integrated into the picture in the picture-word task to the same extent that it is integrated into the color in the standard color-word task. Furthermore, if color/picture and word are separated, as in SOA studies (e.g., Glaser \& Glaser, 1982; Glaser \& Düngelhoff, 1984) or in the bar-above-word procedure (Kahneman \& Chajczyk, 1983), do results from these modifications translate readily back to the original task?

There were some hints as to the importance of integration even 30 years ago (e.g., Gardner et al., 1959; Gardner \& Long, 1962). More recently, though, Flowers and Stoup (1977) observed that interference persisted virtually unchanged over four practice sessions in a card-sorting task where word and color were integrated (i.e., the word red printed in green ink), but vanished with the same amount of practice when they were not integrated (i.e., the word red inside a green-outlined rectangle). Moreover, interference was greater in the integrated case.

Although there is no doubt that nonintegrated Stroop stimuli can show interference and facilitation (Dyer, 1973a; Gatti \& Egeth, 1978; Glaser \& Glaser, 1982; Kahneman \& Chajczyk, 1983; Merikle \& Gorewich, 1979), this does not mean that (all of) the same mechanisms are involved. As Kahneman and Henik (1981) demonstrated, if the incompatible word and color patch appear in the same attended location, there is more interference ( $202 \mathrm{~ms}$ ) than if they appear in adjacent locations, only one of which is the focus of attention $(50 \mathrm{~ms})$. Kahneman and Henik also observed that compatible words facilitated color naming if the words were in the attended location $(48 \mathrm{~ms})$, but interfered if they were nonattended ( $38 \mathrm{~ms})$.

Bradlyn and Rollins (1980) obtained interference in the integrated version but not in a nonintegrated one (the word in black ink above a color patch); however, this result appears not to generalize. Thus, Gatti and Egeth (1978) observed a decrease in interference from 90 to $\mathbf{4 0} \mathrm{ms}$ as the word moved farther from the to-be-named color patch (from one to five degrees), but all cases produced reliable interference. The integrated version of the Stroop task is harder, but both versions produce interference.

Although it seems that nonintegrated stimuli do produce interference fairly reliably, the amount is relatively small, apparently falling off as separation increases. Using the picture-word task, Underwood (1976) argued that locational uncertainty with respect to the two dimensions of the task was very influential. When subjects knew where to expect the relevant picture versus the irrelevant word, they showed a small amount of interference from the competing word. When they did not know where to expect picture versus word, interference was considerably greater. Apparently, not being able to prepare for where to direct attention makes the separated case more analogous to the integrated case.

What is needed is a systematic parametric comparison of the two versions of the task, perhaps manipulating practice as in the Flowers and Stoup (1977) study. Until such time, the extent of importance of dimensional integration is difficult to ascertain. Certainly, though, it seems to matter, so here is my somewhat tentative general conclusion: If the to-be-named color and the to-be-ignored word are presented in separate spatial locations, interference will be reduced (but not eliminated) relative to the standard, integrated version of the task. Locational uncertainty makes an important contribution in nonintegrated situations.

We have seen what happens when the dimensions of a single Stroop trial are varied; let us now examine what happens with manipulations intended to affect the entire task.

\section{Experiment-Wide Manipulations of Information}

This section focuses on variables affecting more than one trial in a Stroop experiment. Some of these variables-such as the presence or probability of certain trial types-only exist with reference to more than one trial. Others-such as SOAoccur at the level of a single trial, but have broader implications. These variables all may be thought of as affecting how the subject approaches the task as a whole.

\section{Probability of Various Trial Types}

Probably the most straightforward way to set up a Stroop experiment is Stroop's (1935b). He used four conditions, each in an independent block of trials: incongruent color naming, control color naming, incongruent word reading, and control word reading. At first glance, this might also appear to be the "safest" way, reducing the likelihood of subjects adopting special strategies to deal with a mixture of trial types. Does blocking conditions minimize strategy use or does it promote creating a special strategy for this special case? The most reassuring results are those that hold up under both mixed and blocked conditions. No doubt, too, the composition of the entire set of trials influences the subject's strategy. In the limit, if all trials in a block were congruent and the task was to name the ink colors, clever subjects could decrease their response time by reading the words instead. Such a strategy would not work if all of the trials were incongruent. The question, then, is what happens at intermediate values.

I have already mentioned that Dalrymple-Alford and Budayr (1966) found no change in interference when some congruent trials were added to a card made up largely of incongruent trials, but they did not systematically manipulate the frequency of trial types. Zajano and Gorman (1986) showed that total color-naming time per card decreased as more congruent trials were added to the card. Shor (1975) used Hamers's (1973) highlow auditory analog and found more interference when half of the trials were congruent and half incongruent than when all of the trials were incongruent. This counterintuitive result might be a consequence of subjects listening to the word and saying its opposite in the incongruent case, a strategy that could be eliminated by using more than two responses. My guess is that Shor's result would reverse itself with such a modification.

Logan and Zbrodoff (1979) used the above/below spatial analog of the Stroop task where subjects are to read the word and ignore its spatial location. (Note that in this task interference 
occurs in reading the word, unlike in the Stroop task.) As the frequency of incongruent trials increased from $10 \%$ to $90 \%$ over experiments, response times shifted from congruent trials being faster to incongruent trials being faster. Logan and Zbrodoff were careful to point out that low error rates indicated subjects were not simply "cheating" by attending to the supposedly unattended dimension. Apparently, subjects adopted a strategy of dividing attention over the two dimensions.

Still it would be better to use a larger set of items to preclude the strategies possible with only two stimuli. Lowe and Mitterer (1982) used three ink colors (red, blue, and green), the three corresponding color words, and three neutral words ( far, most, and slant). On each trial, two words were presented. The target was always a neutral word in color, and the subject was to name the ink color. The other word was always printed in black ink, but could be a color word or neutral word. When this irrelevant word was a color word, it could either be congruent or incongruent with the target ink color.

Lowe and Mitterer manipulated the proportion of congruent stimuli in steps of .25 from 0 to .75 . Relative to the neutral control, interference increased from $35 \mathrm{~ms}$ with $0 \%$ congruent trials to $66 \mathrm{~ms}$ with $75 \%$ congruent trials; however, facilitation hardly changed (12 to $17 \mathrm{~ms}$ ). This was taken as evidence of automatic word encoding in both conditions, but with a further conflict-resolution process in the incongruent case following Taylor's (1977) arguments. Note, too, the different effects on facilitation and interference.

Although there are limited data, it seems that the composition of the entire set of trials does matter. As the proportion of congruent trials increases, the "irrelevant" word becomes progressively more relevant. Here, then, is the general conclusion: The presence of congruent trials among the incongruent and control trials will tend to invoke the tactic of splitting attention over the two dimensions, thereby increasing interference on incongruent trials. For this reason, it is probably best to conduct novel experiments initially without a congruent condition, and then to add that condition and observe whether its presence changes interference fundamentally. Thus far very few experiments have taken this tack. We should also determine the extent to which this attention-splitting strategy is under subject control, perhaps through a manipulation of instructions or payoffs.

\section{Stimulus Set Size}

There is typically quite a small set of stimuli in the colorword task and quite a large set in the picture-word task. Probably this is because creating large, differentiable sets of items is easier with pictures than with colors. Indeed, the bulk of the color-word studies use from two to five stimuli. We know that increases in stimulus set size increase time to name but have little impact on time to read (cf. Fraisse, 1969; Gholson \& Hohle, 1968b). Consequently, some investigators adopted setsize manipulations as one way to attack interference.

An illustration of how few colors are typically used in the Stroop task comes from a study of set-size effects by Golden (1974a); he found that using three, four, or five different colors made little difference in interference. Other research supports his conclusion. Gholson and Hohle (1968a) found that, in a choice reaction-time version of the Stroop task, increasing set size from two to four increased overall response time but not interference. Essentially the same result was obtained for set sizes three to five by Ray (1974) and for set sizes two to five by McClain (1983b). Although this is the usual range, I am reluctant to infer from such small variations that set size is not a factor.

Until recently, the only discordant Stroop study was that of Williams (1977), who used the largest variation: from 2 to 8 . She found that both interference and facilitation increased as set size increased. The picture becomes even more complicated as soon as we step beyond the color-word task. In the increasingly common two-word analog, several studies have consistently found decreases in interference coupled with increases in facilitation as set size increased. Taylor (1977) obtained this result in moving from 2 to 4 alternatives; La Heij, Van der Heijden, and Schreuder (1985) obtained it in moving from 2 to 12 alternatives. How are we to bring these disparate findings together?

La Heij and Vermeij (1987) recently tried to answer this question. Varying set size from two to eight in both a letter-reading and a picture-naming task (in separate experiments), they found that interference decreased and facilitation increased for both types of materials relative to a XXXX-type control. Although they claim (p. 359) that it would be difficult to replicate this experiment using the color-word task, I am not convinced: Their pattern is evident even between set sizes two and four. Partly because their findings conflict with those just reviewed, a replication would be useful. Results with the color-word task that corresponded to those of La Heij and Vermeij (1987) would further strengthen the argument that all of these superficially different interference tasks in fact tap a common element.

A general conclusion here, given the conflict in the data base, is risky. Furthermore, there is the issue of response set size yet to be discussed (see Response Set Size and Composition). So I simply note that stimulus set size may influence the Stroop effect. Part of my caution stems from some data that Marina Vanayan and I have collected: Increasing set size in the picture-word task from 4 to 12 increased interference in our study. This disagrees with $\mathrm{La}$ Heij and Vermeij, and we are pursuing possible reasons for the difference. Until such discrepancies are resolved, it would be premature to offer a firm statement about stimulus set-size effects.

\section{Trial Sequence}

People often feel particularly tongue tied when the to-be-ignored word on one trial turns out to be the to-be-named color on the next trial (e.g., green in red ink precedes blue in green ink). Having just suppressed the response "green" seems to make it harder to say it on the next trial: There are sequential effects in the Stroop task. Dalrymple-Alford and Budayr (1966) first pointed out that interference in the list version of the Stroop task was greatest if each ink color was that named by the immediately preceding word.

The most detailed investigations in this area are those of Neill (1977, 1978; Neill \& Westberry, 1987) and Effler (1977a, 1977b, 1978b, 1980; Effler \& Rabenstein, 1979). Effler (1977a) reported a "serial interference": When the irrelevant word on trial $n$ was acoustically similar to the ink color on trial $n+1$, 
interference was enhanced. Conversely, when the ink color on trial $n$ was that of the irrelevant word on trial $n+1$, interference was reduced (Effler, 1977b). He then confirmed and extended these results in a variety of ways (Effler, 1978b, 1980; Effler \& Rabenstein, 1979).

The first of these findings makes sense if it is assumed that the word on trial $n$ must be suppressed, and then has to be given additional activation to become the response on trial $n+1$. The second result can be explained as an instance where having just made a particular response on the last trial makes it easier to discard that as a possible response on this trial. Of course, such explanations are easier after having seen the data.

Neill (1977) extended the Dalrymple-Alford and Budayr (1966) observation to the individual-trial version of the Stroop task, finding the same result that they and Effler (1977a) found: greater interference if the word on trial $n$ matched the ink color on trial $n+1$. Neill labeled the phenomenon the distractor-suppression effect. We now know that the phenomenon is fairly general (e.g., Westberry, 1984), and extends to letter naming (Allport, Tipper, \& Chmiel, 1985; Tipper \& Cranston, 1985) and picture naming (Allport et al., 1985; Tipper, 1985). In the case of pictures, even nonidentical members of the same category can produce the distractor-suppression effect.

Neill (1978) observed that when the word on trial $n+1$ matched the ink color just named on trial $n$, there was facilitation, this time replicating Effler (1977b). He took this as evidence that the set of highly activated competing responses was made smaller by the overlap, hence reducing response competition, as opposed to the suggestion I offered in discussing Effler's (1977b) study.

Lowe $(1979,1985)$ first obtained this successive-trials effect when consecutive items were not all incongruent items of the standard type used by Neill, thereby increasing its generalization. He then manipulated the proportion of trials of various types in subsequent experiments, showing that the distractorsuppression effect could be eliminated or even turned into facilitation. This clearly implicates subject strategies in the phenomenon, and Lowe was unconvinced of the need to propose an inhibitory mechanism of the sort favored by Neill or Tipper. He suggested that subjects may have been trying to match successive stimuli, thereby not treating trials as independent, but later rescinded this argument (Lowe, 1985). Efforts to make successive stimuli less matchable, by using different cases and by varying list composition and SOA, did not noticeably alter the distractor-suppression effect. Still resisting an inhibition argument, Lowe maintained that the problem was in coordinating the color and word codes.

More recently, Neill and Westberry (1987) manipulated speed-accuracy instructions and intertrial interval. Under accuracy instructions, subjects showed the effect, but it disappeared as emphasis on speed increased. As well, the effect persisted with up to a 1-s intertrial interval, but dissipated between 1 and $2 \mathrm{~s}$. Neill and Westberry interpreted these findings as consistent with a selective-inhibition account: After broad activation, selective inhibition is used to restrict processing to just the relevant information, an idea very much in accord with the work on priming of ambiguous words discussed under Semantic Variation (e.g., Oden \& Spira, 1983).

The work on the distractor-suppression effect suggests a gen- eralization beyond the Stroop effect. In addition to activation, there may well be an inhibitory process that helps to constrain the information selected for more extensive processing. For the present, this is seen as an active strategy of inhibition. Whether the facilitation from successive trials has to do with a functional shrinking of the set of competing responses or a suppression of responses recently uttered is less clear. My own bias, in opposition to Neill (1978), is to invoke a suppression idea so that the facilitation and interference effects as a result of item sequence have a common grounding.

As a footnote, it is interesting to contrast these results with those involving a slightly different variation. Thomas (1977) repeated the word component over successive pairs of colorword stimuli, and found that word repetition decreased both interference and facilitation. Effler (1980) confirmed the interference decrease, both when the word named an ink color in the response set and when the word named an ink color not in the response set. However, there were no repetition effects for noncolor words. Subsequently, Effler (1981) tried to determine whether amount of repetition over trials was important, but his odd nonmonotonic pattern provides little insight.

Ellison and Lambert (1968) took a rather different tack. They had subjects repeat the color words continuously before performing the interference trials, with the goal of reducing the meaning of the words and hence their potential for interference. Although performance on the interference card sped up, they could not determine whether this was due to "semantic satiation." A number of additional controls would have been desirable in this work. Still their basic finding is in line with Effler's (1980).

These two different outcomes having to do with the relation of the word on trial $n-1$ to the critical stimulus on trial $n$ actually fit together quite nicely, so I offer the following conclusion: When the irrelevant word on trial $n-1$ is the name of the target ink color on trial $n$, interference with color naming will be enhanced temporarily; when the ink color on trial $n-1$ matches the word on trial $n$, there will be some facilitation of color naming on trial $n$. If the word on trial $n-1$ is repeated on trial $n$, then the word is already suppressed and will cause less interference in naming a different ink color on trial $n$. An interesting study would be to mix these two types of repetition effects in the same experiment, directly comparing their size.

\section{Pretrial Cues}

Very closely related to studies of the effects of one trial on the next are studies of the effects of a cue just before a Stroop trial. Nealis (1974) tackled this problem by presenting color words in colored ink before a to-be-read word. He was able to produce a reverse Stroop effect in that there was interference evident in reading the target word. Hinton (1976) found that prior presentation of the word whose ink color was to be named on the upcoming target trial tended to decrease color-naming time (but see Trial Sequence for conflicting results). However, when that word had to be rehearsed for later recall, response time to its ink color increased. Hinton took the facilitation effect as evidence of reduced competition for entry into a response buffer; the increased interference effect was held to be the result of increased problems in response selection. 
Neill (1978) used the precue as a sort of "warning," the most prevalent use of this procedure. The target was a standard incongruent color-word combination. Neill observed roughly equivalent response times after a neutral cue or the relevant color word. However, interference was increased by cueing either the wrong ink-color name or the irrelevant color word. According to Neill, the number of competing responses and their strength determined interference. The results were inconsistent with the idea that increasing a response's availability could make it easier to reject.

Using the hi-lo analog, Harvey (1984) varied the interval by which a warning preceded the critical stimulus. The warning stimulus signaled the subject whether to respond to the word's meaning or its position. Oddly, only word reading showed interference, which declined as the time between warning and critical stimulus increased. Harvey took this as evidence that when subjects could better focus their attention on the appropriate dimension because they were warned, they were better able to cope with incompatible dimensions. This idea seems worthy of further study.

Logan and Zbrodoff (1982), in their spatial analog of the Stroop task, also used the precue technique. When the cue provided advance information about whether the upcoming trial was compatible or incompatible, response time on cued trials was faster than on uncued trials. When only one cue could appear, its benefit was greater than when two cues could appear. Practice with cues permitted subjects to benefit from them even with shorter warnings, but did not increase the benefit. Overall, these results were taken to reflect successful subject-initiated construction and use of strategies. Because the Stroop task is often seen as a hallmark index of automaticity, such demonstrations of the role of strategic control are important.

Logan, Zbrodoff, and Williamson (1984) pursued this using the color-word task. By making the ink color predictable from the word and then providing advance knowledge of the word, they found that subjects could perform the color-naming task more rapidly with two ink colors but not with four. Their result with only two responses is reminiscent of Shor's (1975); the fact that the advantage of the cue dissipated with four responses suggests that the strategy could not handle the greater uncertainty with more stimuli.

Probably the most provocative recent results are those of Marcel (1983, Experiment 3) on unconscious perceptual processing. He first determined the interval required between a stimulus and a pattern mask such that a subject could not discriminate a word from a blank. Then he ran blocks of trials in which a cue word was either masked with this interval, to prevent conscious perception, or masked with a very long interval, so that it would be easily seen. He included congruent, incongruent, neutral (e.g., the word water), and no-word control trials, and also varied over blocks whether the word was presented simultaneously with the color patch or $\mathbf{4 0 0} \mathrm{ms}$ earlier. Marcel found that performance in the no-word control and the neutral control was essentially identical. Although facilitation and interference effects were a little larger if the subject was aware-particularly when the word preceded the color by $400 \mathrm{~ms}$-both were present even when the subject could not report whether a word cue had been present. Marcel argued against the view that interference arose in response production.

As Marcel pointed out, his was not the first study of "subliminal perception" in the Stroop task. Severance and Dyer (1973) tried but did not obtain a subliminal Stroop effect. Although similar to Marcel's in some ways, their study used extremely brief word exposures followed by a bright blank field to obtain chance performance in pretesting. Marcel argued that their energy masking has its effect much more peripherally than does his pattern masking, so the difference in results is not that surprising.

Cheesman and Merikle (1984) examined Marcel's subliminal Stroop effect using a more stringent forced-choice method for obtaining the optimal threshold of awareness of the cue word. Then, using four colors, they varied the cue-word detectability from $25 \%$ (chance) to $100 \%$ (unmasked prime). At $25 \%$, there was no effect of the cue word; as cue-word detectability increased, so did facilitation and interference. They claimed that their findings refuted Marcel's claim of unconscious perception in the Stroop task.

Cheesman and Merikle (1984) went on to demonstrate that they could obtain effects of the cue at several SOAs when they used a subjective threshold in which subjects claimed not to see the cue word. Subsequently, Cheesman and Merikle (1986) demonstrated that subjective thresholds did convey some information about processing. First, they showed that the cue word had an effect whether it was above or below subjective threshold (so long as it was above objective threshold). They then varied the proportion of trials in which the cue and target were congruent, and discovered that subjects could use this variation to assist their processing, but only if the cue word was above subjective threshold. In other words, a strategy could be implemented only when subjects were aware of the primes, extending the conclusions of Logan and Zbrodoff (1982).

Although there is not a massive amount of evidence here, I will dignify the clear picture with a conclusion: Advance cues conveying information about the upcoming Stroop trial can be used to establish processing strategies that improve performance if these cues are above the level of subjective awareness and if a very small set of cues is used consistently. The major implication of the work in this section is that foreknowledge can permit subjects to construct a beneficial, task-wide strategy. Attentional-allocation policy is a critical element in the Stroop task.

\section{Stimulus Onset Asynchrony (SOA)}

Many explanations of Stroop interference have relied on the relative speed of processing of the two competing stimulus dimensions. Intuitively, if a subject processes two dimensions simultaneously, one could interfere with the other, especially if the dimension that is processed faster is the one that is supposed to be ignored (see Dunbar \& MacLeod, 1984, for a discussion of the "horse-race" metaphor). Logically, then, giving the slower color dimension a head start should reduce the impact of the ordinarily faster word processing, thereby decreasing interference (and facilitation). With the individual-trial procedure, such studies can be performed by manipulating the SOA between the word and color.

The first study to vary SOA was by Dyer (1971c). He used a 
large SOA range (0-500 ms) because he thought it possible that short SOAs would lead to increased interference but longer SOAs would lead to decreased interference. With four common colors and an XXXX-type control, he explored both incongruent and congruent combinations by having a word appear in black at 1 of 10 intervals before that same word appeared in color. The subject's task was to name the ink color.

Dyer (1971c) found facilitation for congruent trials (26 ms) and interference for incongruent trials $(75 \mathrm{~ms})$, relative to the control, at all word-preexposure intervals. However, the time by which the word preceded the ink color also mattered. Interference was about $90 \mathrm{~ms}$ with a $0-\mathrm{ms} \mathrm{SOA}$, increased to $118 \mathrm{~ms}$ at a 40-ms SOA, fell to $68 \mathrm{~ms}$ at a $200-\mathrm{ms}$ SOA, and then further decreased to $32 \mathrm{~ms}$ at a 500-ms SOA. Although a nonmonotonicity is suggested, in fact Dyer's data only allowed the conclusion that interference decreased with SOA. Nevertheless, Dyer claimed that interference peaked in the neighborhood of a 50ms preexposure of the word. He also noted that facilitation increased somewhat from the 0 -ms to the 200-ms SOA.

Rather than preexposing a color word in black and then showing that color word in an ink color, Dyer and Severance (1973) preexposed a color word in black and then showed a XXXX-type stimulus in an ink color. Thus, the color and word were now not integrated. Relative to the earlier study, this cut interference almost in half and eliminated facilitation. Furthermore, varying SOA from 0 to $100 \mathrm{~ms}$ had no effect on interference. When Severance and Dyer (1973) tried to replicate these findings with a "subliminal" preexposure of the irrelevant word, they found no interference.

In 1974, Dyer tried using much longer SOAs between the word and the ink color. Interference decreased to a minimal level with a 2-s SOA, but then increased again as SOA grew beyond $2 \mathrm{~s}$. Facilitation looked to follow the same pattern but with diminished magnitude. Relative to randomized SOAs, blocking SOA produced faster color naming at short SOAs, but the effect on interference was minimal. Taken together, all of Dyer's SOA results suggest an elongated S-shaped time course in the Stroop effect: Interference initially increased with greater SOA, then decreased, and finally increased again at very long SOAs. Such a pattern is not easily reconciled with any simple relative speed-of-processing interpretation.

In a thesis modeled after Dyer's work, Thomas (1977) varied SOA from the ink color leading the word by $300 \mathrm{~ms}$ to the word leading the ink color by $300 \mathrm{~ms}$. Interference with color naming was greater for shorter SOAs. This result was also extended to facilitation and confirmed by Neumann (1980), Goolkasian (1981), and Long and Lyman (1987). Precisely the same pattern was reported by Flowers (1975) in a sorting version of the colorword task; Flowers and Wilcox (1982) extended this to the flanker procedure using two letters or digits. In Thomas's study, facilitation occurred whenever the word preceded or even when it closely followed the corresponding ink color (up to $50 \mathrm{~ms}$ after). Overall, the evidence was not consistent with a simple differential rate-of-processing model.

Lassen (1975) extended SOA studies to the picture-word task. Interference with picture naming peaked when the incongruent word led the picture by about $100 \mathrm{~ms}$. On the other hand, although pictures did cause a small amount of interference with word reading, manipulation of SOA had no effect on reading words. These results are reminiscent of the data found in the standard Stroop task, as are Magee's (1982) data on SOA manipulations in the picture-word task.

The definitive pair of studies on the relation between SOA and interference has been reported quite recently. Glaser and Glaser (1982, Experiment 1) used the color-word task and included incongruent, control, and congruent trials. When the task was to read the word, there was no interference or facilitation regardless of whether ink color or word was presented up to $400 \mathrm{~ms}$ earlier: SOA had no effect on word reading. However, SOA had a powerful effect on ink-color naming. If the word was presented before or even as late as $100 \mathrm{~ms}$ after the ink color, both interference and facilitation occurred. Interference was maximal in a 100-ms window around simultaneous, consistent with Dyer's results.

In other experiments, Glaser and Glaser (1982) showed that increasing the frequency of congruent trials could lead to a reverse Stroop effect (ink color interferes with word reading), with both interference and facilitation in word reading when the word preceded the ink color by $200 \mathrm{~ms}$ or more. They argued that the high probability of the "irrelevant" word also being the name of the ink color led subjects to prepare the word for output. However, their main conclusion was that the SOA pattern did not readily fit a simple speed-of-processing model. They maintained that there was a fast, strong inhibition plus slower facilitation and inhibition deriving from response bias.

Glaser and Düngelhoff (1984) varied SOA in the pictureword task. The pattern was very similar to that in the colorword task: Word-reading time was unaffected by SOAs of up to $400 \mathrm{~ms}$ in either direction, whereas picture naming showed a strong influence. Again, when the word appeared within 100 ms of the picture, both interference and facilitation were evident in picture naming. When the word appeared more than $100 \mathrm{~ms}$ before the picture, there was considerable facilitation but little interference, as Thomas (1977) reported for the colorword task. Differing patterns of facilitation and interference in response to SOA manipulation have also been reported in the flanker task (Grice, Boroughs, \& Canham, 1984; Grice \& Gwynne, 1985).

Basically, the SOA pattern seems quite consistent in both the color-word and picture-word tasks. This permits the following generalization to be made: When the color (or picture) is to be named, maximal impact of a congruent or incongruent word will be observed when the two dimensions begin within $100 \mathrm{~ms}$ of each other. Facilitation may extend to longer SOAs than interference when the word comes first. Manipulating SOA has virtually no impact on word reading unless a very high proportion of congruent trials biases use of the color to initiate response production. The major significance of the SOA studies is that they call into question the idea that interference is due simply to words being processed faster than ink colors. If that were true, there ought to be a point at which an ink color presented sufficiently before a word would cause reverse Stroop interference (and facilitation). Concerted empirical efforts have failed to find any evidence of such a point.

\section{The Reverse Stroop Effect}

If a word normally interferes with naming a color or a picture, but a situation is created wherein the color or picture inter- 
feres with reading the word, this is an instance of a reverse Stroop effect. Such findings are of theoretical interest because they relate to the idea that interference depends on the relative speed of processing of each of the two dimensions.

The first report of a reverse Stroop effect was by Stroop (1935b, Experiment 3) himself in the seminal article. This effect arose only after considerable training and was quite transient. Since then, others have been more successful in creating stable reverse Stroop situations, but their success has usually relied on substantially changing the task, making it difficult to compare their results to the standard Stroop situation. Still the existence of the reverse Stroop effect is now widely accepted.

As an illustration, Palef and Olson (1975; see also Seymour, 1973) had subjects respond either to the meanings of the words above and below or to their spatial locations on the screen. In Experiment 1, spatial position was made easier (and hence faster) to process than word meaning. In this case, incongruent spatial position interfered with a keypress decision about word meaning, but incongruent word meaning did not interfere with a keypress decision about spatial position. In Experiment 2, where spatial position was made harder to process, the pattern of interference reversed. In general, the faster dimension interfered with the slower one but not vice versa.

Quite a number of other studies have demonstrated reverse Stroop effects as well (e.g., Abramczyk, Jordan, \& Hegel, 1983; Chen \& Ho, 1986; Chmiel, 1984; Dunbar \& MacLeod, 1984; Francolini \& Egeth, 1980; Glaser \& Dolt, 1977; MacLeod \& Dunbar, 1988; Martin, 1981; Morikawa, 1981; Nealis, 1974; Pritchatt, 1968; Shor, 1975; Warren \& Marsh, 1979). Many of these studies used nonverbal responses, although it is not clear how crucial response mode was because the stimuli generally were rather different from the basic Stroop task as well.

The two studies generally cited as illustrative of reverse Stroop interference are those of Gumenik and Glass (1970) and Dyer and Severance (1972). Both involved reducing the readability of the words by partial obliteration. Both found a reverse Stroop effect in that ink colors influenced word reading for hard-to-read words. Unfortunately, like many of the others in the list, these two did not examine interference in both "directions" in the same experiment.

It seems possible, then, to have interference occur from dimension A on dimension B and vice versa. However, many of these experiments are quite far removed from the standard task. Cases where exactly the same stimuli and responses were used with only an instructional difference are rare, leaving room for more work in this area. Yet interference can occur in both directions when the only change is from naming colors to reading words (e.g., Dunbar \& MacLeod, 1984), conflicting with the belief that the faster process interferes with the slower one, and not vice versa. For this reason, the following conclusion is added to the list, although it must remain a little vague at this point: $A$ reverse Stroop effect (i.e., interference with word reading caused by an incompatible, irrelevant ink color) appears to be possible, but this effect is not simply a consequence of the relative speeds of processing each dimension.

\section{Practice}

An obvious and theoretically critical question is: Does the Stroop effect change as a consequence of (type of) practice at the task? If so, how does it change, and what does this tell us about the cause of the phenomenon? Stroop and his predecessors realized the importance of this factor; now I will examine what has been found out since then in studies manipulating practice.

On the view that words interfere with color naming because of our extensive reading experience, Stroop interference is a direct consequence of differential practice. Thus, variation in practice should have direct impact on the task. Stroop (1935b, Experiment 3) recognized this, although he thought that considerable practice might be needed to modify existing response tendencies. It is unfortunate, then, that the relevant studies often involve very little practice (e.g., Alperson, 1967, used the range of 3 to 50 trials). It is hardly surprising that such studies conclude that practice is not a particularly critical variable. Perhaps the Jensen and Rohwer (1966) claim that almost all practice effects occur within the first 5 trials is responsible for this. I believe they were wrong.

Intuitively, extended practice with the Stroop task should lead to reduced interference as subjects develop a strategy for coping more successfully with the task. This result has indeed been observed (e.g., Effler, 1978a; Ogura, 1980), but not always (e.g., Harbeson et al., 1982; Shor et al., 1972; White, 1978). Furthermore, this is not the whole story. As one illustration of how much more complex the situation is, the stimuli and responses chosen are also important in training studies. Flowers and Stoup (1977) found that interference dissipated with practice for nonintegrated stimuli when the task was sorting, but not when it was oral naming. Nielsen (1975) found initially greater interference for a vocal than for a manual response, but then found a greater decline in interference over practice for the manual than for the vocal response. The results of Roe, Wilsoncraft, and Griffiths (1980) confirm that manual responding is affected more quickly by practice, which is interesting given that manual responding is faster to begin with and therefore closer to a "performance floor."

It also seems that there is a good deal of specificity to practice effects. Ménard-Buteau and Cavanagh (1984) found that, for items like "blue banana," there was interference in saying "blue" to the word or the picture in color. However, extended practice on the word version did not transfer to the picture version. They argued that the semantic element of interference did not coincide in the two tasks, and that interference might be more at the encoding stage for pictures and the response stage for words. This seems worth pursuing, particularly because it suggests that the common assumption of process identity in these two tasks may be at least partly incorrect.

In contrast to Ménard-Buteau and Cavanagh (1984), Reisberg, Baron, and Kemler (1980) did obtain transfer along semantic lines. They used the counting task where the items to be counted are themselves digits. With practice, interference declined but in a very specific way. Subjects who had practiced with the digits 2 and 4 to be ignored showed no benefit on a counting test where the digits 1 and 3 or the words to and for were to be ignored. However, there was good transfer when the words $t w o$ and four were to be ignored. Thus, meaning appears to be involved.

Regan (1977) compared a well-practiced to an unpracticed task. She had English-speaking subjects learn the names of Ar- 
menian letters. She then composed large English and Armenian letters out of small English and Armenian letters, and required subjects to name the small letters while ignoring the large letters, using the Navon (1977) procedure. Interference was equivalent for the very familiar set and for the newly learned set. This result speaks to what is meant by "automatic" processing: Although such processing appears to be involuntary, it apparently does not require extensive practice.

Reasoning that a novel orientation would slow down word processing, Liu (1973) had subjects rotate their Stroop cards upside down and then name the ink colors. Interference was reduced compared with normally oriented words. However, using several unique word orientations, Dunbar and MacLeod (1984) failed to confirm Liu's result. In fact, we found equivalent interference regardless of the word's orientation, so that previous practice differences could not be the critical factor.

Most recently, MacLeod and Dunbar (1988) took on the practice issue directly. We had subjects learn to call each of four unique shapes by a different color name (green, pink, orange, or blue). We could then present each shape in a neutral color (white), a congruent color, or an incongruent color, and require subjects to name the shape or the ink color. With a small amount of shape-naming practice, ink color interfered with shape naming but shape name did not interfere with ink-color naming. With moderate practice, interference was equivalent in both directions. With extensive practice, only shape names interfered with ink-color naming and not vice versa. Practice had a systematic impact, interestingly in a task with no "word" dimension at all and where shape naming never became faster than ink-color naming.

Practice warrants further investigation. Along the way, variables such as intertrial interval (see Doten, 1955) could also be examined. In our work (MacLeod \& Dunbar, 1988), we manipulated practice on one dimension, leaving the other in its "natural state"; it would be informative to covary practice on the two dimensions, a project that Diane Williams and I have under way in my laboratory. For the present, my general conclusion about practice is probably too general: Degree of practice in processing each of the dimensions of a multidimensional stimulus is influential in determining the extent of interference from one dimension on another. The greater the practice in processing a dimension, the more capable that dimension is of influencing the processing of another dimension. Practice may turn out to be one of the most effective manipulations for disentangling theories of the Stroop effect.

This ends the section on manipulations over multiple trials. Of course, there are isolated articles examining more esoteric effects. One example is studies in which feedback is manipulated, as when vocal feedback is minimized (Breslow, Grand, \& Freedman, 1980; Grand, Breslow, \& Freedman, 1980) or delayed (Doehrman, Landau, \& O'Connell, 1978) or when response feedback is varied in some other way (e.g., Hochman, 1973). Another is the case of manipulation of effort in the task (e.g., MacKinnon, Geiselman, \& Woodward, 1985). However, the main findings are those outlined previously. I now shift the focus from stimulus manipulations to those concentrating on the response side of the task.

\section{Response-Related Manipulations}

Under the view that interference derives from a logjam at a limited-capacity response buffer because the irrelevant word has entered before the relevant ink color (e.g., Morton, 1969; Morton \& Chambers, 1973), the locus of interference is placed squarely in the response stage. Thus, manipulations affecting how or when the response is made, or how many responses might possibly be made, become very important in testing such a view.

\section{Order of Response}

Few studies have required subjects to make two responses to the same stimulus as, for example, when consecutive responses to the ink color and the word (or vice versa) are required. The prototype work in this domain is that of Schweickert (1978, 1983), who argued that only one decision can be made at a time in the Stroop task. As illustrations, he cited several studies (e.g., Gholson \& Hohle, 1968a; Hock \& Egeth, 1970; Rieck \& Coates, 1977), all involving only one response. To demonstrate that at least some of the processing of the word and the ink color is concurrent, he cited Greenwald (1972). Here subjects saw an arrow pointing left or right and heard the word left or right simultaneously. They had to respond orally to one dimension and manually to the other. Greenwald varied whether one or both arrows or words could occur in a block of trials, and whether there was conflict between the dimensions. His data showed clear evidence of interaction among these variables.

Schweickert's (1983) experiment used a colored rectangle above a color word. There were 2 subjects. One was to press a key indicating the color of the rectangle before reading the word aloud; her data suggested that she decided about the ink color first. The other subject was to press a key for the word and then name the ink color aloud; her data suggested that she decided about the word first. This outcome is difficult to handle under a differential speed-of-processing account, which explains the usual asymmetry as being due to the decision about the word preceding the decision about the ink color. This appears to be true when the subject names the ink color. However, the decision order is reversed when the word must be read, so why is there an asymmetry in the standard Stroop task?

Work involving two responses (see also Virzi \& Egeth, 1985, Experiment 4) may help to explain how the various processes are scheduled. Of course, as Schweickert was well aware, the danger is that scheduling is influenced by whether one or more than one response is required. This may also be reflected in memory. Corballis and Luthe (1971) presented subjects with three incongruent Stroop items in rapid succession, and varied whether subjects had to recall on an item by item basis (i.e., the ink color and word for each item) or dimensionally (i.e., all three ink colors and then all three words). When words were reported before colors, dimensional recall was better than item-based recall. When colors were reported before words, the pattern reversed. Again scheduling of processes apparently was driven by task demands. We need to know more about how sequencing is governed.

\section{Response Modality: Oral Versus Manual}

If interference occurs at or near response output, it seems reasonable to examine the form of response. The critical contrast has been between vocal-response output-naming-and manual-response output-a keypress. The question is whether 
interference differs over mode of response in the Stroop task. In particular, does the compatibility of the verbal response and the irrelevant word account for some or all of the interference, as studies such as those of Gholson and Hohle (1968b) and Beller (1975) might suggest?

Pritchatt (1968) suggested that the Stroop effect was a consequence of verbal output because the effect was reduced when a matching response was used. However, White (1969) was the first to make the explicit comparison of verbal and nonverbal responses. For the standard Stroop task, he reported less interference with the nonverbal keypress response than with the oral response. Unfortunately, he used as his dependent variable the ratio of incongruent time to control time, so it is difficult to tell exactly what the pattern looked like in the individual conditions.

One of the best known response-related studies was by Keele (1972), although he used only manual responses. He reasoned that if interference arises during memory retrieval, then any word should interfere with naming ink color be it a noncolor word or a color word. In contrast, if noncolor words do not interfere but color words do, then the retrieval stage cannot be the locus of interference. His results supported the latter prediction, leading him (and Posner \& Snyder, 1975) to a late-selection theory of attention. In fact, though, the Keele (1972) study does not directly address the issue of response modality; his study is more a replication of Klein's (1964) logic using keypresses instead of oral responses. ${ }^{8}$

More crucial are studies where the two response modes are directly compared in the same experiment. Nielsen (1974) varied the irrelevant stimulus from control Xs to color words, roughly following Klein (1964). Interference much like Klein's was observed for both vocal and keypress responses, although interference was greater for vocal responses. Even with practice, vocal-response interference exceeded manual-response interference. Using similar logic, Majeres (1974) had subjects either say or write their response (only the first letter had to be written). There was a clear gradient of interference for both response modes, but less interference when writing than when saying the response.

Redding and Gerjets (1977) demonstrated that incongruent words produced $177 \mathrm{~ms}$ of interference when the response to ink color was oral and only $98 \mathrm{~ms}$ when the response was manual; congruent words produced $23 \mathrm{~ms}$ of facilitation for oral responses and $67 \mathrm{~ms}$ for manual responses. Curiously, there appeared to be less interference but more facilitation when the response was manual compared with oral. Whether this generalizes remains to be seen.

Perhaps the pivotal question is whether interference consistently appears when responding is manual. In general, the answer appears to be "yes." Several articles have confirmed interference with a manual response (e.g., Logan et al., 1984; Roe et al., 1980; Schmit \& Davis, 1974; Virzi \& Egeth, 1985; Warren \& Marsh, 1979). Some, such as that of Roe et al. (1980), even found no overall differences between the two response modes. The only case where there was no interference with a manual response appears to be the experiment by McClain (1983b) described shortly.

A feature of any task that contributes to its difficulty is the degree to which the responses map readily onto the various dimensions of the stimulus. Fitts and Posner (1967) referred to this as the stimulus-response compatibility issue. Treisman and Fearnley (1969) stressed this in their account of the Stroop effect. Put simply, does the word interfere with naming the color because the verbal nature of the word matches that of the response?

McClain manipulated compatibility in both the standard Stroop task and its auditory analog. In the color-word task (McClain, 1983b), interference in color naming declined as the response moved from oral to pressing buttons labeled with color names to pressing buttons labeled with color patches. In fact, interference was not significant in the last condition, but such complete absence of interference is an unusual result. ${ }^{9}$ In the auditory experiment (McClain, 1983c), subjects had to identify either the pitch (high or low) or the word (high or low). When pitch was to be identified, interference occurred for an oral or a keypress response, but not for a hummed response. When the word was to be identified, the pattern reversed.

Although Morton and Chambers (1973) questioned the role of stimulus-response compatibility, it seems to matter (Flowers et al., 1979; Simon \& Sudalaimuthu, 1979; Zakay \& Glicksohn, 1985). Of course, comparing response times across oral and manual responses can be a thorny interpretive problem (see, e.g., Stanovich \& Pachella, 1977). Recall that Neill (1977) showed that if the irrelevant word on trial $n-1$ named the relevant ink color on trial $n$, this slowed oral responding (relative to unrelated items). Yet when response modality was manual, the same sequential relation actually speeded responding. Why? Neill argued that suppression occurred only when the response had to be spoken, whereas activation in the manual task helped eliminate the word faster from contention as a possible response. Simon and Sudalaimuthu (1979) reported a related effect obtained within single trials.

Such results are puzzling. Nevertheless, there is sufficient convergence to permit the following conclusion: Although still significant, interference (but perhaps not facilitation) is reduced when response modality is switched from oral to manual. Stimulus-response compatibility matters; if the normal processing of the irrelevant dimension leads to a response in the mode designated for the relevant dimension, interference is likely to be heightened. However, neither response mode alone nor the interaction of stimulus and response modes can account for the Stroop effect. The effect is due to more than a queuing problem at the finish line.

\section{Response Set Size and Composition}

It frequently is argued that people read the irrelevant word in Stroop variations because it usually is an eligible response (e.g., Klein, 1964; Proctor, 1978; see Stimulus Set Size). If interfer-

\footnotetext{
${ }^{8}$ It should be noted that Keele (1972) did report substantial interference when comparing incongruent stimuli to control stimuli despite the manual response mode.

${ }^{9} \mathrm{McClain}$ used the difference between incongruent and congruent times as her measure of interference, which unfortunately combines interference and facilitation. Wheeler (1977) found no difference between color naming and word reading in the incongruent condition using a manual response, but this is a very unconventional way to contrast response modes.
} 
ence occurs in responding, then manipulations of the set of responses might be expected to have some effect.

Both Klein (1964) and Scheibe et al. (1967) reported twice as much interference when the color word was the name of another possible ink color in the set. Even controlling for word frequency and association, Proctor (1978) still found 24 to 30 $\mathrm{ms}$ more interference when the words and ink colors coincided. Other studies support this conclusion in the color-word task (e.g., Stirling, 1979) and in the picture-word task (Lupker \& Katz, 1981). Lupker and Katz found more interference when irrelevant words named the categories of possible picture names than when they did not. Dunbar (1986) provided an extensive discussion of the relevant picture-word literature, and La Heij (1988) reported careful studies showing that response-set members produce heightened interference. Studies using the flanker task (e.g., La Heij et al., 1985) also found that a target word suffers more when a nearby word is a potential response than when it is not.

There are two logical possibilities for what should happen as set size increases. First, interference might increase because more potential responses are vying for output, making managing the contents of working memory more effortful. Second, interference might decrease because the probability that any particular response is actually in working memory would decrease with larger response set size. Nielsen (1974) found that interference increased with increasing set size, Ray (1974) found that it was unaffected, and La Heij et al. (1985) found that it decreased. There are other studies that could be aligned with each of these findings (see also Stimulus Set Size). The manipulation of response set size seems so straightforward that these conflicting findings are frustrating. Thus, the recent emphasis on this issue in the work of La Heij and colleagues (e.g., La Heij, 1988; La Heij et al., 1985) is timely.

The findings on response set are clear with respect to the overlap of the two dimensions, but not with respect to the effect of set-size variation. This is captured in the following conclusion: When the irrelevant dimension of a set of stimuli includes names that are eligible responses for the relevant dimension, more interference results than when the sets are nonoverlapping. Although variations in response set size might be expected to affect interference, existing results are unclear.

\section{Individual Differences}

A great many articles have examined the relation between Stroop interference and some individual differences parameter. The purpose of most of these clearly is not to explain the Stroop effect, so for this reason I omit many of these studies. Instead, I select only a few dimensions of individual variation to review here. As Kareev (1982) illustrated, certain analyses at the level of the individual have considerable potential in helping us to understand the Stroop effect.

\section{Sex Differences}

The most obvious difference between individuals is sex, so much effort has been directed to exploring sex differences (cf. Maccoby \& Jacklin, 1974). The Stroop task has not escaped: There are now over a dozen studies of how men and women differ in degree of interference. Even before Stroop, Ligon (1932; see also Brown, 1915) noted that girls named colors faster than did boys, although there was no difference in word-reading speed. Stroop (1935b) confirmed this, but critically showed that men and women did not display differential interference. This result has been replicated often (e.g., Golden, 1974b; Sarmanay, 1977; Sladekova \& Daniel, 1981), yet investigators still pursue the matter (e.g., Peretti, 1969, 1971).

Naish (1980) suggested that men may encode irrelevant words both orthographically and phonemically when sorting the colors in which they are written, whereas women encode only phonemically. However, he also suggested that this strategy difference might be unique to certain Stroop-like situations and not evident in normal reading.

Several studies have examined the relation between Stroop interference and some test of interest, with sex differences as a subsidiary analysis. In a factor-analytic study of extraversion and field dependence, loadings on a Stroop factor were higher for men than for women (Bone \& Eysenck, 1972). In a study of the relation between a test of matching familiar figures and the Stroop test (Boyden \& Gilpin, 1978), errors on the two tests were positively correlated for men but not for women, which the authors took as an indication of distractibility and impulsivity being related in men.

Jorgenson and her colleagues (Davis, Jorgenson, Kritselis, \& Opella, 1981; Davis, Jorgenson, \& Opella, 1983; Jorgenson, Davis, Opella, \& Angerstein, 1980, 1981; Jorgenson, Davis, Wilbon, \& Opella, 1983) have been especially interested in hemispheric differences and sex differences in the Stroop task. In brief, sex differences in both grade-school and college students did not appear to account for much of the variance in Stroop performance in their studies.

In grade-school children, girls have been shown to be generally faster but not better at color recognition and not different in terms of interference, the most interesting measure theoretically (Dash \& Dash, 1982). Bettner, Jarvik, and Blum (1971) studied an aged population and found poorer Stroop performance in men than in women (average age of 84 years).

On the whole, research has failed to find much difference in Stroop interference between men and women at any age. Although women may be somewhat faster, especially in naming colors, this relates to general response speed (see Jensen, 1965), not to the derived measure of interference. Here is a summary statement: There are no sex differences in Stroop interference at any age. Perhaps this is too strong, but I remain to be convinced.

\section{Age Differences}

The development of color and word-form processing with age was of interest before the Stroop task was created (e.g., Brian \& Goodenough, 1929; Ligon, 1932). Basically, more recent studies make similar points. Thus, Cramer (1967) supported Ligon's claim that form processing dominates over color processing, although preschoolers may show the reverse preference (Arochova, 1971), having not yet learned to recognize letter forms very well.

Interest in development with regard to the Stroop task itself did not arise until the mid-1960s. There are some three dozen 
pertinent studies, the first being a life-span study by Comalli, Wapner, and Werner (1962; see also Rand et al., 1963). Testing subjects from ages 7 to 80 years, they observed greatest interference in the young children; interference declined into adulthood and then increased again with advanced age. They saw young children and older adults as having relatively more difficulty in screening out interfering stimuli. Ehri and Wilce (1979) produced an experimental analog of this result by training first and second graders on a set of words to be used in the pictureword task. Initially, as the subjects were learning to read the words, interference increased; however, once the words were learned and further training simply improved response speed to the words, interference decreased.

Schiller (1966) helped to clarify the nonmonotonicity in interference with age in children. Interference was minimal for children in Grade 1, younger than the youngest subjects in the Comalli et al. (1962) study. Interference then became maximal in Grades 2 and 3 (Comalli et al's youngest subjects), and declined thereafter. The strong suggestion is that this early rise and then fall in interference reflects the onset of reading skills. Dash and Dash (1982) confirmed Schiller's result (see also Friedman, 1971). Using the picture-word task, Ehri (1976) showed a similar pattern, except that poor readers in the second grade did not show interference, behaving rather like normal first graders in the other studies. Attempts to create Stroop-like situations for younger, prereading children have not been very informative (e.g., Butollo, Bauer, \& Riedl, 1971; Cammock \& Cairns, 1979). Furthermore, attempts to categorize subgroups of development in the task have not been successful (e.g., Rand et al., 1963; Silverstein \& Franken, 1965).

The decrease in interference through adulthood and before the age of 60 that Comalli et al. (1962) observed has been confirmed (e.g., Wise, Sutton, \& Gibbons, 1975), as has the increase in interference for adults older than 60 years (see Cohn, Dustman, \& Bradford, 1984; Panek, Rush, \& Slade, 1984). There may be exceptions (e.g., Baumler, 1969), but even studies of aging twins reveal the increased interference with age greater than 60 years (Bettner et al., 1971; Jarvik, Blum, \& Varma, 1972), together with the suggestion that identical twins show more similar interference than do fraternal twins. Attempts at remediation of the exaggerated interference shown by older adults have not been notably successful (e.g., White, 1978).

Many of the developmental Stroop studies focus on reading skill (e.g., Bakan \& Shotland, 1969; Corbitt, 1978; Fournier, Mazzarella, Ricciardi, \& Fingeret, 1975; Frey, 1971; Ludwig \& Lazarus, 1983; West \& Stanovich, 1978; Wilder, 1969). The Corbitt (1978) dissertation provides a good example. He showed that reading ability and interference were closely related: Intermediate and good readers read words faster than they named colors, and showed a Stroop effect without a reverse Stroop effect. Poor readers named colors faster than they could read words and showed the opposite pattern.

How about reading comprehension? Using the picture-word task, Golinkoff and Rosinski (1976) showed that good versus poor comprehenders in Grades 3 and 5 did not differ in the degree of interference shown in naming pictures containing single words. Similar findings were reported by Ehri (1977) and Underwood et al. (1984). Rosinski (1977) showed that the semantic gradient for words that differentially relate to colors was also consistent from Grade 2 through college. Merrill et al. (1981) went on to show that, with sentence contexts, good comprehenders in Grade 5 displayed interference only for targets appropriate to the context, whereas poor comprehenders showed interference regardless of context appropriateness. A study by Kareev (1980) further investigated development of sentence encoding in children using the color-word task.

Interestingly, children with reading disabilities often show robust Stroop interference (Alwitt, 1966), as do autistic children (Bryson, 1983), hyperactive children (DeHaas \& Young, 1984), aphasics (Cohen, Meier, \& Schulze, 1983), and retardates (Bassett \& Schellman, 1976; Tschopp \& Jorswieck, 1976). Recent work by Ellis, Woodley-Zanthos, Dulaney, and Palmer (1989) suggests that automatic word reading may be even harder for retardates to control than it is for normals, causing greater interference in retardates. Das (1970) reported a similar result, although the pattern reversed when very poor readers were included in the retarded group (Das, 1969).

The overall picture of development, then, can be summarized fairly concisely by the Comalli et al. (1962) result. Here is the conclusion: Interference begins early in the school years, rising to its highest level around Grades 2 to 3 as reading skill develops. With continued development of reading, interference declines through the adult years until approximately age 60, at which point it begins to increase again. Virtually everyone who can read shows a robust Stroop effect from an early age.

\section{Hemispheric Differences}

A number of investigators have examined laterality in the Stroop task, using Dyer's (1973a) study as a springboard. Basically, he showed that presenting the word and the color separately to the left and right of fixation did not destroy the Stroop effect: Both interference and facilitation were still evident. Furthermore, the effect does not seem to be altered by presenting the words vertically (McCown \& Arnoult, 1981), although it may be somewhat reduced in the periphery as opposed to foveally (Goolkasian, 1978). Such findings opened the door for hemispheric-differences research.

Schmit and Davis (1974) tested subjects with Stroop stimuli displayed in only the left or right visual field using a buttonpress response. They observed greater interference in the left hemisphere, consistent with that hemisphere's dominant role in verbal processing. Guiard (1981) corroborated this using a manual-response task. The finding was also confirmed in the standard oral-response procedure by Tsao, Feustel, and Soseos (1979), although only in their error data (see also Newman, 1981). However, not all investigators have agreed: Warren and Marsh (1978) found equivalent interference for the two hemispheres using color-word stimuli, whereas Long and Lyman (1987) found greater interference when the word was processed in the right hemisphere (with the color presented foveally).

Tsao, Wu, and Feustel (1981) showed that the Schmit and Davis pattern was reversed for Chinese speakers, consistent with the idea that both logographs and colors are handled by the right hemisphere. Analogously, Morikawa (1981) showed that idiographic Kanji characters produced greater right-hemisphere interference in Japanese subjects. Hatta (1981; see also Hatta, Katoh, \& Aitani, 1983) confirmed the result for Kanji, 
but found no hemispheric difference for orthographic Kana. Interestingly, Morikawa emphasized the overall reduced size of interference effects with Japanese subjects, itself a result worth pursuing.

Cohen and Martin (1975) presented auditory stimuli to the left or right ear using the Hamers (1973) high/low procedure. Again, the Stroop effect was larger in the left hemisphere, and was accentuated by simultaneous irrelevant distraction in the other ear (see also Vaid \& Lambert, 1979, with the same task, and Pieters, 1981, using an auditory left/right position versus word-discrimination task). Alivisatos and Wilding (1982) used the global/local-letters task (with a manual response) to show that the local level of a foveally presented first stimulus interfered with processing a second stimulus in the right hemisphere but not in the left. The global aspect of the first stimulus interfered with the second stimulus in both hemispheres, with a tendency to more interference in the right hemisphere.

Toma and Tsao (1985) obtained greater interference in the left hemisphere for the picture-word task. Using the same task, Lupker and Sanders (1982) hypothesized that the verbal-response competition in the left hemisphere gave way to a perceptual type of interference in the right hemisphere, a hypothesis worthy of further investigation. In particular, though, more work is needed where the two dimensions are presented separately to the two hemispheres rather than together to the same hemisphere. SOA studies might also be informative by controlling which hemisphere is stimulated first and by which dimension of the stimulus.

Evoked (event-related) potentials are part of a new technology for studying the Stroop effect. Scott, Hoffman, and Bickford (1967) were pioneers in this area, demonstrating that lambda waves in the parietal-occipital region showed increased amplitude in the interference condition, although they admitted that this could relate to muscle potentials as easily as to mental activity. The technology has advanced a great deal since then (e.g., Johnston \& Venables, 1982). More in the current mold of such studies, Warren and Marsh (1979) took their neural-activity measurements to suggest that standard Stroop interference was due to response-selection processes, but that the reverse Stroop effect was due to complex encoding interactions.

Duncan-Johnson and Kopell $(1980,1981)$ used oral response time together with P300 latency (cf. Pritchard, 1981) in the discrete-trials version of the Stroop task with congruent, incongruent, and neutral words and two ink colors. Blocks of trials required word reading or ink-color naming. The usual pattern was observed in the response times, but $P 300$ was unaffected by experimental condition. Because P300 is taken to be an index of encoding, the conclusion was that interference must stem from response competition.

Aine and Harter (1984a, 1984b) adapted the study of evoked potentials to examining hemispheric differences in the Stroop task. Basically, they claimed that the activity associated with interference occurs in the left hemisphere, converging on the response time and error-rate measures already described. Taking all of this evidence together, the following conclusion is offered: The left hemisphere generally shows more interference than the right. A study by Posner, Walker, Friedrich, and Rafal (1984) suggests that the left parietal lobe may be particularly involved in disengaging attention, although the left frontal lobe may also play a role (Perret, 1974). Undoubtedly, we will see more work on the topic of localization in the near future.

\section{Language Differences: The Case of the Bilingual}

If Stroop interference stems from an irresistible urge to read the word, what would happen if you were naming ink colors in one language but the words were in another language? About two dozen studies have been directed at this question. This work began with Dalrymple-Alford (1968), but his items were either incongruent items in the same language or congruent items in different languages, a confound that does not permit us to obtain a clear picture of the Stroop effect within versus between languages. For this, we must examine studies by Preston and Lambert (1969) and by Dyer (1971a).

Preston and Lambert (1969) found substantial interference whether the ink colors were to be named in the same language as the distracting words appeared or in the other language. English-Hungarian bilinguals showed roughly $68 \%$ of the interference across languages that they showed within a single language; for English-French bilinguals, the overlap was 95\%. Preston and Lambert concluded that interference between languages could be as great as that within languages, but that it depended on relative familiarity with the two languages in question.

Dyer (1971a) showed that English monolinguals naming colors in English displayed maximal interference when the words were in English and declining interference as the similarity of the irrelevant words to English decreased. Using Spanish-English bilinguals in his second experiment, Dyer found maximal interference when the naming and distracting languages coincided, but there was also substantial interference when the languages did not coincide. Roughly, the different-language conditions showed about $63 \%$ of the interference seen in the samelanguage conditions.

Shortly after Dyer's study, Hamers (1973; Hamers \& Lambert, 1972) used her auditory Stroop analog with French-English bilinguals and reached the same conclusion: The differentlanguage condition produced about $76 \%$ of the interference seen in the same-language condition. This pattern recurs for Spanish-English bilinguals in the picture-word task (Ehri \& Ryan, 1980), French-English bilinguals in the flanker-word task (Guttentag et al., 1984), and diverse languages in the color-word task (e.g., Chinese-English and Japanese-English; Fang, Tzeng, \& Alva, 1981; Turkish-English: Kiyak, 1982). Fang et al. (1981) also confirmed that the ratio of between-language to withinlanguage interference declines as language similarity decreases.

Complicating matters, the weightings of interference within and between languages are also affected by relative proficiency in the two languages. Mägiste $(1984,1985)$ observed a changing pattern with the development of the individual's second language. Initially, her subjects were German dominant and showed more interference when responding in German regardless of whether the words were Swedish or German. Gradually, as their experience with Swedish increased, they reached a point of equivalence; then, as Swedish came to dominate, they showed most interference when naming in Swedish. Chen and Ho (1986), using Chinese-English bilinguals, suggested that within-language interference was always greater for their Chi- 
nese-dominant subjects, but that the pattern when naming in English shifts with increased English-language experience. From initially greater between-language interference, their subjects moved to finally greater within-language interference. There is also evidence to suggest that this difference in interference depends on the dominance of the naming language. If the naming language is the nondominant one, interference between and within languages tends to be close to identical (e.g., Dornic, 1982; Dornic \& Wirberg, 1983).

Furthermore, certain languages, such as Chinese, may be more vulnerable to interference than others. Biederman and Tsao (1979; see also Morikawa, 1981, using Japanese subjects) showed much greater interference for Chinese students naming the ink colors of logographic characters than for English students naming the ink colors of words. They concluded that the processes involved in reading Chinese are more similar to those involved in naming colors than are those involved in reading English. Tsao et al. (1981; see also Morikawa, 1981, using Japanese subjects) provided some support for this claim by showing that more interference occurred in the right hemisphere for Chinese speakers, unlike the usual pattern of maximal interference in the left hemisphere for speakers of romance languages. However, Smith and Kirsner (1982) obtained more symmetrical data using Chinese-English and French-English bilinguals, so this issue has yet to be resolved.

What can we conclude about Stroop interference in bilinguals for the present? Interference between the two languages of a bilingual, although not as great as that within either one of the languages, is very robust: Between-language interference typically is about $75 \%$ of within-language interference. Furthermore, a dominant language has more potential for interfering than does a nondominant one. There may also be differences in the processing of orthographic and idiographic languages. Overall, the cross-language semantic contribution to Stroop interference is substantial.

\section{Theoretical Accounts of the Stroop Effect}

It seems only appropriate to preface discussion of current theories with a comment on how Stroop himself interpreted his data. Here is what he concluded over a half-century ago:

The associations that have been formed between the word stimuli and the reading response are evidently more effective than those that have been formed between the color stimuli and the naming response. Since these associations are products of training, and since the difference in their strength corresponds roughly to the difference in training in reading words and naming colors, it seems reasonable to conclude that the difference in speed in reading names of colors and in naming colors may be satisfactorily accounted for by the difference in training in the two activities. (Stroop, 1935b, pp. 659-660)

Stroop's (1935b, 1938) general view corresponded closely to one of the two prevalent accounts of the Stroop effect-the relative speed-of-processing view-and was compatible with the other one-the automaticity view. Because of their preeminence in the literature, and because they are conceptually close cousins, these two explanations are examined first.

\section{Relative Speed of Processing}

In its simplest form, the relative speed-of-processing view begins with the fact that words are read faster than colors are named (e.g., Cattell, 1886; Fraisse, 1969). This speed difference is seen as particularly critical when two potential responses (e.g., one from a word and one from an ink color) compete to be the response actually produced. The time cost of this competition is "interference." This general interpretation is referred to as response competition occurring at the end of a horse race, because the two codes are seen as racing to control final output.

A quarter of a century ago, Klein (1964) saw interference as resulting from the need to "restimulate" with the ink color to overcome the strong tendency to produce the word, although the mechanism of restimulation was not specified. Klein's view was not altogether inconsistent with Stroop's, and it characterized earlier attempts to explain the Stroop effect in terms of "habit strength" and related associationistic ideas of learning. Today most psychologists think of the Stroop task as a hallmark measure of attention, not learning. Thus, Treisman (1969) saw the problem as difficulty in deciding whether to attend to the ink color or to the word analyzers when they led to different potential responses, an idea Dyer (1973c) adopted in his review.

Ideas like Treisman's underlie what came to be the best known realizations of response competition: those of Morton (1969; Morton \& Chambers, 1973) and Posner and Snyder (1975). It was this general response-competition idea that Dyer (1973c) endorsed in his review. In the words of Morton and Chambers (1973),

\begin{abstract}
The various stimulus analyzers [for word and ink color] are supposed to operate in parallel and will each give rise to an appropriate naming response. If multiple responses are available they will compete for entry into the single channel exit from the Logogen System . . the crucial variable is the relative speed of naming the various attributes of the stimuli. (p. 388)
\end{abstract}

This is a very clear statement of the relative speed-of-processing view, including its response-competition element.

Very similar ideas are contained in the account offered by Posner and Snyder (1975):

First, the usual Stroop effect arises because of response competition between vocal responses to the printed word and the ink color. . . . Second, the direction of interference depends upon the time relations involved. Words are read faster than colors can be named, thus a color naming response receives stronger interference from the word than the reverse.. . . Third, words often facilitate the vocal output to colors with which they share a common name. . . These three results suggest that color naming and reading go on in parallel and without interference until close to the output. (p. 57)

Again, the elements of relative speed and interference at the stage of response output are highlighted. These are the two essential elements of the relative speed-of-processing account of the Stroop effect. Appendix B summarizes the 18 major results that must be handled by any successful theory. Let us consider now how this evidence accords with this account.

Certainly, the relative speed-of-processing idea allows for numerous analogs of the task (Result 1); all that is required is differential processing time for two competing stimuli. Regarding the effects of nonsemantic relations (Result 2), this view holds that greater similarity between the names of two competing responses should make it harder to select the correct one at the response-production stage. Regarding semantic effects ( $R e$ - 
sult 3), disambiguation at the response stage should also be more difficult for more highly related responses.

Posner and Snyder (1975) pointed out that words more highly related to the concept of color would be primed by processing of the ink-color names, increasing the likelihood of those words reaching the response stage first. This logic explains the fact that overlap of response set for the relevant and irrelevant dimensions influences interference (Result 14); the two dimensions are priming each other. Priming also explains why noncolor words preceded by related words cause more interference in color naming (Result 4). Basically, words are processed faster when primed and hence are more likely to win the race to the response stage and to interfere with color naming. Of course, the priming mechanism is not fundamental to the relativespeed hypothesis per se. It must be grafted on, and represents an additional element to this explanation.

Facilitatory congruence effects (Result 5) should occur because the response to both dimensions is the same, so production can be based on whichever arrives first at the response stage. Indeed, they probably even prime each other. Increased interference from mixing congruent with incongruent trials (Result 7) might be thought of as being due to greater uncertainty at the response stage regarding which dimension (on incongruent trials) is to provide the output. Of course, this requires an additional assumption beyond the two main ones mentioned earlier, but it seems a reasonable one.

Although the fact that integrated stimuli result in more interference than nonintegrated stimuli (Result 6) is not a direct prediction from the relative speed-of-processing view, it can be handled. Assume that it is easier to ascertain which potential response derived from which stimulus dimension when the dimensions are more easily separated. Dealing with the fact that manual responding displays less interference than oral responding (Result 13) is even more straightforward. Simply assume that there are different response-output routines (or buffers) for different modalities, which also fits with effects of stimulus-response compatibility.

Pretrial cues should assist processing (Result 9) because they can be used to "tune" the response-output system. These cues help in deciding which dimension is salient and perhaps also what value to expect on that dimension. However, too many so-called cues would probably lead the subject to ignore them, as has been found. What about sequential trial effects (Result 8)? Two problems arise in the system. First, there may be some trace of the two potential responses from the previous trial still resident in the response buffer when the subsequent trial begins. Second, there is probably priming of the responses on trial $n$ by the responses on trial $n-1$. With some jockeying, this horse race can be made sensitive to neighboring trials.

Although silent on sex differences (Result 15), the relative speed view would predict greater left hemisphere involvement (Result 17) because of the importance of reading. Both the developmental pattern (Result 16) and the bilingual pattern (Result 18) make sense under this view because both development and language proficiency ought to affect word processing speed.

So far, so good. Fifteen of the 18 results are comfortably accommodated. However, the remaining three-without doubt the most direct predictions of the relative speed-of-processing view-appear to be wrong. The most obvious prediction is that the relative speed of processing each of the two dimensions of the compound stimulus should determine interference. The naive intuition is that the faster dimension should interfere with the slower one and not vice versa; interference should always be completely asymmetrical. Of course, this extreme position need not be true, in fact, because we are dealing with distributions of processing times over trials, and any overlap in those distributions could produce interference. Figure 1 portrays this point; it is apparent that orderly patterns of interference are predicted.

In fact, though, interference is not an orderly function of relative speed of processing: The careful SOA studies of Glaser and Glaser (1982) and Glaser and Düngelhoff (1984) convincingly make this point (see $S O A$ ). Previewing the slower dimension does not lead to the clear reversal of the direction of interference expected, thereby violating two major results (Results 10 and 11). Also relevant are the studies conducted by Kevin Dunbar and myself (Dunbar \& MacLeod, 1984; MacLeod \& Dunbar, 1988): Direct manipulation of the speed of processing of a dimension through reorientation or practice (Result 12) does not produce results consistent with this theoretical perspective.

The relative speed-of-processing hypothesis contains three key assumptions. First, there is assumed to be parallel processing of the two dimensions of the stimulus at differential speeds. Second, there is a limited-capacity response channel into which only one of the two potential responses can be admitted at a time; priority is determined by speed. Third, there is potential for priming of possible responses from several sources, including preceding trials and other response-set elements. This is actually quite a powerful set of assumptions. Together they are capable of accommodating 15 of the 18 critical findings in Appendix $B$, although some corollary assumptions were introduced along the way. However, they fail in the face of the most direct test of the view: explicit manipulations of relative speed of processing by SOA or by practice. On this basis, I contend that the relative speed-of-processing hypothesis must be rejected.

\section{Automaticity}

The second prevalent explanation is the automaticity account, which was rooted in Cattell's (1886) work over a century ago. Here the basic idea is that processing of one dimension requires much more attention than does processing of the other dimension. Thus, naming the ink color draws more heavily on attentional resources than does reading the irrelevant word. Moreover, reading the word is seen as obligatory, whereas naming the ink color is not. Presumably, this imbalance derives from our extensive history of reading words as opposed to naming ink colors. Under this view, the asymmetry that is the fundamental characteristic of the Stroop task must occur. Words are read very automatically; colors require considerably more attention to be named.

This description is based on the theorizing of LaBerge and Samuels (1974), Posner and Snyder (1975), Shiffrin and Schneider (1977), and Logan (1978) among others (see, e.g., Hunt \& Lansman, 1986). Contrary to the all-or-none view of 
LATENCY DISTRIBUTIONS

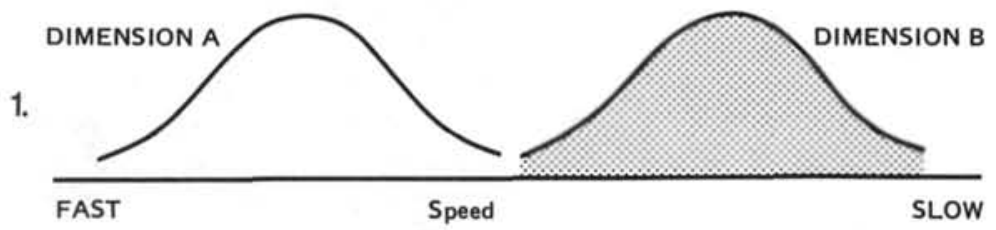

2.

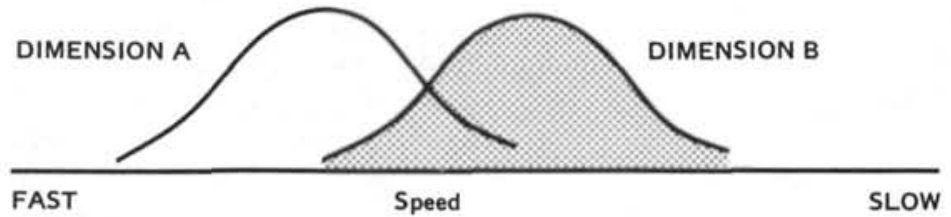

3.

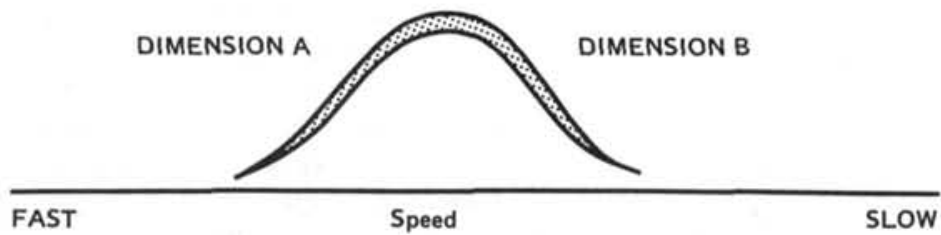

4.
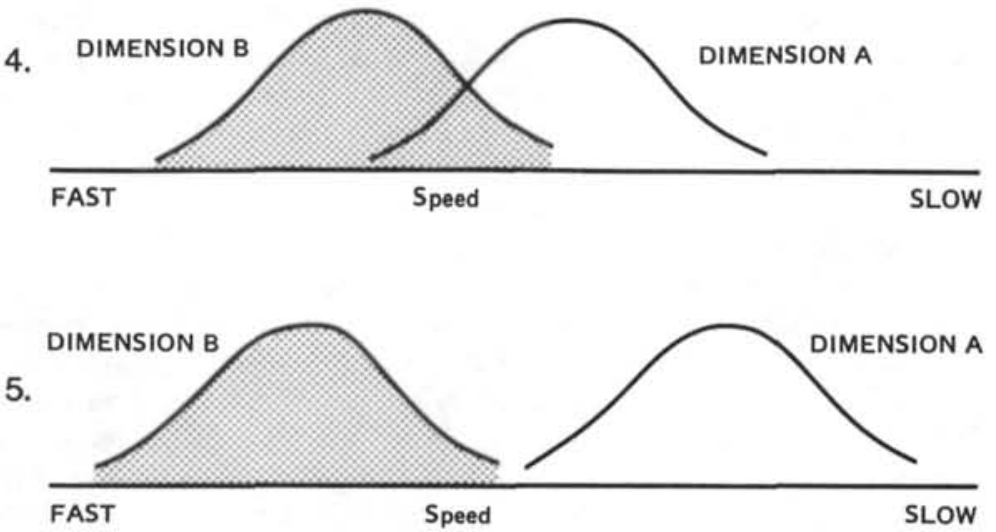

\section{QUTCOME}

A interferes with $\mathbf{B}$; $B$ does not interfere with A

$A$ interferes more with $B$ than $B$

does with $\mathrm{A}$
$A$ and $B$ interfere with each other to the same extent
$B$ interferes more with $A$ than $A$ does with $B$

Figure 1. Relative speed of processing and interference. As the latency distributions for the processing of the two dimensions shift, so should the patterns of interference.

automaticity popular in secondary sources, all of these investigators saw automaticity as a gradient that developed with learning. Thus, word reading was very automatic, and color (or picture) naming was much less automatic. More automatic processing could then interfere with less automatic processing, but not vice versa. The Stroop task is an interesting case expressly because the two dimensions differ so much in how automatically they are processed.

Let us consider how such a view comes to grips with the 18 key results in Appendix B. Certainly whenever the irrelevant dimension of a two-dimensional stimulus is a word, the potential for interference exists. Thus, many analogs of the Stroop color-word task (Result 1) are expected. Although an all-ornone version of automaticity would have trouble handling interference in situations where neither dimension was a word, this would not be the case for the continuum version (e.g., MacLeod \& Dunbar, 1988).

The real strength of automaticity theories lies in their ability to capture priming situations. Recall that priming required an additional assumption for the speed-of-processing account. In contrast, it is at the very heart of the automaticity explanation, as is evident in reading Posner and Snyder (1975), for example. Priming occurs through the automatic spread of activation, essentially the same mechanism used to explain interference.

Thus, orthographic/acoustic effects (Result 2) should result from automatic activation of parts of the relevant and irrelevant response words. In like manner, semantic effects should be evident, particularly given that Posner and Snyder aimed to explain lexical facilitation with the same mechanism as Stroop interference (see also Logan, 1980, for a similar idea). As the 
irrelevant words become more color related, they automatically activate more common features with the relevant ink colors, resulting in interference (Result 3). Primes should be able to accomplish this in a prime-target procedure (Result 4), and previous trials should be able to do it in a continuous-trials procedure (Result 8 ). Set overlap should also influence the extent of automatic activation of competing features on any given trial through priming (Result 14). Finally, facilitation from congruent dimensions ought to occur (Result 5). In sum, automatic priming is the most "natural" consequence of the automaticity account.

Also a straightforward outgrowth of the automaticity account is the fact that practice affects interference (Results 12 ). Practice can also be seen as encompassing the changes that occur with the development of reading skill (Result 16) and with increasing language proficiency in bilinguals (Result 18). Automatic processes (e.g., reading words) have to be learned; the more automatic a process becomes with practice, the more it is capable of causing interference with a less automatic process. This also helps to explain apparent instances of reversed Stroop interference (Result 11 ): When a normally more automatic process associated with one stimulus dimension is altered by an experimental manipulation, the normally less automatic process associated with the other dimension may become relatively more automatic. In such an instance, the direction of interference reverses.

The modality effect-that interference is reduced when the response mode is switched from oral to manual (Result 13) makes sense because, although it may be quite automatic to process a word for oral output, it may be less automatic when the required response is in some other modality. Of course, this is an additional assumption, but not an unreasonable one.

The effects of SOA (Result 10) are much less nettlesome for the automaticity view, which does not hinge on processing speed. Indeed, the fact that SOA manipulation has little impact on word reading fits with the automaticity view. Unfortunately, this advantage is offset by the fact that tests of automaticity are less direct than tests of speed. Probably for this reason, Stroop researchers have not measured the automaticity of the two dimensions directly (cf. the discussion in MacLeod \& Dunbar, 1988, p. 134).

Like the speed of processing view, the automaticity account would predict a greater role for the left hemisphere (Result 17), because reading is what is becoming automated. There is also nothing in this account that predicts sex differences (Result 15).

The remaining three results in Appendix B pose more serious threats to the automaticity account. First, as long as both dimensions of a display are perceivable simultaneously, it might seem that whether they are separate or integrated should not matter very much. In either event, once seen, a word would be processed automatically. Yet integration versus separation does matter (Result 6); generally interference effects are substantially larger in the integrated version of the task (e.g., Kahneman \& Henik, 1981).

Because automatic processes do not require attention, strategies should have little effect on their execution. Yet particular mixtures of congruent and incongruent trials alter the degree of interference (Result 7), as can cues about what to expect on an upcoming trial (Result 9). These straightforward attentional-al- location effects run against the grain of the automaticity idea. Perhaps the best illustration of this is the study by Kahneman and Chajczyk (1983) in which they observed diluted Stroop effects when irrelevant additional words occurred in the display. How could reading a word, which is claimed to require no resources, draw resources away from color naming? Why should an extra, unrelated word draw away further resources? These questions are not resolved by the automaticity hypothesis.

It seems, then, that automaticity fails to provide a comprehensive account of the Stroop effect. However, this failure may apply only to the strong, all-or-none view of automaticity. Kahneman and Chajczyk (1983) described a process as strongly automatic if it is unaffected by attentional-allocation strategy. $A$ process is partly automatic if it can occur largely without attention, but nevertheless is affected by attention. They suggested that the partly automatic designation is more appropriate for the Stroop situation, leaving room for attentional-allocation strategies to exert some influence.

MacLeod and Dunbar (1988) reemphasized the view of automaticity as a continuum, not a dichotomy. This position harks back to earlier explanations of the Stroop effect by reinstating learning history as a critical element in interference. Better learned processes will be more automatic and will lead to such consequences as interference. Although response-speed improvements may also be an outgrowth of practice or experience, speed per se will not be the important factor. A well-learned but slow process could interfere with a less well-learned but faster process because interference arises throughout the course of processing, not just at some late response stage.

Unfortunately, Stroop experiments rarely have provided any independent measure of automaticity. The specificity of the relative speed-of-processing view allowed it to be put to stringent test (and to fail). To provide a reasonable test of automaticity views, we must be able to identify a priori which processes are more automatic so that conclusions about interference asymmetries are not entirely ad hoc. Studies carefully controlling learning history and using methodologies such as the secondary-task procedure hold promise in this regard. At present, automaticity accounts remain potentially viable, but in need of greater specification and more stringent test.

\section{Perceptual Encoding}

As Dyer (1973c, p. 114) noted, "Most of these explanations have considered the phenomenon in terms of response competition." Such views are often referred to as "late selection" accounts, in that the conflict occurs late in processing at a response stage as opposed to "early selection" at encoding, for example. Preference for late-selection accounts has been consistent throughout the history of Stroop research; relative speed and automaticity are just the two most prevalent examples. However, it is worthwhile to consider the early selection idea.

The best known version of early selection was put forward by Hock and Egeth (1970): the perceptual-encoding account. The basic idea is that perceptual encoding of ink-color information is slowed by incompatible information from a color word as opposed to a neutral control. Hock and Egeth (1970) presented evidence from a short-term memory scanning task, which they 
saw as incompatible with a late, response-conflict account. Using oral yes-no responses (to avoid a semantic relation with the printed words), they suggested that color-related words are recognized earlier and thereby more likely to distract from encoding ink color.

However, Dalrymple-Alford and Azkoul (1972) and Dyer (1973c) questioned their interpretation, arguing that Hock and Egeth (1970) failed to distinguish between identification and covert naming, and that their conclusions rested on accepting the null hypothesis. The only other finding consistent with the Hock and Egeth (1970) position-that of Tecce and Dimartino (1965) that words spoken at the time of ink-color encoding can either facilitate or inhibit that encoding-was also criticized by Dyer (1973c, pp. 114-116) as relying on a questionable assumption about the rates of processing word versus color information. The perceptual encoding account has not been very prominent since then. At any rate, it would have trouble with several of the key results in Appendix B (e.g., Results 7 and 14 among others). Processing subsequent to encoding definitely seems to matter to the Stroop effect.

\section{Parallel Models: Accruing Evidence Toward a Decision}

Virtually all earlier theories of the Stroop task were sequential. Information was encoded from each dimension and then analyzed, and then a response was produced, perhaps with an additional disambiguation stage. Processing at one stage had to be complete (or very close to complete) before the next stage could begin. Even if parallel processing did appear in a model, it was limited to occurring within a stage; stage transitions were sequential. Thus, Morton and Chambers (1973) saw processing within the identification stage as parallel, but transition to the response stage as sequential. Interference occurred at the entry to the response stage.

In recent years, models have begun to relax this strict sequential emphasis, discarding the idea of a limited-capacity response stage (e.g., Eriksen \& Schultz, 1979; Flowers \& Wilcox, 1982; Logan, 1980; McClelland \& Rumelhart, 1981; Taylor, 1977). Capacity limitations seen as system-resource limits (e.g., Kahneman, 1973) lead to quite different conceptions than did limitations seen as stage-specific bottlenecks (e.g., Broadbent, 1958).

Logan (1980, pp. 528-529) cast his model of the Stroop effect as a decision process gathering evidence. Evidence accumulates over time until a response threshold is reached; evidence from each dimension is processed at a rate governed by its weight. Two weights determine each dimension's contribution to the decision (in terms of evidence): a stable, automatic weight and a flexible, strategic attentional weight. Total evidence at threshold is the sum of all evidence from all dimensions. If the evidence from other dimensions is consistent with the desired dimension, this reduces the threshold and hence the processing time for the desired dimension. However, if irrelevant dimensions provide evidence conflicting with the desired dimension, response speed will be slowed. The extent of intrusion of another dimension will be a function of its weights; those with larger weights will have a greater impact on the composite decision process.

Logan's model provides a reasonable prototype for such paral- lel models. In general, evidence is accrued for a response without requiring a "response stage." Instead, interference arises because of the amount of priming received by competing responses (i.e., the amount of evidence accrued for them). This interference occurs during the gathering of evidence, a continuous process. Some models assume independent evidence gathering along the dimensions, but many allow interaction (e.g., McClelland \& Rumelhart, 1981; Taylor, 1977), greatly increasing the ability of these models to capture data.

Nevertheless, two problems arise in Logan's model (and presumably in similar parallel models). First, the model appears to predict symmetrical facilitation and interference; Logan certainly portrayed the model that way in $1980 .{ }^{10}$ Yet facilitation is virtually always substantially smaller than interference. Logan's model can accommodate this by assuming that equal changes in activation for the congruent and incongruent conditions, represented geometrically as equal angles of departure from the neutral condition, intersect the response threshold at different angles because the point of origin is not perpendicular to the response threshold (see, e.g., Ratcliff, 1978, Figure 4, p. 65). Note that such a model still must predict that the same manipulations will affect the magnitudes of both facilitation and interference, a prediction definitely worthy of empirical test.

The second problem with Logan's model is familiar: Asymmetrical interference for color naming versus word reading is explained by differential time of availability of the evidence from the two dimensions. As Logan (1980, p. 543) put it, "sources available sooner can influence (speeded) decisions about sources that become available later, but not vice versa." This is tantamount to a relative speed-of-processing assumption, which I have already argued against. How serious a problem is this for this class of models?

As it turns out, this is not a necessary consequence of such models, particularly those allowing interaction across dimensions. To illustrate with the bulletin-board metaphor, the provisional evidence from every dimension is continuously updated on a bulletin board visible to all processors and studied by the decision maker. Although the desired dimension may be closer to complete processing on a given trial, partial evidence still will be present from other dimensions and will contribute to the composite decision. Thus, even the "early returns" from a dimension being processed more slowly can influence output based on a dimension processed relatively quickly. There is still a speed element in this account (e.g., a very slow process might not return any evidence early enough to have any effect), but the strict speed of processing assumption need not hold. Indeed, the variability in finishing times inherent in this stochastic representation also permits deviations from strict speed of processing predictions.

Logan's model handles the major data in Appendix B quite well. He would expect many analogs of the Stroop effect when multiple dimensions are being processed in parallel (Result 1). Because evidence would be collected at different levels of analysis, both orthographic (Result 2) and semantic (Result 3) influ-

\footnotetext{
${ }^{10}$ Jonathan Cohen, Kevin Dunbar, and Gordon Logan all independently pointed this out to me. The possible solution offered here was provided in a letter from Gordon Logan.
} 
ences should make their presence known. This implicates a greater role for the linguistic processing of the left hemisphere (Result 17), but without any anticipated sex differences (Result 15).

Prior activation of some information should provide a head start to the evidence-gathering process, increasing the weight of that dimension (Result 4). Facilitation follows naturally: Evidence collected from different dimensions points to the same response and makes the decision easier (Result 5). Perceptual integration should make it difficult to assign differential weights to dimensions, whereas separation should make it easier (Result 6). Mixing congruent and incongruent trials (Result 7) should also disrupt the assigning of weights from trial to trial because sometimes it will be helpful to incorporate information from other dimensions and sometimes it will be a hindrance. The logic is similar for successive trial effects (Result 8) and for advance cueing (Result 9), both of which will cause temporary adjustments of dimensional weights.

A reverse Stroop effect (Result 11) occurs when some manipulation of the usual situation changes the direction of interference. In Logan's model, the relative weights of the two dimensions would also shift, as might the speed of gathering evidence for each. Practice (Result 12) should also affect the priority of each dimension and hence its weight. Once again, the development of reading (Result 16) and of language ability (Result 18) can be seen as instances of naturally occurring practice. Because evidence is being gathered for one of a set of possible responses, the overlap of this set across the two or more dimensions would be important (Result 14).

Only the SOA and the response modality effects do not flow easily from the Logan model, although they can be handled. The word-reading task might not be affected by SOA (Result 10) because it is difficult to alter the weight of the evidence drawn from the word; it is already highly weighted in the standard Stroop task. Apparent perceptual integration may also play a role in the largest interference being seen at the shortest SOAs. As for response mode (Result 13), less evidence may be required for a manual response than for an oral one, although this speculation should be tested.

With some fine tuning, Logan's model can encompass the existing data. However, parallel models expressed only at the conceptual level tend to have more "free parameters" than do sequential models, which may be part of why they appear to be more successful. What is required is a parallel model expressed formally, so that its predictions can be tested and evaluated.

\section{A Parallel Distributed Processing Model}

The most exciting recent development in models of cognition is the parallel distributed processing framework (e.g., McClelland, 1979; Rumelhart, Hinton, \& McClelland, 1986). Cohen, Dunbar, and McClelland (1990) used this framework to build a model of the Stroop effect. It incorporates many of the virtues of automaticity and relative speed of processing but few of the liabilities. Furthermore, it is quite a natural extension of the kinds of ideas embodied in the parallel models just described.

At the core of the Cohen et al. (1990) model is the idea that processing occurs in the system through activation moving along pathways of different strength. Consequently, relative speed-of-processing predictions need not always hold; it is strength, not speed, that is basic. Nor is strong automaticity appropriate; a gradient of automaticity makes sense (cf. Logan, 1985; MacLeod \& Dunbar, 1988) wherein degree of automaticity is a function of the strength of each pathway.

Processing is performed in a system comprised of interconnected modules. Within each module are continuously operating elementary processing units responsible for accepting inputs from other units and providing output. Knowledge is represented as a pattern of activation over units, which can change with time in a continuous, nonlinear manner. Processing occurs by the spread of activation along connections that exist both within modules and between modules. For simplification, Cohen et al. (1990) assumed that information flows in one direction-bottom up-from input to output.

When the model is instructed to perform a task, it selects a pathway that includes some or all of the units in one or more modules. The set of connections in this pathway specifies its strength, and the choice of pathway therefore determines both the speed and accuracy of processing. Individual units can be members of more than one pathway, allowing interactions between processes when their pathways intersect. Thus, if two pathways are active simultaneously and produce conflicting activation at their intersection, interference results; if they produce coinciding activation, facilitation results. Such intersections can occur anywhere in processing, and there can be multiple intersections. This realizes the essential details of the Logan model. An important difference from Logan's model is the nonlinearity of the processing units, permitting asymmetry between facilitation and interference.

One of the nice features of this model is its incorporation of a clear role for attention. Attention tunes, or modulates, the operation of processing units in a pathway. However, attention accomplishes this tuning simply as another source of information would; it has no privileged status. This can be seen in Figure 2, which presents a minimalist view of the model.

In this simple case, there are two pathways-one for ink-color information and one for word information-that share a re-

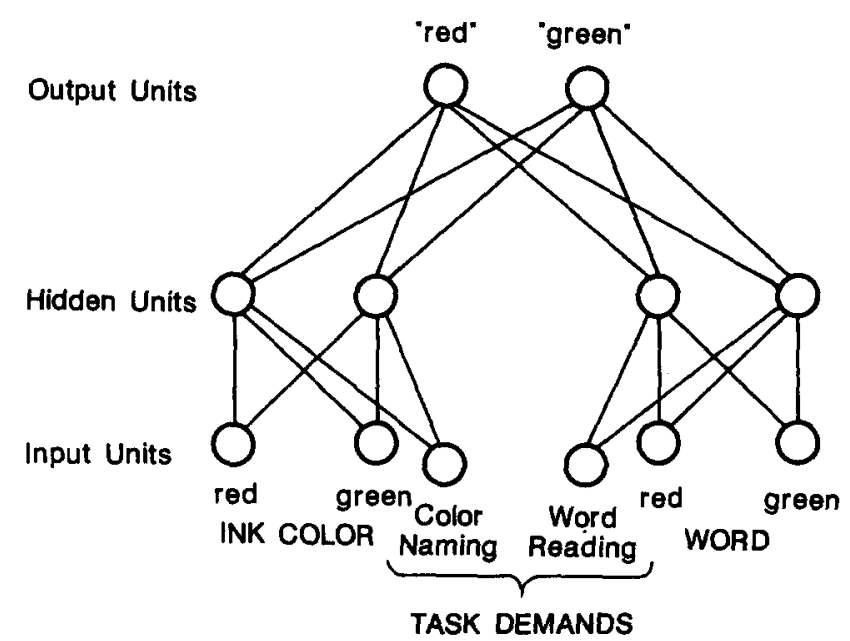

Figure 2. A parallel distributed processing model of the Stroop effect (after Cohen, Dunbar, \& McClelland, 1990). 
sponse mechanism. Each pathway has a set of input units, each of which connects to every intermediate unit. In turn, each intermediate unit connects to all output units. Processing begins with the input units and feeds upward to the response units, one of which will eventually accrue sufficient activation to exceed threshold and produce a response. The only other element is the task-specific attentional units attached to the task-appropriate intermediate units and capable of tuning attention by gating information flow.

Cohen et al. (1990) represented each potential input and output as a single unit in the model, although they pointed out that this one-to-one mapping is not essential. Like Logan's, the model works by accruing evidence forward through the system, and the level of activation of a unit is a weighted sum of the inputs reaching it. Learning occurs by changing connection strengths based on minimizing mismatch between the desired response and the actual response produced. Successive cycles, or trials, allow these strength adjustments to occur. In this way, the network can be trained to produce particular responses under particular sets of circumstances. Furthermore, their learning algorithm shows the power function widely seen in automaticity research.

A response occurs when a particular output unit's threshold is exceeded. A unit's response strength is the ratio of its activation to total activation. Attention, also a pattern of activation over some set of units, picks the pathway that determines the response, based on task instructions. Ordinarily, intermediate units rest near zero activation, but relevant attentional connections (stemming from task demands) push these units toward a higher resting state, where they are more responsive to inputs. It is through this kind of priming that attention tunes pathways.

Cohen et al. (1990) simulated a number of key results, including not only the basic Stroop asymmetry, but also the fact that interference usually exceeds facilitation (e.g., Dunbar \& MacLeod, 1984), the SOA effects of Glaser and Glaser (1982), the practice effects of MacLeod and Dunbar (1988), the responseset effects of Klein (1964), and other more general patterns such as the power law with practice (e.g., Logan, 1988) and a reasonable response-time distribution (Ratcliff, 1978). Although there are problems (e.g., when the word precedes the color and the task is to name the color, the word locks in and produces massive interference regardless of SOA), the model fares very well. What is particularly compelling is that they set out to deal primarily with the MacLeod and Dunbar training studies, yet the model does a fine job of reproducing a diverse group of results, even in instances where speed of processing and strong automaticity have made incorrect predictions.

The Cohen et al. (1990) model provides a promising avenue for testing ideas about attention, and is eminently testable in its own right. As with the Logan model, all 18 of the results in Appendix B are readily accommodated. All that is required are the notions of relative strength and attentional tuning of strength of connections between units in various pathways, coupled with nonlinearity of processing units. That it is a functioning model that makes explicit the underlying assumptions is surely a mark in its favor. Of course, it would be most convincing to simulate all 18 critical results and to derive novel (and correct) predictions, but the model's initial success is still impressive. No doubt it will be put to more extensive test.
How different is the parallel distributed processing model from earlier explanations? My impression is that it amalgamates the speed-of-processing and continuum-of-automaticity ideas. Like Logan's account, it rests on parallel processing, but defeats the speed problem by emphasizing strength of connections. It also makes clear that strength determines the extent of automaticity of a process. Finally, it recognizes the importance of response processes in the Stroop task without requiring a limited-capacity response channel. In this way, the model successfully retains the powerful ideas of earlier explanations without being saddled with their flaws. ${ }^{.1}$

\section{The Final Word}

The first five sections set out the data base to be explained. Then the final section surveyed existing theories, evaluating them against this evidence. The two predominant ones-relative speed of processing and automaticity-were seen as inadequate. Ultimately, a new theoretical framework relying on parallel processing was considered. This is a rather different perspective than the one put forth by Dyer (1973c) that is still widely accepted. It will be interesting to see how such theories fare when put to empirical test in upcoming years. I strongly suspect that the Stroop effect will continue to be a challenging phenomenon for cognitive psychologists to explain for many years to come. For now, I look forward to the progress that will be examined in the subsequent review of the Stroop literature some time early in the next millennium.

\footnotetext{
"Another connectionist model appeared subsequent to the final version of this review. Phaf, van der Heijden, and Hudson (1990) use an architectural property-direct connections between compatible stimuli and responses-instead of the differential weights favored by $\mathrm{Co}$ hen et al. (1990) to explain the Stroop effect.
}

\section{References}

Abramczyk, R. R., Jordan, D. E., \& Hegel, M. (1983). "Reverse" Stroop effect in the performance of schizophrenics. Perceptual and Motor Skills, 56, 99-106.

Aine, C. J., \& Harter, M. R. (1984a). Event-related potentials to Stroop stimuli: Color and word processing. Annals of the New York Academy of Sciences, $425,152-153$.

Aine, C. J., \& Harter, M. R. (1984b). Hemispheric differences in eventrelated potentials to Stroop stimuli: Attention and color-word processing. Annals of the New York Academy of Sciences, 425, 154-156.

Alivisatos, B., \& Wilding, J. (1982). Hemispheric differences in matching Stroop-type letter stimuli. Cortex, 18, 5-21.

Allport, D. A., Tipper, S. P., \& Chmiel, N. R. J. (1985). Perceptual integration and postcategorical filtering. In M. I. Posner \& O. S. M. Marin (Eds.), Attention and performance XI (pp. 107-132). Hillsdale, NJ: Erlbaum.

Alperson, B. L. (1967). The effect of semantic relatedness and practice on the color-word test. Unpublished doctoral dissertation, Michigan State University, East Lansing.

Alwitt, L. F. (1966). Attention in a visual task among non-readers and readers. Perceptual and Motor Skills, 23, 361-362.

Arochova, O. (1971). The use of a modified Stroop Test in pre-school children. Psychologia a Patopsychologia Dietata, 6, 261-266. (From Psychological Abstracts, 1972, 48, Abstract No. 11282)

Babbitt, B. C. (1982). Effect of task demands on dual coding of pictorial 
stimuli. Journal of Experimental Psychology: Learning, Memory, and Cognition, 8, 73-80.

Bakan, P., \& Alperson, B. (1967). Pronounceability, attensity, and interference in the color-word test. American Journal of Psychology, 80 , 416-420.

Bakan, P., \& Shotland, R. L. (1969). Lateral eye movement, reading speed, and visual attention. Psychonomic Science, 15, 93-94.

Bartlett, F. C. (1932). Remembering: A study in experimental and social psychology. New York: Macmillan.

Bassett, J. E., \& Schellman, G. C. (1976). Performance of retardates on the Stroop color-word test. Perceptual and Motor Skills, 43, 12591262.

Baumler, G. (1969). Decrease in achievement capacity as a result of age with particular reference to the Stroop-interference tendency. Psychologische Beitrage, 11, 34-68. (From Psychological Abstracts, 1970, 44, Abstract No. 10163)

Beller, H. K. (1975). Naming, reading and executing directions. Journal of Experimental Psychology: Human Perception and Performance, 1, 154-160.

Besner, D., Davies, J., \& Daniels, S. (1981). Reading for meaning: The effects of concurrent articulation. Quarterly Journal of Experimental Psychology, 33A, 415-437.

Bettner, L. G., Jarvik, L. F., \& Blum, J. E. (1971). Stroop color-word test, non-psychotic organic brain syndrome, and chromosome loss in aged twins. Journal of Gerontology, 26, 458-469.

Biederman, I., \& Tsao, Y.-C. (1979). On processing Chinese ideographs and English words: Some implications from Stroop-test results. $\mathrm{Cog}$ nitive Psychology, 11, 125-132.

Bills, A. G. (1931). Blocking: A new principle of mental fatigue. American Journal of Psychology, 43, 230-245.

Bone, R. N., \& Eysenck, H. J. (1972). Extraversion, field-dependence, and the Stroop test. Perceptual and Motor Skills, 34, 873-874.

Boyden, J. G., \& Gilpin, A. R. (1978). Matching familiar figures test and Stroop test performance in adults. Perceptual and Motor Skills, 46,854

Bradlyn, A. S., \& Rollins, H. A. (1980). Incidental memory for the color-word association in the Stroop Color-Word Test. Bulletin of the Psychonomic Society, 16, 269-272.

Breslow, R., Grand, S., \& Freedman, N. (1980). Effect of vocal feedback on Stroop color-word interference. Perceptual and Motor Skills, 50, 447-451.

Brian, C. R., \& Goodenough, F. L. (1929). The relative potency of color and form perception at various ages. Journal of Experimental Psychology, 12, 197-213.

Briggs, P., \& Underwood, G. (1982). Phonological coding in good and poor readers. Journal of Experimental Child Psychology, 34, 93-112.

Broadbent, D. E. (1958). Perception and communication. London: Pergamon Press.

Brown, W. (1915). Practice in associating color names with colors. Psychological Review, 22, 45-55.

Bryson, S. E. (1983). Interference effects in autistic children: Evidence for the comprehension of single stimuli. Journal of Abnormal Psychology, 92, 250-254.

Butollo, W. H., Bauer, B., \& Riedl, H. (1971). The equivalence to the Stroop test for the preschool age? An experimental investigation of interference tendency and its development in young children. Zeitschrift fur Entwicklungpsychologie und Padagogische Psychologie, 3, 181-194. (From Psychological Abstracts, 1972, 48, Abstract No. 622)

Cammock, T., \& Cairns, E. (1979). Concurrent validity of a children's version of the Stroop Color-Word Test: The fruit distraction test. Perceptual and Motor Skills, 49, 611-616.

Cattell, J. M. (1886). The time it takes to see and name objects. Mind, $11,63-65$.
Cheesman, J., \& Merikle, P. M.(1984). Priming with and without awareness. Perception and Psychophysics, 36, 387-395.

Cheesman, J., \& Merikle, P. M. (1986). Distinguishing conscious from unconscious perceptual processes. Canadian Journal of Psychology, 40, 343-367.

Chen, H.-C., \& Ho, C. (1986). Development of Stroop interference in Chinese-English bilinguals. Journal of Experimental Psychology: Learning, Memory, and Cognition, 12, 397-401.

Chmiel, N. (1984). Phonological recoding for reading: The effect of concurrent articulation in a Stroop task. British Journal of Psychology, 75, 213-220.

Clark, H. H., \& Brownell, H. H. (1975). Judging up and down. Journal of Experimental Psychology: Human Perception and Performance, 1 , 339-352.

Cohen, G., \& Martin, M. (1975). Hemisphere differences in an auditory Stroop task. Perception and Psychophysics, 17, 79-83.

Cohen, J. D., Dunbar, K., \& McClelland, J. L. (1990). On the control of automatic processes: A parallel distributed processing account of the Stroop effect. Psychological Review, 97, 332-361.

Cohen, R., Meier, E., \& Shulze, V. (1983). Spontaneous reading in aphasics (Stroop-test). der Nervenarzt, 54, 299-303.

Cohn, N. B., Dustman, R. E., \& Bradford, D. C. (1984). Age-related decrements in Stroop Color Test performance. Journal of Clinical Psychology, 40, 1244-1250.

Comalli, P. E., Jr., Wapner, S., \& Werner, H. (1962). Interference effects of Stroop color-word test in childhood, adulthood, and aging. Journal of Genetic Psychology, 100, 47-53.

Compton, R. P., \& Flowers, J. H. (1977). Pictorial interference with geometric shapes and achromatic shades. Perception and Psychophysics, 22, 303-309.

Conrad, C. (1974). Context effects in sentence comprehension: A study of the subjective lexicon. Memory and Cognition, 2, 130-138.

Corballis, M. C., \& Luthe, L. (1971). Two-channel visual memory. Perception and Psychophysics, 9, 361-367.

Corbitt, J. R. (1978). Cognitive organization for words and colors as related to reading ability level: $A$ developmental approach. (Doctoral dissertation, University of Wyoming, 1977) Dissertation Abstracts International, 38, 4501-B.

Cramer, P. (1967). The Stroop effect in preschool aged children: A preliminary study. Journal of Genetic Psychology, 111, 9-12.

Dallas, M., \& Merikle, P. M. (1976). Semantic processing of non-attended visual information. Canadian Journal of Psychology, 30, 1521.

Dalrymple-Alford, E. C. (1968). Interlingual interference in a colornaming task. Psychonomic Science, 10, 215-216.

Dalrymple-Alford, E. C. (1972a). Associative facilitation and interference in the Stroop color-word task. Perception and Psychophysics, 11, 274-276.

Dalrymple-Alford, E. C. (1972b). Sound similarity and color word interference in the Stroop task. Psychonomic Science, 28, 209-210.

Dalrymple-Alford, E. C., \& Azkoul, J. (1972). The locus of interference in the Stroop and related tasks. Perception and Psychophysics, 11, 385-388.

Dalrymple-Alford, E. C., \& Budayr, B. (1966). Examination of some aspects of the Stroop Color-Word Test. Perceptual and Motor Skills, $23,1211-1214$.

Daniel, J. (1968). Certain correlates in the Stroop interference test. Ceskoslovenska Psychologie, 12, 282-287.

Daniel, J. (1969). Performance in an interference test and some changes in the vegetative functions. Siudia Psychologica, 11, 267271. (From Psychological Abstracts, 1970, 44, Abstract No. 20661)

Daniel, J. (1970a). Achievement in the Stroop interference test in relation to profession. Studia Psychologica, 12, 99-102. (From Psychological Abstracts, 1971, 45, Abstract No. 7107) 
Daniel, J. (1970b). Further variants of Stroop's interference test. Studia Psychologica, 12, 80-81. (From Psychological Abstracts, 1971, 45, Abstract No. 1658)

Das, J. P. (1969). Development of verbal abilities in retarded and normal children as measured by Stroop test. British Journal of Social and Clinical Psychology, 8, 59-66.

Das, J. P. (1970). Changes in Stroop-test responses as a function of mental age. British Journal of Social and Clinical Psychology, 9, 6873.

Dash, J., \& Dash, A. S. (1982). Cognitive developmental studies of the Stroop phenomena: Cross-sectional and longitudinal data. Indian Psychologist, 1, 24-33. (From Psychological Abstracts, 1984, 71, Abstract No. 9134)

Davis, W., Jorgenson, C. B., Kritselis, A., \& Opella, J. (1981). Hemispheric asymmetry in the processing of Stroop stimuli: The effect of enhancement of spatial skills. International Journal of Neuroscience, $15,179-183$.

Davis, W., Jorgenson, C. B., \& Opella, J. (1983). Hemispheric asymmetry in the processing of Stroop stimuli: An altered format. International Journal of Neuroscience, 19, 227-230.

DeHaas, P. A., \& Young, R. D. (1984). Attention styles of hyperactive and normal girls. Journal of Abnormal Child Psychology, 12, 531545.

Dennis, I., \& Newstead, S. E. (1981). Is phonological recoding under strategic control? Memory and Cognition, 9, 472-477.

Doehrman, S., Landau, R., \& O'Connell, D. (1978). The Stroop phenomenon: Perceptual conflict or response competition? Perceptual and Motor Skills, 47, 1127-1131.

Dornic, S. (1982). Semantic interference as a function of arousal. $R e$ ports from the Department of Psychology, University of Stockholm, No. 590, 1-8. (From Psychological Abstracts, 1984, 71, Abstract No. 19521)

Dornic, S., \& Wirberg, A. (1983). Note on intralingual and interlingual interference in the Stroop task. Reports from the Department of Psychology, University of Stockholm, No. 611, 1-7. (From Psychological Abstracts, 1985, 72, Abstract No. 27143)

Dosher, B. A., \& Corbett, A. T. (1982). Instrument inferences and verb schemata. Memory and Cognition, 10, 531-539.

Doten, G. W. (1955). The effects of rest periods on interference of a well-established habit. Journal of Experimental Psychology, 49, 401406.

Dunbar, K. N. (1986). Multiple sources of interference in a picture-word analogue of the Stroop task. Unpublished doctoral dissertation, University of Toronto.

Dunbar, K. N., \& MacLeod, C. M. (1984). A horse race of a different color: Stroop interference patterns with transformed words. Journal of Experimental Psychology: Human Perception and Performance, 10, 622-639.

Duncan-Johnson, C. C., \& Kopell, B. S. (1980). The locus of interference in a Stroop task: When you read "blue," do you see "red"? Psychophysiology, 17, 308-309.

Duncan-Johnson, C. C., \& Kopell, B. S. (1981). The Stroop effect: Brain potentials localize the source of interference. Science, 214, 938-940.

Dyer, F. N. (1971a). Color-naming interference in monolinguals and bilinguals. Journal of Verbal Learning and Verbal Behavior, 10, 297302.

Dyer, F. N. (1971b). A comparison of chromatic and achromatic versions of the Stroop Color-Word Test. Psychonomic Science, 22, 235237.

Dyer, F. N. (1971c). The duration of word meaning responses: Stroop interference for different preexposures of the word. Psychonomic Science, 25, 229-231.

Dyer, F. N. (1972). Latencies for movement naming with congruent and incongruent word stimuli. Perception and Psychophysics, 11, 377380.

Dyer, F. N. (1973a). Interference and facilitation for color naming with separate bilateral presentations of the word and color. Journal of Experimental Psychology, 99, 314-317.

Dyer, F. N. (1973b). Same and different judgments for word-color pairs with "irrelevant" words or colors: Evidence for word-code comparisons. Journal of Experimental Psychology, 98, 102-108.

Dyer, F. N. (1973c). The Stroop phenomenon and its use in the study of perceptual, cognitive, and response processes. Memory and Cognition, 1, 106-120.

Dyer, F. N. (1974). Stroop interference with long preexposures of the word: Comparison of pure and mixed preexposure sequences. Bulletin of the Psychonomic Society, 3, 8-10.

Dyer, F. N., \& Severance, L. J. (1972). Effects of irrelevant colors on reading of color names: A controlled replication of the "reversed Stroop" effect. Psychonomic Science, 28, 336-338.

Dyer, F. N., \& Severance, L. J. (1973). Stroop interference with successive presentations of separate incongruent words and colors. Journal of Experimental Psychology, 98, 438-439.

Effler, M. (1977a). Experimental contributions toward an analysis of the interference phenomenon observed with the Stroop test. Zeitschrift fitr Experimentelle und Angewandte Psychologie, 24, 244281. (From Psychological Abstracts, 1978, 60, Abstract No. 2368)

Effler, M. (1977b). The influence of serial factors on the Stroop test. Psychologische Beitrage, 19, 189-200. (From Psychological Abstracts, 1978, 60, Abstract No. 184)

Effler, M. (1978a). Colour-distant versus colour-congruent colour words, their influence on naming times in the Stroop-test. Psychologische Beitrdge, 20, 345-359. (From Psychological Abstracts, 1980, 64, Abstract No. 2591)

Effler, M. (1978b). The influence of similarity in names of Stroop items. Archiv fur Psychologie, 131, 21-37. (From Psychological Abstracts, 1981, 65, Abstract No. 11873)

Effler, M. (1980). Processes in naming Stroop-stimuli: An analysis with word repetition effects. Archiv für Psychologie, 133, 249-262. (From Psychological Abstracts, 1983, 69, Abstract No. 276)

Effler, M. (1981). Interference by Stroop items depending on word frequency training and reaction times of the word components. Zeitschrift fur Experimentelle und Angewandte Psychologie, 28, 5479. (From Psychological Abstracts, 1982, 67, Abstract No. 7459)

Effler, M. \& Rabenstein, E. (1979). Serial effects: A possibility for the analysis of the interference phenomenon in the Stroop-test? Psychologische Beitrage, 21, 417-438. (From Psychological Abstracts, 1981, 65, Abstract No. 9227)

Egeth, H. E., Blecker, D., \& Kamlet, A. S. (1969). Verbal interference in a perceptual comparison task. Perception and Psychophysics, 6, 355356.

Ehri, L. C. (1976). Do words really interfere in naming pictures? Child Development, 47, 502-505.

Ehri, L. C. (1977). Do adjectives and functors interfere as much as nouns in naming pictures? Child Development, 48, 697-701.

Ehri, L. C., \& Ryan, E. B. (1980). Performance of bilinguals in a picture-word interference task. Journal of Psycholinguistic Research, 9 , 285-302.

Ehri, L. C., \& Wilce, L. S. (1979). Does word training increase or decrease interference in a Stroop task? Journal of Experimental Child Psychology, 27, 352-364.

Ellis, N. R., Woodley-Zanthos, P., Dulaney, C. L., \& Palmer, R. L. (1989). Automatic-effortful processing and cognitive inertia in persons with mental retardation. American Journal on Mental Retardation, 93, 412-423.

Ellison, A. E., \& Lambert, W. E. (1968). Reduction of response interfer- 
ence through verbal repetition. British Journal of Psychology, 59, 147-155.

Eriksen, B. A., \& Eriksen, C. W. (1974). Effects of noise letters upon the identification of a target letter in a nonsearch task. Perception and Psychophysics, 16, 143-149.

Eriksen, C. W., \& Hoffman, J. E. (1972). Temporal and spatial characteristics of selective encoding from visual displays. Perception and Psychophysics, 12, 201-204.

Eriksen, C. W., \& Schultz, D. W. (1979). Information processing in visual search: A continuous flow conception and experimental results. Perception and Psychophysics, 25, 249-263.

Fang, S.-P., Tzeng, O. J., \& Alva, L. (1981). Intralanguage vs. interlanguage Stroop effects in two types of writing systems. Memory and Cognition, 9, 609-617.

Fitts, P. M., \& Posner, M. I. (1967). Human performance. Monterey, CA: Brooks Cole.

Flowers, J. H. (1975). "Sensory" interference in a word-color matching task. Perception and Psychophysics, 18, 37-43.

Flowers, J. H., \& Blair, B. (1976). Verbal interference with visual classification: Optimal processing and experimental design. Bulletin of the Psychonomic Society, 7, 260-262.

Flowers, J. H., \& Dutch, S. (1976). The use of visual and name codes in scanning and classifying colors. Memory and Cognition, 4, 384-390.

Flowers, J. H., \& Stoup, C. M. (1977). Selective attention between words, shapes and colors in speeded classification and vocalization tasks. Memory and Cognition, 5, 299-307.

Flowers, J. H., \& Wilcox, N. (1982). The effect of flanking context on visual classification: The joint contribution of interactions at different processing levels. Perception and Psychophysics, 32, 581-591.

Flowers, J. H., Warner, J. L., \& Polansky, M. L. (1979). Response and encoding factors in "ignoring" irrelevant information. Memory and Cognition, 7, 86-94.

Fournier, P. A., Mazzarella, M. M., Ricciardi, M. M., \& Fingeret, A. L. (1975). Reading level and locus of interference in the Stroop colorword task. Perceptual and Motor Skills, 41, 239-242.

Fox, L. A., Shor, R. E., \& Steinman, R. J. (1971). Semantic gradients and interference in naming color, spatial direction, and numerosity. Journal of Experimental Psychology, 91, 59-65.

Fraisse, P. (1969). Why is naming longer than reading? Acta Psychologica, 30, 96-103.

Francolini, C. M., \& Egeth, H. E. (1980). On the non-automaticity of "automatic" activation: Evidence of selective seeing. Perception and Psychophysics, 27, 331-342.

Frey, P. D. (1971). The effects of age, language, and reading ability on color word interference under two conditions of responding. Unpublished doctoral dissertation, Catholic University of America, Washington, DC.

Friedman, R. (1971). The relationship between intelligence and performance on the Stroop color-word test in second- and fifth-grade children. Journal of Genetic Psychology, 118, 147-148.

Friedman, H., \& Derks, P. L. (1973). Simultaneous motor and verbal processing of visual information in a modified Stroop test. Perception and Psychophysics, 13, 113-115.

Gails, G. S. (1922). Individual differences as affected by practice. $A r$ chiv fuer Psychologie, 8, 1-74.

Gardner, R. M. (1985). The reverse affect test: A new interference task. Perceptual and Motor Skills, 60, 384-386.

Gardner, R. W., Holzman, P. S., Klein, G. S., Linton, H., \& Spence, D. P. (1959). Cognitive control: A study of individual consistencies in cognitive behavior. Psychological Issues, 1, 1-185.

Gardner, R. W., \& Long, R. I. (1962). Cognitive controls of attention and inhibition: A study of individual consistencies. British Journal of Psychology, 53, 381-388.
Garner, W. R. (1974). The processing of information and structure. Hillsdale, NJ: Erlbaum.

Garrett, H. E., \& Lemmon, V. W. (1924). An analysis of several wellknown tasks. Journal of Applied Psychology, 8, 424-438.

Gatti, S. V., \& Egeth, H. E. (1978). Failure of spatial selectivity in vision. Bulletin of the Psychonomic Society, 11, 181-184.

Gholson, B., \& Hohle, R. H. (1968a). Choice reaction times to hues printed in conflicting hue names and nonsense words. Journal of Experimental Psychology, 76, 413-418.

Gholson, B., \& Hohle, R. H. (1968b). Verbal reaction times to hues vs hue names and forms vs form names. Perception and Psychophysics, 3, 191-196.

Glaser, M. O., \& Glaser, W. R. (1982). Time course analysis of the Stroop phenomenon. Journal of Experimental Psychology: Human Perception and Performance, 8, 875-894.

Glaser, W. R., \& Dolt, M. O. (1977). A functional model to localize the conflict underlying the Stroop phenomenon. Psychological Research, 39, 287-310.

Glaser, W. R., \& Düngelhoff, F.-J. (1984). The time course of pictureword interference. Journal of Experimental Psychology: Human Perception and Performance, 10, 640-654.

Glaser, W. R., \& Glaser, M. O. (1989). Context effects in Stroop-like word and picture processing. Journal of Experimental Psychology: General, 118, 13-42.

Golden, C. J. (1974a). Effect of differing number of colors on the Stroop Color and Word Test. Perceptual and Motor Skills, 39, 550.

Golden, C. J. (1974b). Sex differences in performance on the Stroop Color and Word Test. Perceptual and Motor Skills, 39, 1067-1070.

Golden, C. J. (1975). A group version of the Stroop Color and Word Test. Journal of Personality Assessment, 39, 386-388.

Golinkoff, R. M., \& Rosinski, R. R. (1976). Decoding, semantic processing, and reading comprehension skill. Child Development, 47, 252-258.

Goolkasian, P. (1978). Reading and detecting color-word stimuli presented at various retinal locations. Journal of Psychology, 100, 167181.

Goolkasian, P. (1981). Retinal location and its effect on the processing of target and distractor information. Journal of Experimental Psychology: Human Perception and Performance, 7, 1247-1257.

Grand, S., Breslow, R., \& Freedman, N. (1980). On the role of reduced auditory feedback and kinesic self-stimulation during Stroop ColorWord performance. Journal of Personality, 48, 173-189.

Green, E. J., \& Barber, P. J. (1981). An auditory Stroop effect with judgments of speaker gender. Perception and Psychophysics, 30 , 459-466.

Green, E. J., \& Barber, P. J. (1983). Interference effects in an auditory Stroop task: Congruence and correspondence. Acta Psychologica, 53, 183-194.

Greenwald, A. G. (1970). A double stimulation test of ideomotor theory with implications for selective attention. Journal of Experimental Psychology, 84, 392-398.

Greenwald, A. G. (1972). On doing two things at once: Time sharing as a function of ideomotor compatibility. Journal of Experimental Psychology, 94, 52-57.

Grice, G. R., Boroughs, J. M., \& Canham, L. (1984). Temporal dynamics of associative interference and facilitation produced by visual context. Perception and Psychophysics, 36, 499-507.

Grice, G. R., \& Gwynne, J. W. (1985). Temporal characteristics of noise conditions producing facilitation and interference. Perception and Psychophysics, 37, 495-501.

Guiard, Y. (1981). Effect of processing mode on the degree of motor asymmetry in the manual Stroop test. Cortex, 17, 427-433.

Gumenik, W. E., \& Glass, R. (1970). Effects of reducing the readability 
of the words in the Stroop Color-Word Test. Psychonomic Science, 20, 247-248.

Guttentag, R. E., \& Haith, M. M. (1978). Automatic processing as a function of age and reading ability. Child Development, 49, 707-716.

Guttentag, R. E., Haith, M. M., Goodman, G. S., \& Hauch, J. (1984). Semantic processing of unattended words by bilinguals: $A$ test of the input switch mechanism. Journal of Verbal Learning and Verbal Behavior, 23, 178-188.

Hall, R., \& Swane, D. (1973). Memory in a bisensory selective attention task. Quarterly Journal of Experimental Psychology, 25, 309-315.

Hamers, J. F.-A. (1973). Interdependent and independent states of the bilingual's two languages. Unpublished doctoral dissertation, McGill University, Montreal, Quebec, Canada.

Hamers, J. F., \& Lambert, W. E. (1972). Bilingual interdependencies in auditory perception. Journal of Verbal Learning and Verbal Behavior, 11, 303-310.

Harbeson, M. M., Kennedy, R. S., \& Bittner, A. C. (1981). A comparison of the Stroop test to other tasks for studies of environmental stress. US Naval Biodynamics Laboratory, 80R008, 20-28. (From Psychological Abstracts, 1983, 69, Abstract No. 7060)

Harbeson, M. M., Krause, M., Kennedy, R. S., \& Bittner, A. C. (1982). The Stroop as a performance evaluation test for environmental research. Journal of Psychology, 111, 223-233.

Harms, L., \& Bundesen, C. (1983). Color segregation and selective attention in a nonsearch task. Perception and Psychophysics, 33, 11-19.

Harrison, N. S., \& Boese, E. (1976). The locus of semantic interference in the "Stroop" color-naming task. Perception and Psychophysics, 20, $408-412$.

Harvey, N. (1984). The Stroop effect: Failure to focus attention or failure to maintain focusing? Quarterly Journal of Experimental Psychology: Human Experimental Psychology, 36, 89-115.

Hatta, T. (1981). Differential processing of Kanji and Kana stimuli in Japanese people: Some implications from Stroop-test results. Neuropsychologia, 19, 87-93.

Hatta, T., \& Kirsner, K. (1983). Language processing in partial English-Japanese bilinguals: Evidence from Stroop-test results. International Journal of Neuroscience, 20, 241-248.

Hatta, T., Hatae, T. I., \& Kirsner, K. (1984). Orthographic dominance and interference effects in letter recognition among Japanese-English and English-Japanese bilinguals. Psychologia: An International Journal of Psychology in the Orient, 27, 1-9. (From Psychological Abstracts, 1985, 72, Abstract No. 11353)

Hatta, T., Katoh, H., \& Aitani, N. (1983). Does single Kanji process dominantly in the right hemisphere? Some implication from Strooptest results. International Journal of Neuroscience, 18, 67-72.

Henik, A., Friedrich, F. J., \& Kellogg, W. A. (1983). The dependence of semantic relatedness effects upon prime processing. Memory and Cognition, 11, 366-373.

Hentschel, U. (1973). Two new interference tests compared to the Stroop Color-Word Test. Psychological Research Bulletin, Lund University, 13, 1-24. (From Psychological Abstracts, 1974, 51, Abstract No. 8163)

Hinton, W. M., Jr. (1976). The effects of the number and spacing of base item repetitions on reaction time to Stroop-like stimuli (Doctoral dissertation, State University of New York at Buffalo, 1976). Dissertation Abstracts International, 37, 1005-B.

Hintzman, D. L., Carre, F. A., Eskridge, V. L., Owens, A. M., Shaff, S. S., \& Sparks, M. E. (1972). "Stroop" effect: Input or output phenomenon? Journal of Experimental Psychology, 95, 458-459.

Hochman, S. H. (1973). The effects of drive level, non-contingent success-failure feedback, and stimulus conflictfulness on color-word performance (Doctoral dissertation, City University of New York, 1972). Dissertation Abstracts International, 32, 6681-B.

Hock, H. S., \& Egeth, H. (1970). Verbal interference with encoding in a perceptual classification task. Journal of Experimental Psychology, 83, 299-303.

Hollingworth, H. L. (1912). Psychological aspects of drug action. Psychological Bulletin, 9, 420-423.

Hollingworth, H. L. (1915). Articulation and association. Journal of Educational Psychology, 6, 99-105.

Hollingworth, H. L. (1923). The influence of alcohol. Journal of Abnormal and Social Psychology, 18, 204-237.

Hunt, E., \& Lansman, M. (1986). Unified model of attention and problem solving. Psychological Review, 93, 446-461.

Irwin, D. I., \& Lupker, S. J. (1983). Semantic priming of pictures and words: A levels of processing approach. Journal of Verbal Learning and Verbal Behavior, 22, 45-60.

Irwin, H. J. (1978). Input encoding strategies and attenuation of Stroop interference. Australian Journal of Psychology, 30, 177-187.

Jaensch, E. R. (1929). Grundformen menschlichen Seins. Berlin: Otto Elsner.

James, W. (1890). The principles of psychology. New York: Holt.

Jarvik, L. F., Blum, J. E., \& Varma, A. O. (1972). Genetic components and intellectual functioning during senescence: A 20-year study of aging twins. Behavior Genetics, 2, 159-171.

Jensen, A. R. (1965). Scoring the Stroop test. Acta Psychologica, 24, 398-408.

Jensen, A. R., \& Rohwer, W. D., Jr. (1966). The Stroop color-word test: A review. Acta Psychologica, 25, 36-93.

Job, R., \& Rumiati, R. (1984). Effect of the degree of category membership in the figure-word interference task. Ricerche di Psicologia, 8 , 165-181. (From Psychological Abstracts, 1985, 72, Abstract No. 11358)

Johnston, A., \& Venables, P. H. (1982). Specificity of attention in the Stroop test: An EP study. Biological Psychology, 15, 75-83.

Jonides, J., \& Mack, R. (1984). On the cost and benefit of cost and benefit. Psychological Bulletin, 96, 29-44.

Jorgenson, C., Davis, J., Opella, J., \& Angerstein, G. (1980). Hemispheric-asymmetry in the processing of Stroop-stimuli: An examination of gender, hand-preference, and language differences. International Journal of Neuroscience, $11,165-169$.

Jorgenson, C. B., Davis, J., Opella, J., \& Angerstein, G. (1981). Hemispheric asymmetry in the processing of Stroop stimuli: An examination of age and gender differences. International Journal of Neuroscience, 13, 113-116.

Jorgenson, C. B., Davis, W. P., Wilbon, P., \& Opella, J. L. (1983). Hemispheric asymmetry in the processing of Stroop stimuli: A balanced design. International Journal of Neuroscience, 21, 171-174.

Kahneman, D. (1973). Attention and effort. Englewood Cliffs, NJ: Prentice-Hall.

Kahneman, D., \& Chajczyk, D. (1983). Tests of the automaticity of reading: Dilution of Stroop effects by color-irrelevant stimuli. Journal of Experimental Psychology: Human Perception and Performance, 9, 497-509.

Kahneman, D., \& Henik, A. (1981). Perceptual organization and attention. In M. Kubovy \& J. R. Pomerantz (Eds.), Perceptual organization (pp. 181-211). Hillsdale, NJ: Erlbaum.

Kalkofen, H. (1969). Critical investigations of the interference phenomenon (STROOP). Unpublished doctoral dissertation, University of Carolo-Wilhelmina, Braunschweig.

Kalkofen, H. (1970). Change in degree of interference in a Stroop-like test (SWT) when the incongruent combinations are mixed with congruent ones: A reply to Prof. G. J. W. Smith. Psychologische Forschung, 34, 97-98. (From Psychological Abstracts, 1971, 46, Abstract No. 355)

Kamlet, A. S., \& Egeth, H. E. (1969). Note on construction of Strooptype stimuli. Perceptual and Motor Skills, 29, 914.

Kareev, Y. (1980). Developmental changes in the internal encoding of 
sentences as measured by the Stroop technique. Journal of Verbal Learning and Verbal Behavior, 19, 549-561.

Kareev, Y.(1982). Minitypologies from within-subjects designs: Uncovering systematic individual differences in experiments. Journal of Verbal Learning and Verbal Behavior, 21, 363-382.

Keele, S. (1972). Attention demands of memory retrieval. Journal of Experimental Psychology, 93, 245-248.

Keenan, J. M., Potts, G. R., Jennings, T. M., \& Golding, J. M. (1988, November). Can naming detect inferences? Paper presented at the annual meeting of the Psychonomic Society, Chicago, IL.

Kinchla, R. A., Solis-Macias, V., \& Hoffman, J. (1983). Attending to different levels of structure in a visual image. Perception and Psychophysics, 33, 1-10.

Kipnis, D., \& Glickman, A. S. (1958). The development of a non-cognitive battery to predict enlisted performance. USN Bureau of Naval Personnel Technical Bulletin, 58-9. (From Psychological Abstracts, 1960, 34, Abstract No. 2233)

Kipnis, D. \& Glickman, A. S. (1959a). The development of a non-cognitive battery: Prediction of radioman performance. USN Bureau of Naval Personnel Technical Bulletin, 59-14. (From Psychological Abstracts, 1960, 34, Abstract No. 3475)

Kipnis, D., \& Glickman, A. S. (1959b). Validity of non-cognitive tests at Nuclear Power School (submarine). USN Bureau of Naval Personnel Technical Bulletin, 59-6. (From Psychological Abstracts, 1960, 34, Abstract No. 3551)

Kipnis, D., \& Glickman, A. S. (1962). The prediction of job performance. Journal of Applied Psychology, 46, 50-56.

Kiyak, H. A. (1982). Interlingual interference in naming color words. Journal of Cross-Cultural Psychology, 13, 125-135.

Klein, G. S. (1964). Semantic power measured through the interference of words with color-naming. American Journal of Psychology, 77, 576-588.

LaBerge, D., \& Samuels, S. J. (1974). Toward a theory of automatic information processing in reading. Cognitive Psychology, 6, 293323.

La Heij, W. (1988). Components of Stroop-like interference in picture naming. Memory and Cognition, 16, 400-410.

La Heij, W., Van der Heijden, A. H. C., \& Schreuder, R. (1985). Semantic priming and Stroop-like interference in word-naming tasks. Journal of Experimental Psychology: Human Perception and Performance, 11, 62-80.

La Heij, W., \& Vermeij, M. (1987). Reading versus naming: The effect of target set size on contextual interference and facilitation. Perception and Psychophysics, 41, 355-366.

Langer, J., \& Rosenberg, B. G. (1966). Symbolic meaning and color naming. Journal of Personality and Social Psychology, 4, 364-373.

Langlois, J. (1974). Frequency of occurrence as a factor in interference on the Stroop word-color test. Perceptual and Motor Skills, 38, 986.

Lassen, G. L. (1975). Extension of the Stroop interference effect to pictures and words (Doctoral dissertation, University of Arizona, 1974). Dissertation Abstracts International, 35, 0223-B.

Ligon, E. M. (1932). A genetic study of color naming and word reading. American Journal of Psychology, 44, 103-122.

Liu, A.Y. (1973). Decrease in Stroop effect by reducing semantic interference. Perceptual and Motor Skills, 37, 263-265.

Logan, G. D. (1978). Attention in character-classification tasks: Evidence for the automaticity of component stages. Journal of Experimental Psychology: General, 107, 32-63.

Logan, G. D. (1980). Attention and automaticity in Stroop and priming tasks: Theory and data. Cognitive Psychology, 12, 523-553.

Logan, G. D. (1985). Skill and automaticity: Relations, implications, and future directions. Canadian Journal of Psychology, 39, 367-386.

Logan, G. D. (1988). Toward an instance theory of automatization. Psychological Review, 95, 492-527.
Logan, G. D., \& Zbrodoff, N. J. (1979). When it helps to be misled: Facilitative effects of increasing the frequency of conflicting stimuli in a Stroop-like task. Memory and Cognition, 7, 166-174.

Logan, G. D., \& Zbrodoff, N. J. (1982). Constraints on strategy construction in a speeded discrimination task. Journal of Experimental Psychology: Human Perception and Performance, 8, 502-520.

Logan, G. D., Zbrodoff, N. J., \& Williamson, J. (1984). Strategies in the color-word Stroop task. Bulletin of the Psychonomic Society, 22, 135138.

Long, G. M., \& Lyman, B. J. (1987). Foveal and parafoveal processing of asynchronous Stroop stimuli. British Journal of Psychology, 78, 151-162.

Lowe, D. G. (1979). Strategies, context, and the mechanism of response inhibition. Memory and Cognition, 7, 382-389.

Lowe, D. G. (1985). Further investigations of inhibitory mechanisms in attention. Memory and Cognition, 13, 74-80.

Lowe, D. G., \& Mitterer, J. O. (1982). Selective and divided attention in a Stroop task. Canadian Journal of Psychology, 36, 684-700.

Ludwig, R. P., \& Lazarus, P. J. (1983). Relationship between shyness in children and constricted cognitive control as measured by the Stroop Color-Word Test. Journal of Consulting and Clinical Psychology, 51, 386-389.

Lund, F. H. (1927). The role of practice in speed of association. Journal of Experimental Psychology, 10, 424-434.

Lupker, S. J. (1979). The semantic nature of response competition in the picture-word interference task. Memory and Cognition, 7, 485495.

Lupker, S. J. (1982). The role of phonetic and orthographic similarity in picture-word interference. Canadian Journal of Psychology, 36, 349367.

Lupker, S. J., \& Katz, A. N. (1981). Input, decision, and response factors in picture-word interference. Journal of Experimental Psychology: Human Learning and Memory, 7, 269-282.

Lupker, S. J., \& Katz, A. N. (1982). Can automatic picture processing influence word judgments? Journal of Experimental Psychology: Learning, Memory, and Cognition, 8, 418-434.

Lupker, S. J., \& Sanders, M. (1982). Visual-field differences in pictureword interference. Brain and Cognition, 1, 381-398.

Maccoby, E. M., \& Jacklin, C. N. (1974). The psychology of sex differences. Stanford, CA: Stanford University Press.

MacKinnon, D. P., Geiselman, R. E., \& Woodward, J. A. (1985). The effects of effort on Stroop interference. Acta Psychologica, 58, 225235.

MacLeod, C. M. (1986). [A replication of the classic Stroop effect]. Unpublished raw data.

MacLeod, C. M. (in press). John Ridley Stroop: Creator of a landmark cognitive task. Canadian Psychology.

MacLeod, C. M., \& Dunbar, K. (1988). Training and Stroop-like interference: Evidence for a continuum of automaticity. Journal of Experimental Psychology: Learning, Memory, and Cognition, 14, 126-135.

Magee, L. (1982). Pictures, words, and access to information. Unpublished doctoral dissertation, University of Toronto.

Măgiste, E. (1984). Stroop tasks and dichotic translation: The development of interference patterns in bilinguals. Journal of Experimental Psychology: Learning, Memory, and Cognition, 10, 304-315.

Mägiste, E. (1985). Development of intra- and interlingual interference in bilinguals. Journal of Psycholinguistic Research, 14, 137-154.

Majeres, R. L. (1974). The combined effects of stimulus and response conditions on the delay in identifying the print color of words. Journal of Experimental Psychology, 102, 868-874.

Marcel, A. J. (1983). Conscious and unconscious perception: Experiments on visual masking and word recognition. Cognitive Psychology, 15, 197-237. 
Martin, M. (1978). Speech recoding in silent reading. Memory and Cognition, 6, 108-114.

Martin, M. (1979). .Local and global processing: The role of sparsity. Memory and Cognition, 7, 476-484.

Martin, M. (1981). Reverse Stroop effect with concurrent tasks. Bulletin of the Psychonomic Society, 17, 8-9.

McClain, L. (1983a). Color priming affects Stroop interference. Perceptual and Motor Skills, 56, 643-651.

McClain, L. (1983b). Effects of response type and set size on Stroop color-word performance. Perceptual and Motor Skills, 56, 735-743.

McClain, L. (1983c). Stimulus-response compatibility affects auditory Stroop interference. Perception and Psychophysics, 33, 266-270.

McClelland, J. L. (1979). On the time relations of mental processes: An examination of systems of processes in cascade. Psychological Review, 86, 287-330.

McClelland, J. L., \& Rumelhart, D. E. (1981). An interactive activation model of context effects in letter perception: Part 1. An account of basic findings. Psychological Review, 88, 375-407.

McCown, D., \& Arnoult, M. D. (1981). Interference produced by modified Stroop stimuli. Bulletin of the Psychonomic Society, 17, 5-7.

Ménard-Buteau, C., \& Cavanagh, P. (1984). Localization of the form/ colour interference at the perceptual level in a Stroop task with stimuli drawings. Canadian Journal of Psychology, 38, 421-439.

Merikle, P. M., \& Gorewich, N. J. (1979). Spatial selectivity in vision: Field size depends upon noise size. Bulletin of the Psychonomic Society, 14, 343-346.

Merrill, E. C., Sperber, R. D., \& McCauley, C. (1981). Differences in semantic encoding as a function of reading comprehension skill. Memory and Cognition, 9, 618-624.

Meyer, D. E., \& Schvaneveldt, R. W. (1976). Meaning, memory structure, and mental processes. Science, 192, 27-33.

Morikawa, Y. (1981). Stroop phenomena in the Japanese language: The case of ideographic characters (kanji) and syllabic characters (kana). Perceptual and Motor Skills, 53, 67-77.

Morton, J. (1969). Categories of interference: Verbal mediation and conflict in card sorting. British Journal of Psychology, 60, 329-346.

Morton, J., \& Chambers, S. M. (1973). Selective attention to words and colours. Quarterly Journal of Experimental Psychology, 25, 387-397.

Murray, D. J., Mastronardi, J., \& Duncan, S. (1972). Selective attention to "physical" vs "verbal" aspects of colored words. Psychonomic Science, 26, 305-307.

Naish, P. (1980). Phonological recoding and the Stroop effect. British Journal of Psychology, 71, 395-400.

Navon, D. (1977). Forest before trees: The precedence of global features in visual perception. Cognitive Psychology, 9, 353-383.

Nealis, P. M. (1973). The Stroop phenomenon: Some critical tests of the response competition hypothesis. Perceptual and Motor Skills, 37, 147-153.

Nealis, P. M. (1974). Reversal of Stroop test: Interference in word reading. Perceptual and Motor Skills, 38, 379-382.

Neill, W. T. (1977). Inhibitory and facilitatory processes in selective attention. Journal of Experimental Psychology: Human Perception and Performance, 3, 444-450.

Neill, W. T. (1978). Decision processes in selective attention: Response priming in the Stroop color-word task. Perception and Psychophysics, 23, 80-84.

Neill, W. T., \& Westberry, R. L. (1987). Selective attention and the suppression of cognitive noise. Journal of Experimental Psychology: Learning, Memory, and Cognition, 13, 327-334.

Neumann, O. (1980). Selection of information and control of action. Unpublished doctoral dissertation, University of Bochum, Federal Republic of Germany.

Newman, J. P. (1981). Induced anxiety and Stroop Color-Word Test performance: Hemispheric processing implications. International Journal of Neuroscience, 12, 63-66.

Nielsen, G. D. (1975). The locus and mechanism of the Stroop color word effect (Doctoral dissertation, University of Wisconsin-Madison, 1974). Dissertation Abstracts International, 35, 5672-B.

Oden, G. C., \& Spira, J. L. (1983). Influence of context on the activation and selection of ambiguous word senses. Quarterly Journal of Experimental Psychology, 35A, 51-64.

Ogura, C. (1980). Formation of learning-set in the task of Stroop colorword test. Journal of Child Development, 16, 30-36.

Palef, S. R. (1978). Judging pictorial and linguistic aspects of space. Memory and Cognition, 6, 70-75.

Palef, S. R., \& Olson, D. R. (1975). Spatial and verbal rivalry in a Stroop-like task. Canadian Journal of Psychology, 29, 201-209.

Panek, P. E., Rush, M. C., \& Slade, L. A. (1984). Focus of the age-Stroop interference relationship. Journal of Genetic Psychology, 145, 209216.

Peretti, P. O. (1969). Cross-sex and cross-educational level performance in a color-word interference task. Psychonomic Science, 16, 321-323.

Peretti, P. O. (1971). Effects of noncompetitive, competitive instructions, and sex on performance in a color-word interference task. Journal of Psychology, 79, 67-70.

Perret, E. (1974). The left frontal lobe of man and the suppression of habitual responses in verbal categorical behaviour. Neuropsychologia, 12, 323-330.

Peterson, J., Lanier, L. H., \& Walker, H. M. (1925). Comparisons of white and negro children in certain ingenuity and speed tests. Journal of Comparative Psychology, 5, 271-283.

Phaf, R. H., Van der Heijden, A. H. C., \& Hudson, P. T. W. (1990). SLAM: A connectionist model for attention in visual selection tasks. Cognitive Psychology, 22, 273-341.

Pieters, J. M. (1981). Ear asymmetry in an auditory spatial Stroop task as a function of handedness. Cortex, 17, 369-379.

Podell, H. A. (1963). Note on successive dimensional analysis applied to affective, cognitive, and personality traits. Psychological Reports, $13,813-814$

Posnansky, C. J., \& Rayner, K. (1977). Visual-feature and response components in a picture-word interference task with beginning and skilled readers. Journal of Experimental Child Psychology, 24, 440460.

Posnansky, C. J., \& Rayner, K. (1978). Visual vs. phonemic contributions to the importance of the initial letter in word identification. Bulletin of the Psychonomic Society, 11, 188-190.

Posner, M. I. (1978). Chronometric explorations of mind. Hillsdale, NJ: Erlbaum.

Posner, M. I., \& Snyder, C. R. R. (1975). Attention and cognitive control. In R. L. Solso (Ed), Information processing and cognition: The Loyola symposium (pp. 55-85). Hillsdale, NJ: Erlbaum.

Posner, M. I., Walker, J. A., Friedrich, F. J., \& Rafal, R. D. (1984). Effects of parietal injury on covert orienting of attention. Journal of Neuroscience, 4, 1863-1874.

Preston, M. S., \& Lambert, W. E. (1969). Interlingual interference in a bilingual version of the Stroop color-word task. Journal of Verbal Learning and Verbal Behavior, 8, 295-301.

Pritchard, W. (1981). Psychophysiology of P300. Psychological Bulletin, 89, 506-540.

Pritchatt, D. (1968). An investigation into some of the underlying associative verbal processes of the Stroop colour effect. Quarterly Journal of Experimental Psychology, 20, 351-359.

Proctor, R. W. (1978). Sources of color-word interference in the Stroop color-naming task. Perception and Psychophysics, 23, 413-419.

Quantz, J. O. (1897). Problems in the psychology of reading. Psychological Review Monographs, 2(No. 5). 
Rand, G., Wapner, S., Werner, H., \& McFarland, J. H. (1963). Age differences in performance on the Stroop color-word test. Journal of Personality, 31, 534-558.

Ratcliff, R. (1978). A theory of memory retrieval. Psychological Review, 85, 59-108.

Ray, C. (1974). The manipulation of color response times in a colorword interference task. Perception and Psychophysics, 16, 101-104.

Rayner, K., \& Posnansky, C. J. (1978). Stages of processing in word identification. Journal of Experimental Psychology: General, 107, 64-80.

Rayner, K., \& Springer, C. J. (1986). Graphemic and semantic similarity effects in the picture-word interference task. British Journal of Psychology, 77, 207-222.

Redding, G. M., \& Gerjets, D. A. (1977). Stroop effect: Interference and facilitation with verbal and manual responses. Perceptual and Motor Skills, 45, 11-17.

Regan, J. E. (1979). Automatic processing. (Doctoral dissertation, University of California, Berkeley, 1977). Dissertation Abstracts International, 39, 1018-B.

Regan, J. E. (1978). Involuntary automatic processing in color-naming tasks. Perception and Psychophysics, 24, 130-136.

Regan, J. E. (1981). Automaticity and learning: Effects of familiarity on naming letters. Journal of Experimental Psychology: Human Perception and Performance, 7, 180-195.

Reiner, M. B., \& Morrison, F. J. (1983). Is semantic interference really automatic? Bulletin of the Psychonomic Society, 21, 271-274.

Reisberg, D., Baron, J., \& Kemler, D. G. (1980). Overcoming Stroop interference: The effects of practice on distractor potency. Journal of Experimental Psychology: Human Perception and Performance, 6, 140-150.

Ridley, D. R. (1980). Color-word connotative incongruity: A replication. Perceptual and Motor Skills, 50, 1309-1310.

Ridley, D. R., Johnson, D. E., \& Braisted, P. D. (1978). The color-word connotative incongruity effect. Perceptual and Motor Skills, 46, 939946.

Rieck, A. M., \& Coates, G. D. (1977, November). Irrelevant information effects in the Stroop color-word test. Paper presented at the annual meeting of the Psychonomic Society, Washington, DC.

Roe, W. T., Wilsoncroft, W. E., \& Griffiths, R. S. (1980). Effects of motor and verbal practice on the Stroop task. Perceptual and Motor Skills, $50,647-650$.

Rosinski, R. R. (1977). Picture-word interference is semantically based. Child Development, 48, 643-647.

Rosinski, R. R., Golinkoff, R. M., \& Kukish, K. S. (1975). Automatic semantic processing in a picture-word interference task. Child Development, 46, 247-253.

Rumelhart, D. E., Hinton, G. E., \& McClelland, J. L. (1986). A general framework for parallel distributed processing. In D. E. Rumelhart, J. L. McClelland, \& the PDP Research Group (Eds.), Parallel distributed processing: Explorations in the microstructure of cognition, Vol. 1 (pp. 45-76). Cambridge, MA: MIT Press.

Santos, J. F., \& Montgomery, J. R. (1962). Stability of performance on the color-word test. Perceptual and Motor Skills, 15, 397-398.

Sarmanay, I. (1977). Different performance in Stroop's Interference Test from the aspect of personality and sex. Studia Psychologica, 19, 60-67. (From Psychological Abstracts, 1978, 59, Abstract No. 2543)

Saunders, D. R. (1980). Definition of Stroop interference in volunteers and non-volunteers. Perceptual and Motor Skills, 51, 343-354.

Scheibe, K., Shaver, P. R., \& Carrier, S. C. (1967). Color association values and response interference on variants of the Stroop test. Acta Psychologica, 26, 286-295.

Schiller, P. H. (1966). Developmental study of color-word interference. Journal of Experimental Psychology, 72, 105-108.
Schmit, V., \& Davis, R. (1974). The role of hemispheric specialization in the analysis of Stroop stimuli. Acta Psychologica, 38, 149-158.

Schneider, W., \& Shiffrin, R. M. (1977). Controlled and automatic human information processing: I. Detection, search, and attention. Psychological Review, 84, 1-66.

Schubo, W., \& Hentschel, U. (1977). Reliability and validity of the serial Color-Word Test: Further results. Psychological Research Bulletin, Lund University, 17. (From Psychological Abstracts, 1979, 61, Abstract No. 5169)

Schubo, W., \& Hentschel, U. (1978). Improved reliability estimates for the serial Color-Word Test. Scandinavian Journal of Psychology, 19, 91-95.

Schulz, T. (1979). Components of the reaction time Stroop-task. Psychological Research, 40, 377-395.

Schweikert, R. (1978). A critical path generalization of the additive factor method: Analysis of a Stroop task. Joumal of Mathematical Psychology, 18, 105-139.

Schweikert, R. (1983). Latent network theory: Scheduling of processes in sentence verification and the Stroop effect. Journal of Experimental Psychology: Learning, Memory, and Cognition, 9, 353-383.

Scott, D. F., Hoffman, H. J., \& Bickford, R. G. (1967). Changes in summated visual potentials (lambda waves) during mental tasks using the Stroop test. Perceptual and Motor Skills, 25, 993-996.

Severance, L. J., \& Dyer, F. N.(1973). Failure of subliminal word presentations to generate interference to color naming. Journal of Experimental Psychology, 101, 186-189.

Seymour, P. H. (1973). Stroop interference in naming and verifying spatial locations. Perception and Psychophysics, 14, 95-100.

Seymour, P. H. (1974). Stroop interference with response, comparison, and encoding stages in a sentence-picture comparison task. Memory and Cognition, 2, 19-26.

Seymour, P. H. (1977). Conceptual encoding and locus of the Stroop effect. Quarterly Journal of Experimental Psychology, 29, 245-265.

Shaffer, W. O., \& LaBerge, D. (1979). Automatic semantic processing of unattended words. Journal of Verbal Learning and Verbal Behavior, $18,413-426$.

Shiffrin, R. M., \& Schneider, W. (1977). Controlled and automatic human information processing: II. Perceptual learning, automatic attending and a general theory. Psychological Review, 84, 127-190.

Shor, R. E. (1970). The processing of conceptual information on spatial directions from pictorial and linguistic symbols. Acta Psychologica, 32, 346-365.

Shor, R. E. (1971). Symbol processing speed differences and symbol interference effects in a variety of concept domains. Journal of General Psychology, 85, 187-205.

Shor, R. E. (1975). An auditory analog of the Stroop test. Journal of General Psychology, 93, 281-288.

Shor, R. E., Hatch, R. P., Hudson, L. J., Landrigan, D. T., \& Shaffer, H. J. (1972). Effect of practice on a Stroop-like spatial directions task. Journal of Experimental Psychology, 94, 168-172.

Sichel, J. L., \& Chandler, K. A. (1969). The color-word interference test: The effects of varied color-word combinations upon verbal response latency. Journal of Psychology, 72, 219-231.

Silverstein, A. B., \& Franken, R. E. (1965). Performance of the mentally retarded on the Stroop Color-Word Test. Perceptual and Motor Skills, 21,618 .

Simon, J. R., \& Sudalaimuthu, P. (1979). Effects of S-R mapping and response modality on performance in a Stroop task. Journal of Experimental Psychology: Human Perception and Performance, 5, 176187.

Singer, M. H., Lappin, J. S., \& Moore, L. P. (1975). The interference of various word parts on color naming in the Stroop test. Perception and Psychophysics, 18, 191-193.

Sjöberg, L. (1969). On serial scoring of the color word test. Acta Psychologica, 29, 150-162. 
Sjöberg, L. (1974). Psychometric properties of the serial colour word test. Scandinavian Journal of Psychology, 15, 15-20.

Sladekova, L., \& Daniel, J. (1981). Differences in performance in Stroop's test from the aspect of sex and age. Studia Psychologica, 23, 145-149.

Smekal, V., \& Dvoracek, V. (1977). Relationship of perceptual interference and personality variables in 7th-grade students. Psychologia a Patopsychologia Dietata, 12, 47-54. (From Psychological Abstracts, 1979, 62, Abstract No. 10658)

Smith, G. J. W. (1959). Comparisons between adaptive patterns in two serial experiments. Acta Psychologica, 16, 302-315.

Smith, G. J. W. (1970). Change in degree of interference in a Stroop-like test (SWT) when the incongruent combinations are mixed with congruent ones. Psychologische Forschung, 34, 95-96.

Smith, G. J. W., \& Borg, G. A. V. (1964). The problem of retesting in the serial color-word test. Psychological Research Bulletin, Lund University, 4, 1-8.

Smith, G. J. W., \& K lein, G. S. (1953). Cognitive controls in serial behavior patterns. Journal of Personality, 22, 188-213.

Smith, G. J. W., \& Nyman, G. E. (1974). The validity of the serial colorword test: A reply to Lennart Sjoberg. Scandinavian Journal of Psychology, 15, 238-240.

Smith, M. C., \& Kirsner, K. (1982). Language and orthography as irrelevant features in colour-word and picture-word Stroop interference. Quarterly Journal of Experimental Psychology: Human Experimental Psychology, 34A, 153-170.

Smith, M. C., \& Magee, L. E. (1980). Tracing the time course of pictureword processing. Journal of Experimental Psychology: General, 109, 373-392.

Solso, R. L. (1971). Meaningfulness of colors. Psychonomic Science, 23, 301-303.

Stanovich, K. E., \& Pachella, R. G. (1977). Encoding, stimulus-response compatibility, and stages of processing. Journal of Experimental Psychology: Human Perception and Performance, 3, 411-421.

Stirling, N. (1979). Stroop interference: An input and an output phenomenon. Quarterly Journal of Experimental Psychology, 31, 121132.

Stirling, N., \& Coltheart, M. (1977). Stroop interference in a letter naming task. Bulletin of the Psychonomic Society, 10, 31-34.

Stroop, J. R. (1935a). The basis of Ligon's theory. American Journal of Psychology, 47, 499-504.

Stroop, J. R. (1935b). Studies of interference in serial verbal reactions. Journal of Experimental Psychology, 18, 643-662.

Stroop, J. R. (1938). Factors affecting speed in serial verbal reactions. Psychological Monographs, 50, 38-48.

Tanenhaus, M. K., Flanigan, H. P., \& Seidenberg, M. S. (1980). Orthographic and phonological activation in auditory and visual word recognition. Memory and Cognition, 8, 513-520.

Taylor, A., \& Clive, P. B. (1983). Two forms of the Stroop test. Perceptual and Motor Skills, 57, 879-882.

Taylor, D. A. (1977). Time course of context effects. Journal of Experimental Psychology: General, 106, 404-426.

Tecce, J. J., \& Dimartino, M. (1965). Effects of heightened drive (shock) on performance in a tachistoscopic color-word interference task. Psychological Reports, 16, 93-94.

Tecce, J. J., \& Happ, S. J. (1964). Effects of shock-arousal on a card-sorting test of color-word interference. Perceptual and Motor Skills, 19, 905-906.

Telford, C. W. (1930). Differences in responses to colors and to their names: Some racial comparisons. Journal of Genetic Psychology, 37 , 151-159.

Thomas, J. K. (1977). Stroop interference with word or hue pre-exposure (Doctoral dissertation, University of Michigan, 1977). Dissertation Abstracts International, 38, 1450-B.

Thurstone, L. L. (1944). A factorial study of perception. Chicago: University of Chicago Press.
Tipper, S. P. (1985). The negative priming effect: Inhibitory priming by ignored objects. Quarterly Journal of Experimental Psychology, 37A, 571-590.

Tipper, S. P., \& Cranston, M. (1985). Selective attention and priming: Inhibitory and facilitatory effects of ignored primes. Quarterly Journal of Experimental Psychology, 37A, 591-611.

Toma, R. J., \& Tsao, Y.-C. (1985). Interference effects in the pictureword Stroop task. Perceptual and Motor Skills, 61, 223-228.

Treisman, A. M. (1969). Strategies and models of selective attention. Psychological Review, 76, 282-299.

Treisman, A. M., \& Fearnley, S. (1969). The Stroop test: Selective attention to colours and words. Nature, 222, 437-439.

Tsao, Y.-C., Feustel, T., \& Soseos, C. (1979). Stroop interference in the left and right visual fields. Brain and Language, 8, 367-371.

Tsao, Y.-C., Wu, M.-F., \& Feustel, T. (1981). Stroop interference: Hemispheric difference in Chinese speakers. Brain and Language, 13, 372-378.

Tschopp, M., \& Jorswieck, E. (1976). Comparison of shifting between groups of mentally retarded children, secondary school children and seniors. Praxis der Kinderpsychologie und Kinderpsychiatrie, 25, 22-24. (From Psychological Abstracts, 1981, 65, Abstract No. 1524)

Uechi, Y. (1972). Cognitive interference and intelligence: Reexamination of the measures of SCWT. Japanese Journal of Educational Psychology, 20, 92-100. (From Psychological Abstracts, 1974, 52, Abstract No. 12745)

Uhlman, F. W. (1962). Test of color recognition. Detroit, MI: The Detroit Edison Co.

Uleman, J. S., \& Reeves, J. (1971). A reversal of the Stroop interference effect, through scanning. Perception and Psychophysics, 9, 293-295.

Underwood, G. (1976). Semantic interference from unattended printed words. British Journal of Psychology, 67, 327-338.

Underwood, G., \& Briggs, P. (1984). The development of word recognition processes. British Journal of Psychology, 75, 243-255.

Underwood, G., Briggs, P., \& Underwood, J. D. (1984). Cognitive processes in children's reading attainment. Human Learning: Journal of Practical Research and Applications, 3, 119-128.

Vaid, J., \& Lambert, W. E. (1979). Differential cerebral involvement in the cognitive functioning of bilinguals. Brain and Language, 8, 92110.

Virzi, R. A., \& Egeth, H. E. (1984). Is meaning implicated in illusory conjunctions? Journal of Experimental Psychology: Human Perception and Performance, 10, 573-580.

Virzi, R. A., \& Egeth, H. E. (1985). Toward a translational model of Stroop interference. Memory and Cognition, 13, 304-319.

Warren, L. R., \& Marsh, G. R. (1978). Hemispheric asymmetry in the processing of Stroop stimuli. Bulletin of the Psychonomic Society, 12, 214-216.

Warren, L. R., \& Marsh, G. R. (1979). Changes in event related potentials during processing of Stroop stimuli. International Journal of Neuroscience, 9, 217-223.

Warren, R. E. (1972). Stimulus encoding and memory. Journal of Experimental Psychology, 94, 90-100.

Warren, R. E. (1974). Association, directionality, and stimulus encoding. Journal of Experimental Psychology, 102, 151-158.

Warren, R. E., \& Lasher, M. D. (1974). Interference in a typeface variant of the Stroop test. Perception and Psychophysics, 15, 128-130.

Watts, F. N., McKenna, F. T., Sharrock, R., \& Trezise, L. (1986). Colournaming of phobia-related words. British Journal of Psychology, 77, 97-108.

West, R. F., \& Stanovich, K. E. (1978). Automatic contextual facilitation in readers of three ages. Child Development, 49, 717-727.

Westberry, R. L. (1984). The nature of attentional control as a personality dimension (Doctoral dissertation, University of South Florida, Tampa, 1983). Dissertation Abstracts International, 45, 1043-B. 
Wheeler, D. D. (1977). Locus of interference on the Stroop test. Perceptual and Motor Skills, 45, 263-266.

White, B. W. (1969). Interference in identifying attributes and attribute names. Perception and Psychophysics, 6, 166-168.

White, L. C. (1978). Interference proneness and the ability to shift attention in old age (Doctoral dissertation, University of Notre Dame, 1978). Dissertation Abstracts International, 39, 2549-B.

Whitney, P. (1986). Processing category terms in context: Instantiations as inferences. Memory and Cognition, 14, 39-48.

Whitney, P., \& Kellas, G. (1984). Processing category terms in context: Instantiation and the structure of semantic categories. Journal of Experimental Psychology: Learning, Memory, and Cognition, 10, 95103.

Whitney, P., McKay, T., Kellas, G., \& Emerson, W. A., Jr. (1985). Semantic activation of noun concepts in context. Journal of Experimental Psychology: Learning, Memory, and Cognition, 11, 126-135.

Wilder, L. (1969). A developmental viewpoint concerning the Stroop color-word test and verbal interference. Speech Monographs, 36, 114-117.
Williams, E. (1977). The effects of amount of information in the Stroop color word test. Perception and Psychophysics, 22, 463-470.

Windes, J. D. (1968). Reaction time for numerical coding and naming of numerals. Journal of Experimental Psychology, 78, 318-322.

Wise, L. A., Sutton, J. A., \& Gibbons, P. D. (1975). Decrement in Stroop interference time with age. Perceptual and Motor Skills, 41, 149-1 50.

Wolitzky, D. L., Hofer, R., \& Shapiro, R. (1972). Cognitive controls and mental retardation. Journal of Abnormal Psychology, 79, 296-302.

Woodworth, R. S., \& Wells, F. L. (1911). Association tests. Psychological Review Monograph Supplements, 13(No. 57).

Zajano, M. J., \& Gorman, A. (1986). Stroop interference as a function of percentage of congruent items. Perceptual and Motor Skills, 63, $1087-1096$

Zajano, M. J., Hoyceanyls, E. M., \& Ouellette, J. F. (1981). A confound in the standard control condition of the Stroop experiment. Perceptual and Motor Skills, 53, 835-841.

Zakay, D., \& Glicksohn, J. (1985). Stimulus congruity and S-R compatibility as determinants of interference in a Stroop-like task. Canadian Journal of Psychology, 39, 414-423.

\section{Appendix A}

\section{Organizational Structure of the Review}

\begin{tabular}{|c|c|c|c|}
\hline Topic & Page & Topic & Page \\
\hline Variations on the Stroop procedure & 165 & Trial sequence & 177 \\
\hline The Stroop Color-Word Interference Test & 165 & Pretrial cues & 178 \\
\hline The individual stimulus version of the & & Stimulus onset asynchrony & 179 \\
\hline color-word task & 166 & The reverse Stroop effect & 180 \\
\hline Sorting and matching versions of the color- & & Practice & 181 \\
\hline word task & 166 & Response-related manipulations & 182 \\
\hline The picture-word interference task & 167 & Order of response & 182 \\
\hline Auditory analogs of the Stroop task & 168 & Response modality: oral versus manual & 182 \\
\hline Other analogs of the Stroop task & 168 & Response set size and composition & 183 \\
\hline Manipulations of information on critical trials & 170 & Individual differences & 184 \\
\hline Hue variation & 170 & Sex differences & 184 \\
\hline Acoustic variation & 170 & Age differences & 184 \\
\hline Semantic variation & 172 & Hemispheric differences & 185 \\
\hline Semantic variation and the irrelevant word & 172 & Language differences: the case of the & \\
\hline Semantic variation induced by priming & 173 & $\begin{array}{l}\text { bilingual } \\
\text { Theoretical accounts of the Stroon effect }\end{array}$ & $\begin{array}{l}186 \\
187\end{array}$ \\
\hline Congruency effects & 174 & Relative speed of processing & 187 \\
\hline Integration of the two dimensions & 175 & Automaticity & 188 \\
\hline Experiment-wide manipulations of & & Perceptual encoding & 190 \\
\hline information & 176 & Parallel models: accruing evidence toward a & \\
\hline Probability of various trial types & 176 & decision & 191 \\
\hline Stimulus set size & 177 & A parallel distributed processing model & 192 \\
\hline
\end{tabular}




\section{Appendix B}

\section{Eighteen Major Empirical Results That Must be Explained by Any Successful Account of the Stroop Effect}

1. The Stroop effect is observed with lists of stimuli, with single stimuli, and with many variations on the response required. Similar data patterns are evident in numerous Stroop analogs, such as the picture-word task.

2. Both orthographic and particularly acoustic/articulatory relations between the irrelevant word (or part of the word) and the to-benamed ink color contribute to the interference.

3. Compared with naming the ink color alone, irrelevant verbal stimuli that are unrelated to the concept of color interfere only minimally with color naming. However, as the word's semantic association to the concept of color increases, so does its power to interfere.

4. A color-unrelated word can be made to cause greater interference (or facilitation, or both) with color naming if its meaning is activated by a related word or phrase shortly before the color-naming trial.

5. Congruence between the irrelevant word and the to-be-named ink color often produces facilitation. However, this facilitation is much less than the corresponding interference in the incongruent condition, and the choice of control condition may be crucial.

6. If the to-be-named color and the to-be-ignored word are presented in separate spatial locations, interference will be reduced (but not eliminated) relative to the standard, integrated version of the task. Locational uncertainty makes an important contribution in nonintegrated situations.

7. The presence of congruent trials among the incongruent and control trials will tend to invoke the tactic of splitting attention over the two dimensions, thereby increasing interference on incongruent trials.

8. When the irrelevant word on trial $n-1$ is the name of the target ink color on trial $n$, interference with color naming will be enhanced temporarily; when the ink color on trial $n-1$ matches the word on trial $n$, there will be some facilitation of color naming on trial $n$. If the word on trial $n-1$ is repeated on trial $n$, then the word is already suppressed and will cause less interference in naming a different ink color on trial $n$.

9. Advance cues conveying information about the upcoming Stroop trial can be used to establish processing strategies that improve performance if these cues are above the level of subjective awareness and if a very small set of cues is used consistently.
10. When the color (or picture) is to be named, maximal impact of a congruent or incongruent word will be observed when the two dimensions begin within $100 \mathrm{~ms}$ of each other. Facilitation may extend to longer SOAs than interference when the word comes first. Manipulating SOA has virtually no impact on word reading unless a very high proportion of congruent trials biases use of the color to initiate response production.

11. A reverse Stroop effect (i.e., interference with word reading caused by an incompatible, irrelevant ink color) appears to be possible, but this effect is not simply a consequence of the relative speeds of processing each dimension.

12. Degree of practice in processing each of the dimensions of a multidimensional stimulus is very influential in determining the extent of interference from one dimension on another. The greater the practice in processing a dimension, the more capable that dimension seems of influencing the processing of another dimension.

13. Although still significant, interference (but perhaps not facilitation) is reduced when response modality is switched from oral to manual. Stimulus-response compatibility matters; if the normal processing of the irrelevant dimension leads to a response in the mode designated for the relevant dimension, interference is likely to be heightened.

14. When the irrelevant dimension of a set of stimuli includes names that are eligible responses for the relevant dimension, more interference results than when the sets are nonoverlapping. Although variations in response set size might be expected to affect interference, existing results are unclear.

15. There are no sex differences in Stroop interference at any age.

16. Interference begins early in the school years, rising to its highest level around Grades 2 to 3 as reading skill develops. With continued development of reading, interference declines through the adult years until approximately age 60 , at which point it begins to increase again.

17. The left hemisphere generally shows more interference than the right.

18. Interference between the two languages of a bilingual, although not as great as that within either one of the languages, is very robust: Between language interference typically is about $75 \%$ of within-language interference. Furthermore, a dominant language has more potential for interfering than does a nondominant one.

Received August 18, 1989 